AIRTON MANOEL ROMERO COSTA

\title{
UM SISTEMA DE ROTEIRIZAÇÃO VIA INTERNET PARA O CAMPUS DA USP DE RIBEIRÃO PRETO
}

\author{
Dissertação apresentada à Escola de \\ Engenharia de São Carlos da \\ Universidade de São Paulo, como \\ parte dos requisitos para a obtenção \\ do Título de Mestre em Engenharia Civil - \\ Área de Concentração:Transportes
}

Orientador: Prof. Associado Paulo César de Lima Segantine

São Carlos - SP

2004 


\section{DEDICATÓRIA}

À minha esposa Roseli e aos meus

filhos Luciana e William 


\section{AGRADECIMENTOS}

A Deus pela força recebida em todos os dias de minha vida.

Ao meu orientador, Prof. Associado Paulo César de Lima Segantine pela orientação, incentivo e amizade durante a realização deste trabalho.

Ao Prof. Dr. Ricardo Ernesto Schaal pela sua grande colaboração, apoio técnico e amizade sempre presentes.

Aos colegas e professores do Departamento de Transportes pela amizade e colaboração.

À Prefeitura do Campus Administrativo do Campus de Ribeirão Preto por viabilizar a realização do Programa de Mestrado.

À Coordenadoria do Espaço Físico por ter cedido a planta digitalizada do Campus de Ribeirão Preto.

À minha esposa Roseli pela colaboração e presença em todos os momentos.

Aos alunos Cezar Manechini, Ivan Garde e Bruno P. Ramos, do Instituto de Ciências Matemáticas e de Computação, pela colaboração na parte de informática.

Aos funcionários do Departamento de Transportes e em especial: Heloísa, Beth e Paulinho.

Enfim, agradeço a todos aqueles que, direta ou indiretamente, colaboraram para a elaboração deste trabalho 
ROMERO, A. M. (2004). UM SISTEMA DE ROTEIRIZAÇÃO VIA INTERNET PARA O CAMPUS DA USP DE RIBEIRÃO PRETO. Dissertação (Mestrado) - Escola de Engenharia de São Carlos, Universidade de São Paulo, São Carlos, 2004.

Neste trabalho, uma metodologia é proposta para disponibilizar, via Internet, um serviço de roteirização de endereços para o Campus da USP de Ribeirão Preto, com a determinação do menor caminho entre duas localidades. Esta metodologia pode ser aplicada não apenas ao Campus da USP de Ribeirão Preto, mas ela poderá ser estendida às cidades e/ou regiões que possuam um mapa digital correspondente.

Um sistema, denominado SIGRIB, foi desenvolvido para implementar a metodologia proposta e utiliza o software ARCVIEW como suporte a manipulação de dados geográficos e cadastrais. Para facilitar a interação do usuário com o sistema SIGRIB, uma interface foi desenvolvida para que o usuário possa fornecer duas localidades para as quais ele deseja obter o menor caminho. O resultado desta consulta é um sub mapa contendo o menor caminho correspondente destacado no mapa.

O sistema SIGRIB está disponível na Internet e vários testes são apresentados neste trabalho que demonstram a seu bom desempenho.

Palavras-chave: Roteirização, Menor Caminho, Localização, SIG

\section{ABSTRACT}


In this work, a methodology is proposal to turn available, through Internet, a routing service for addressing at Campus of University of São Paulo, in Ribeirão Preto (SP), including the determination of shortest way between two localities. This methodology can be applied not only to this Campus but it can be extended to various cities and/or regions that have a corresponding digital map.

A system, called SIGRIB, has been developed for implementing the proposed methodology and it utilize ARCVIEW software as support for manipulation of geographical and cadastral data. To turn easy the interaction of user with SIGRIB_system, a interface has been also implemented for that the user can provide two localities for which he desires to obtain the shortest path. The result of this search is a sub map containing the corresponding shortest path highlighted in the map.

The system SIGRIB is available in the Internet and several tests are presented in this work that demonstrate its good performance.

Keywords: routing problem, shortest path, localization, GIS

\section{LISTA DE FIGURAS}


Figura 3.1. Arquitetura do Sistema SIGRIB .......................................................

Figura 3.2. Detalhamento do módulo de Processamento......................................15

Figura 4.1.Planta digitalizada do Campus de Ribeirão Preto utilizando o

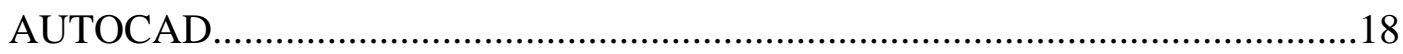

Figura 4.2. Inserção da planta digitalizada no ARCVIEW ...................................19

Figura 4.3. Inserção da planta digitalizada no ARCVIEW ...................................20

Figura 4.4. Ativação do comando ADD THEME.................................................20

Figura 4.5. Escolha do arquivo a ser inserido..............................................21

Figura 4.6. Escolha dos temas de interesse.................................................22

Figura 4.7. Planta digitalizada da cidade de Ribeirão Preto inserida no Projeto...23

Figura 4.8. Criando um novo tema “Traçado_eixo_ruas”....................................24

Figuras 4.9. Definindo o tipo de objeto do tema "Traçado_eixo_ruas"..................24

Figura 4.10 Nomeando o arquivo e salvando o novo tema................................25

Figura 4.11. Iniciando a editar o novo tema................................................26

Figura 4.12. Ativando a ferramenta "Snapping" .............................................26

Figura 4.13. Ativando a ferramenta "Draw Line" ............................................27

Figura 4.14. Executando o traçado de uma linha (eixo)...................................27

Figura 4.15. Definindo os elementos do objeto linha.......................................28

Figura 4.16. Editando a tabela de atributos do objeto linha...............................29

Figura 4.17. Editando a tabela de atributos do objeto linha...............................29

Figura 4.18. Calculando o comprimento do objeto linha....................................30 
Figura 4.19. Calculando o comprimento do objeto linha .30

Figura 4.20. Base Geográfica do Campus da USP de Ribeirão Preto inserida no ARCVIEW com os traçados dos eixos 31

Figura 4.21. Representação dos Identificadores das arestas. .32

Figura 4.22. Tabela de adjacentes e respectivas distâncias 34

Figura 4.23. Tabela de Ids: Arestas com respectivos Idendificações. 35

Figura 4.24. Tabela Entradas: Localidades importantes e pontos associados.......36

Figura 5.1. Página de Entrada para o Campus de Ribeirão Preto. .40

Figura 5.2. Página de saída gerada pela interface

Figura 6.1. Funcionamento do Sistema

Figura 6.2. Exemplo do funcionamento do algoritmo de Dijkstra

Figura 6.3: Visualização de um traçado.

Figura 6.4. Busca pelo menor caminho entre duas casas na Rua Clóvis Vieira.......

Figura 6.5. Visualização do menor caminho entre duas casas na Rua Clóvis Vieira

Figura 6.6. Tela inicial para o Exemplo 2

Figura 6.7. Primeira parte do caminho do Exemplo 2

Figura 6.8. Segunda parte do caminho do Exemplo 2

Figura 6.9. Terceira parte do caminho do Exemplo 2

Figura 6.10. Quarta parte do caminho do Exemplo 2

Figura 6.11. Primeiro Caminho escolhido pelo SIGRIB (distância de 1.091m).

Figura 6.12. Caminho alternativo para o Exemplo 2 (distância de $1.211 \mathrm{~m}$ ) 
SUMÁRIO

1. INTRODUÇÃO

1.1. Objetivos

1.2. Justificativa

1.3. Organização da Dissertação

2. SISTEMAS DE INFORMAÇÃO GEOGRÁFICA

2.1. Sistema de Informação Geográfica

2.2. Trabalhos Relacionados

3. O SISTEMA PROPOSTO

3.1. Arquitetura do Sistema Proposto

3.2. Módulo de Processamento

4. CONSTRUÇÃO DA BASE DE DADOS

4.1. Manipulação da planta digitalizada

4.2. Manipulação de dados no ARCVIEW

4.2.1. Processo de Inserção de uma planta digitalizada no ARCVIEW

4.2.2. Como executar o traçado dos eixos das ruas

4.3. Criação de Banco de Dados

5. DESENVOLVIMENTO DA INTERFACE

5.1. Interface desenvolvida 
5.2. Aplicativos Utilizados

6. IMPLEMENTAÇÃO DO SISTEMA

\subsection{Estudos Preliminares}

6.2. Escolha de softwares para o desenvolvimento da interface

6.3. Página Web (Escrita em Asp/Html)

6.4. Script Isapi (Aplicação Web)

6.4.1. Determinação do menor caminho

6.5. Aplicativo - Map Objects

6.5.1. O script ubiblioteca.pas

6.5.2. O componente projeto.exe

6.6. Processamento do Software

6.7. A Base de dados

6.8. A Estrutura de Diretório

6.9. Resultados

6.9.1. Disponibilização do Sistema SIGRIB

6.9.2. Experimentos

7. CONCLUSÃO

REFERÊNCIAS

ANEXO A

ANEXO B 


\section{Cap. 1 INTRODUÇÃO}

Tem sido comum, em países desenvolvidos, a utilização de sistemas de localização de endereços via Internet.

Este projeto tem como objetivo principal desenvolver uma metodologia para disponibilizar, via internet, um serviço de localização de endereços em uma determinada cidade. O que se pretende é desenvolver uma metodologia, baseada em SIG - Sistema de Informação Geográfica, que poderá ser estendida a diversas cidades e/ou regiões que possuam um mapa digital correspondente.

Em princípio, a metodologia a ser desenvolvida será direcionada para o Campus da USP de Ribeirão Preto. Depois de provado a eficácia da metodologia, ela será estendida para outras regiões da cidade e isto colocará a cidade de Ribeirão Preto, entre as primeiras do Brasil, senão a primeira, a disponibilizar este tipo de serviço a toda a população.

Certamente, a longo prazo, a medida que este projeto for sendo aprimorado, este projeto envolverá muitas pessoas que terão que fazer um trabalho de "campo", levantando os pontos principais de cada rua de uma determinada região, endereço completo de cada localização, tais como, nome da rua, número, CEP, etc e poderá contar com o auxílio da Prefeitura Municipal da cidade envolvida. Isto poderá ser feito, para cada região da cidade, até que toda a cidade, a longo prazo, esteja completamente disponibilizada na internet.

Este é um serviço que os países do primeiro mundo, como por exemplo, os EUA, já fornecem ao mundo todo. Um brasileiro que quiser encontrar um determinado endereço numa certa cidade nos EUA, ele pode acessar a internet e imprimir através de seu computador, o mapa com a localização correspondente à região de interesse. Certamente, este tipo de serviço, um dia, 
o Brasil também terá que oferecer não só a sua população, mas também ao mundo.

Este projeto tem um caráter social de relevância, pois não apenas a sociedade se beneficiará da informação disponível, como também o projeto propiciará a formação de pessoal qualificado na área de SIG, banco de dados, áreas estas carentes dentro da atual Sociedade de Informação.

Para realização desta tarefa necessita-se, primeiramente, de um software do tipo SIG (Sistema de Informações Geográficas) e uma planta digitalizada de uma cidade numa escala adequada às análises.

No Brasil, alguns projetos nesta área estão sendo desenvolvidos devido à sua grande utilidade no aspecto social.

Para o desenvolvimento deste projeto um software do tipo SIG -Sistema de Informação Geográfica será utilizado que auxiliará na manipulação de dados.

Este estudo foi dirigido para o Campus da USP de Ribeirão Preto, cidade com área de 642 km², que está localizada na região central do Estado de São Paulo e que apresenta características de uma cidade de porte médio e uma população de 504.923 habitantes segundo o Censo Demográfico de 2.000. A cidade apresenta um processo de urbanização bastante significativo, atingindo um índice de urbanização, percentual da população urbana em relação à população total, de 99,62\% em 2003 - SEADE Fundação Sistema Estadual de Análise de Dados da Secretaria de Estado de Economia e Planejamento do Estado de São Paulo, o que a coloca situada entre as cidades paulistas com maior índice de urbanização.

O Campus da USP possui uma área 5.859.921,78 $\mathrm{m}^{2}$ e agrega entre funcionários, docentes e estudantes aproximadamente 8600 pessoas.

Entre os estudantes 3.897 são alunos de graduação e 2.257 são alunos de pós-graduação. Existem 12 unidades diferentes, entre elas se encontram: FMRP, FFCLRP, FORP, FCFRP, EERP, FEARP, ECA, PCARP, CIRP, SVOI, Hemocentro e Hospital das Clínicas.

Tem-se disponível uma planta digitalizada (formato DWG - AutoCad da Softdesk), do Campus da USP de Ribeirão Preto - SP, gentilmente, fornecida pela COESF (Coordenadoria do Espaço Físico da Universidade de São Paulo) - Elipsóide SAD 69, Projeção UTM , Meridiano Central 45ํㅡ, Datum Horizontal 
V-Franca 91612/V-Jaboticabal 9163 (IBGE), Datum Vertical RN-2924G (IBGE), data de execução do levantamento outubro de 1998.

No entanto, algumas adaptações foram feitas, isto é, uma base de dados foi montada com as especificações necessárias para que o SIG pudesse manipular e extrair informações desta base de dados.

\subsection{Objetivos}

Este trabalho visa, através do acesso via Internet, disponibilizar a moradores e visitantes da cidade de Ribeirão Preto (SP) e de outras localidades, informações rápidas sobre a melhor maneira de se locomover no Campus da USP e numa segunda etapa, também localizar outros pontos importantes da cidade (hotéis, restaurantes, hospitais, escolas, pontos turísticos, etc), possibilitando a obtenção dessas informações antes mesmo de se chegar à cidade.

Para atingir este objetivo faz-se necessário o desenvolvimento de uma interface para que o usuário, via Internet, possa fornecer o endereço que ele deseja encontrar no Campus e receber como resultado da consulta, o menor caminho entre a localização onde ele se encontra dentro da cidade. Por exemplo, o software deverá fornecer o menor caminho entre a entrada da cidade e a localização desejada pelo usuário.

Após o desenvolvimento e validação desta interface, faz parte também dos objetivos disponibilizar o sistema à população na internet.

Vale ressaltar que esta pesquisa foi desenvolvida juntamente com 0 LABIC - Laboratório de Inteligência Computacional, do Departamento de Computação e Estatística do ICMC - USP.

\subsection{Justicativa}

O presente projeto tem um caráter social de grande importância. Ele auxiliará a população na localização dos principais pontos do Campus e futuramente da cidade. Os visitantes serão também beneficiados, pois, mesmo estando longe, poderão ter acesso a informações tais como: faculdades, laboratórios, prédios administrativos, existentes no Campus de Ribeirão Preto. 
Isto certamente facilitará a vida dos usuários que desejam chegar e/ou se locomover no Campus da USP, da cidade de Ribeirão Preto.

O Campus da USP de Ribeirão Preto é constituído de 12 unidades diferentes, entre elas se encontram: FMRP, FFCLRP, FORP, FCFRP, EERP, FEARP, ECA, PCARP, CIRP, SVOI, Hemocentro e o Hosipital das Clínicas, além de residências de funcionários, o que envolve, certamente, uma grande circulação de pessoas, carros, caminhões de entrega de materiais e equipamentos para laboratórios das Unidades e/ou obras de construção. Este ambiente de micro cidade serve de modelo para implantação do sistema a ser desenvolvido em outras cidades e/ou regiões.

A realização deste projeto colocará a cidade de Ribeirão Preto entre as poucas cidades brasileiras que fornecerá este tipo de serviço à sociedade.

\subsection{Organização da Dissertação}

Esta dissertação está organizada como segue. No Capítulo 2, apresenta-se a definição e conceitos envolvidos em um sistema SIG. No capítulo 3, a arquitetura do sistema proposto é apresentada, isto é, os componentes básicos do sistema de localização de endereços para o Campus de Ribeirão Preto são apresentados. No Capítulo 4, é descrita como a base de dados foi construída. No Capítulo 5, apresenta-se a interface gerada para 0 sistema proposto. Detalhes sobre a implementação do sistema são apresentados no Capítulo 6. Finalmente, no Capítulo 7, vários testes realizados no sistema são apresentados e alguns trabalhos futuros são apontados. 


\section{Cap. 2 SISTEMAS DE INFORMAÇÃO GEOGRÁFICA}

Neste capítulo, apresenta-se uma breve introdução sobre Sistemas de Informação Geográfica, pelo fato de ser utilizado um software deste tipo para auxiliar no desenvolvimento do sistema que está sendo proposto. Em seguida, é apresentada uma descrição dos trabalhos relacionados com o tema abordado neste trabalho.

\subsection{Sistema de Informação Geográfica}

Um Sistema de Informação Geográfica - SIG é um conjunto de ferramentas computacionais composto de equipamentos e programas que por meio de técnicas, integra dados, pessoas e instituições, de forma a tornar possível a coleta, o armazenamento, o processamento, a análise e a disponibilização, a partir de dados georreferenciados, de informação produzida por meio das aplicações disponíveis, visando maior facilidade, segurança e agilidade nas atividades humanas referentes ao monitoramento, planejamento e tomada de decisão, relativos ao espaço geográfico (BURROUGH, 1985).

O conceito SIG foi desenvolvido originalmente nos anos 60 , como um meio de sobrepor e combinar diversos tipos de dados em uma mesma planta. Enquanto o sistema CAD automatiza a função de desenho, o SIG associa 
atributos geográficos e não geográficos de recursos geográficos. Os mapas, cartas ou plantas resultantes mostram dados geográficos, ambientais ou demográficos, separadamente ou em combinação (BURROUGH, 1985).

O SIG possui uma estrutura flexível de dados baseados em relações topológicas. Até pouco tempo atrás, criar um banco de dados georreferenciado urbano significava executar um levantamento aerofotogramétrico, restituir todos os objetos observáveis e gerar um conjunto de plantas. Este processo, extremamente trabalhoso e muito caro, dificultou a entrada de pequenas e médias prefeituras no universo das geotecnologias (GIBBONS, 1995).

Com o tempo, tem-se observado que o desenvolvimento de produtos cartográficos de precisão não é um pré-requisito indispensável para implantar um SIG urbano. Atualmente, faz muito mais sentido construir uma base geográfica urbana simplificada, apoiada por imagens digitais de resolução suficientemente alta para a tarefa, por exemplo, quando se tem disponível um conjunto de imagens, indispensáveis para as aplicações geográficas pretendidas (GIBBONS, 1995).

Uma desvantagem deste modelo no passado era a grande quantidade de espaço em disco ocupado pelas imagens. Porém, acontece que 0 barateamento dos componentes eletrônicos e o aumento da capacidade observada nos microcomputadores tornaram este problema praticamente irrelevante. Um problema maior é, na verdade, inerente à escolha do software para suportar esta solução: nem todos os SIGs disponíveis no mercado conseguem manipular com igual eficiência tanto as imagens quanto os vetores que formam a base geográfica.

$O$ texto que se segue foi retirado de acordo com o exposto em Segantine, 2001, p.11-15, existem na literatura várias definições para o termo Sistema de Informação Geográfica - SIG. Numa tentativa de minimizar as diferenças de definições até aquele momento, em 1988 a Federal Interagency Coordinating Commitee, dos EUA, definiu SIG da seguinte maneira, apud LOGSDON (1995):

"SIG é um sistema composto por equipamentos, programas e procedimentos computacionais designados para auxiliar na coleta, gerenciamento, manipulação, análise e apresentação de dados 
georreferenciados para resolver problemas complexos de gerenciamento e planejamento".

O SIG é uma inovação tecnológica das últimas décadas. Pode-se afirmar, sem cometer nenhum engano, que a tecnologia SIG é de extrema utilidade em nossos dias, permitindo aos usuários a organização de tarefas, a resolução e a tomada de decisões de vários tipos de problemas, de uma forma inovadora.

Assim como há diferença entre dado e informação, há também diferença entre bancos de dados e sistema de informação. Um banco de dados é simplesmente uma coleção de dados e como tal é somente parte de um sistema de informação, enquanto que um sistema de informação é um arranjo de entidades que propicia relação entre eles e relação entre o sistema e seu ambiente.

Um SIG deve oferecer a possibilidade de gerar documentos de diversas formas, para permitir a distribuição das informações recuperadas e calculadas neles. Em primeiro lugar esses sistemas devem oferecer recursos flexíveis para geração de relatórios, de maneira a permitir a apresentação das diversas informações que podem ser recuperadas. As diferentes etapas de trabalho produzem alterações nos dados armazenados. Todo o processo, desde a coleta e a entrada de dados, até as operações de manipulação e saída podem gerar erros que alteram a qualidade dos dados e fazem com que a confiabilidade das informações obtidas seja afetada.

O SIG está inserido em um contexto técnico-científico de grande potencialidade a aplicações relativas a pesquisas e interpretação da organização espacial de informações através da relação de um dado fenômeno com sua localização espacial.

O SIG é uma tecnologia que tem apresentado um enorme impacto em todos os campos do conhecimento que manipulam e analisam dados distribuídos espacialmente; estes sistemas auxiliam a investigação de fenômenos de diversas áreas tais como a Engenharia Urbana, o Meio Ambiente, a Geologia, a Hidrologia, etc.

Os SIGs devem ser capazes de representar estes fenômenos dinâmicos no espaço e tempo. Os SIGs são capazes de auxiliar nas tomadas de 
decisões, na complementação e na representação de informações numa forma mais aproximada da representação humana no espaço geográfico.

Os SIGs podem ser considerados, de uma maneira simples, como um mapa de alta tecnologia. Um mapa contém muitas informações que podem ser usadas por diferentes tipos de usuários. Os SIGs oferecem a facilidade de extrair diferentes tipos de informações de uma mapa (rodovias, rede de drenagem, rede fluvial, assentamentos, vegetação, área de queimadas, etc.) e usá-las de acordo com a necessidade do projeto. Em adição, os SIGs propiciam grande flexibilidade, permitindo a obtenção de mapas temáticos de maneira rápida, de acordo com a necessidade do usuário.

O principal objetivo de um sistema de informação é manter um conjunto de informações espaciais, de tal forma que elas possam ser usadas em tomadas de decisões em diferentes situações e por diferentes organizações. De uma maneira geral, os SIGs são compostos por dois grandes conjuntos de informações: Bancos de Dados Espaciais ou Geográficos e Bancos de Dados de Atributos.

Os Bancos de Dados Espaciais descrevem as características geográficas da superfície levantada (forma e posição) em relação a um sistema padrão de coordenadas que podem ser relacionadas a um sistema puramente local, a um sistema de coordenadas geográficas (latitude e longitude) ou um sistema de projeção cartográfica. A organização destes bancos de dados pode ser feita segundo a sua classificação em geométricos e não-geométricos. As estruturas geométricas descrevem os diversos atributos gráficos de um elemento (posição, vizinhança, contigüidade), ou seja, sua topologia. As estruturas não-geométricas utilizam dados que incluem atributos alfanuméricos (nome, posição e renda, etc). Os atributos alfanuméricos são associados com os elementos gráficos, fornecendo informações descritivas sobre eles. Os dados alfanuméricos e os dados gráficos são armazenados em bases separadas. Os Bancos de Dados de Atributos descrevem as qualidades das características levantadas.

Uma vez que os dados tenham sido inseridos em um SIG, estes proporcionam a visualização de um modelo acessível e realístico do mundo real, permitindo ao usuário a identificação de objetos e a sua localização espacial de forma georreferenciada. Essas possibilidades tornam os SIGs uma 
poderosa ferramenta de trabalho de análise que deve ser sempre levada em consideração nos processos de decisão. Desta forma, pode-se afirmar que os SIGs promovem a otimização na manipulação dos dados de entrada, gerando um aumento de produtividade na capacidade de análise e uma redução de recursos financeiros quanto ao gerenciamento e auxílio na tomada de decisões.

Os SIGs têm sido usados pelos mais diferentes tipos de usuários, destacando-se as empresas publicas, as empresas privadas e os centros educacionais. Os dados alimentadores destes sistemas podem advir de levantamentos topográficos e geodésicos, plantas, cartas e mapas existentes, fotos aéreas, imagens de satélites, dados estatísticos e tabulares e outros. As informações podem ser classificadas de acordo com o interesse de análise e distribuídas em " layers" ou camadas de informações. E importante citar que os dados apresentados num SIG devem ser georreferenciados a um sistema único de coordenadas.

Diante do exposto, pode-se dizer que os dados em um SIG podem ser originados a partir de diferentes fontes, que podem ser classificadas, de uma forma geral, em primárias e secundárias. As fontes primárias são relativas àquelas de levantamentos realizados diretamente no campo ou sobre produtos do Sensoriamento Remoto. As fontes secundárias utilizam mapas existentes e censos originários das fontes primárias.

A finalidade de um SIG é permitir o gerenciamento de informações temáticas e georreferenciadas de uma determinada zona e ser capaz de oferecer, ao usuário, a capacidade de manipular os dados referentes a essa zona. Para tanto, um SIG permite que o usuário tenha:

- disponibilidade constante de informações variadas, passíveis de serem atualizadas periodicamente;

- melhoria substancial das possibilidades de planificação devido a integração de uma multiplicidade de dados;

- concepção assistida por computador;

- facilidade para a aplicação em modelos complexos e análises de variantes;

- subsídios para as tomadas de decisões, baseadas sobre uma descrição completa do território; 
- elaboração simplificada de representações cartográficas e relatórios dos resultados dos trabalhos.

Para o desenvolvimento do sistema proposto neste trabalho, que a partir de agora, será denominado SIGRIB, não será desenvolvido um SIG no seu conceito pleno, mas sim um SIG que disponibiliza um sistema de roteirização de endereços, fornecendo o menor caminho entre duas localidades, onde temse a troca de informações geográficas das localidades com informações dos endereços e nomes dos pontos principais de localização.

No entanto, acredita-se que o sistema que está sendo proposto poderá servir como tal se a sua base de dados agregar outros tipos de dados, além dos que estão sendo utilizados, descritos nos próximos capítulos.

\subsection{Trabalhos Relacionados}

Souza (Souza, 2000) desenvolveu um sistema para determinar a localização dos pontos de potencial de risco de incêndios, das centrais de atendimento do Corpo de Bombeiros e dos hidrantes na área urbana da cidade de São Carlos - SP, utilizando a tecnologia do Sistema de Posicionamento Global (GPS) para a integração de dados no Sistema de Informações Geográficas. O sistema desenvolvido possibilitou efetuar o mapeamento da cidade de São Carlos-SP, localizando com precisão, os pontos com eventuais riscos de ocorrência de incêndios, bem como, a distribuição espacial das centrais de atendimento do corpo de bombeiros desta cidade. Graças a utilização de um SIG, foi possível detectar a necessidade de novas localizações de centrais de atendimento, ou seja, alocar melhor tais centrais em relação aos pontos de risco de incêndios.

Em (Pfeiffer, 2001) foi utilizado um SIG para a localização/seleção preliminar de áreas adequadas à disposição de resíduos sólidos. Foram identificados os principais elementos de avaliação, tais como, critérios, fatores e ponderações envolvidos em processos de localização de aterros de resíduos sólidos e estes dados foram aplicados em um estudo de caso, em torno da cidade de Ribeirão Preto-SP. Para a seleção de áreas com viabilidade ambiental foram utilizados três diferentes métodos: lógica booleana, ponderação de fatores e lógica fuzzy. 
No trabalho desenvolvido por Alves (Alves, 1997), os processos de localização de atividades econômicas foram considerados, de maneira geral, para atividades agrícolas e industriais, buscando identificar, dentro de um espaço geográfico definido, áreas com potencial para o desenvolvimento dessas atividades econômicas. Para a construção dos cenários de ocupação agrícola e industrial foram utilizados diferentes módulos do software Idrisi, componente de SIG, aplicados para uma área de $156 \mathrm{~km}^{2}$ nos entornos da represa do Lobo, situada nas proximidades da cidade de Itirapina-SP.

Um sistema de apoio à decisão para localização de serviços de educação e saúde sob a ótica dos transportes foi proposto por (Lima, 2003). O objetivo deste trabalho consistiu em otimizar a distribuição de infra-estrutura pontual, principalmente os serviços de saúde e educação, em cidades médias brasileiras, objetivando reduzir custos de transporte. O sistema foi desenvolvido utilizando-se o software TransCAD e dirigido à cidade de São Carlos-SP.

Em (Sá, 2001) encontra-se um modelo físico que foi formulado com base na Emergência Médica, obtendo-se um sistema que integra programas de saúde para localização de pacientes. Foi utilizado um sistema do tipo SIG, o que possibilitou o desenvolvimento de sistemas aplicativos interativos, abordando-se conceitos relativos a modelagem de dados espaciais. Um estudo de caso foi realizado para os hospitais de emergência em Recife.

Um outro trabalho que utiliza o software TransCAD, versão 3.0, para Windows (Caliper, 1996) é o proposto por Santos, Silva e Panico (Santos, 2000), que utiliza modelos de localização e destaca a importância de um SIG em aplicações na área de saúde. Algumas técnicas de localização são apresentadas neste trabalho. Entre elas se encontra o trabalho desenvolvido por Lea e Simmons (Lea e Simmons, 1995), o qual consistiu em encontrar um subconjunto de três centros comerciais de um total de setenta e quatro candidatos, que fornecesse uma visão melhor do mercado como um todo, para a região de Toronto. É também citado o trabalho proposto por Dutra (Dutra, 1998) que utiliza um SIG integrado com um modelo de localização para propor possíveis arranjos de localização de novas escolas ou na realocação de matrículas, de forma a melhor atender à comunidade e de reduzir os custos de deslocamentos casa-escola. Oppong e Hodgson (Oppong, 1994) realizaram um estudo sobre a realocação de serviços em postos de saúde no país de 
Gana. Eles mediram a acessibilidade espacial usando modelos de localização e distribuição, definindo a acessibilidade de duas formas: pela proximidade, quando se trata de medir a distância, medida em termos de distância média ( $p$ mediana), e pelo alcance, quando a acessibilidade é dada em termos de distância máxima de alcance.

Em (Pelizaro, 2000), encontra-se uma avaliação do Delivery, que é um software comercial de roteirização de veículos. Foi realizada uma análise comparativa entre os softwares Delivery e TransCAD em problemas testes e um caso real. Resultados demonstraram que a heurística do software TransCAD apresenta melhor desempenho que a do software Delivery.

Um site onde se pode encontrar um sistema de localização de endereços para várias cidades de São Paulo é 0 site www.terra.com.br/mapas. No entanto, ele apenas localiza um endereço no mapa, mas não forncece uma rota ou o menor caminho existente entre duas localidades. 


\section{Cap. 3 O SISTEMA PROPOSTO}

Neste Capítulo, será apresentada a arquitetura do sistema proposto. Este sistema denominado por SIGRIB, cujo significado é um SIG para o Campus da USP de Ribeirão Preto, é um sistema de roteirização de endereços, via Internet, que possibilita a usuários de toda parte, encontrar a rota do menor caminho entre duas localidades no Campus da USP de Ribeirão Preto.

\subsection{Arquitetura do Sistema Proposto}

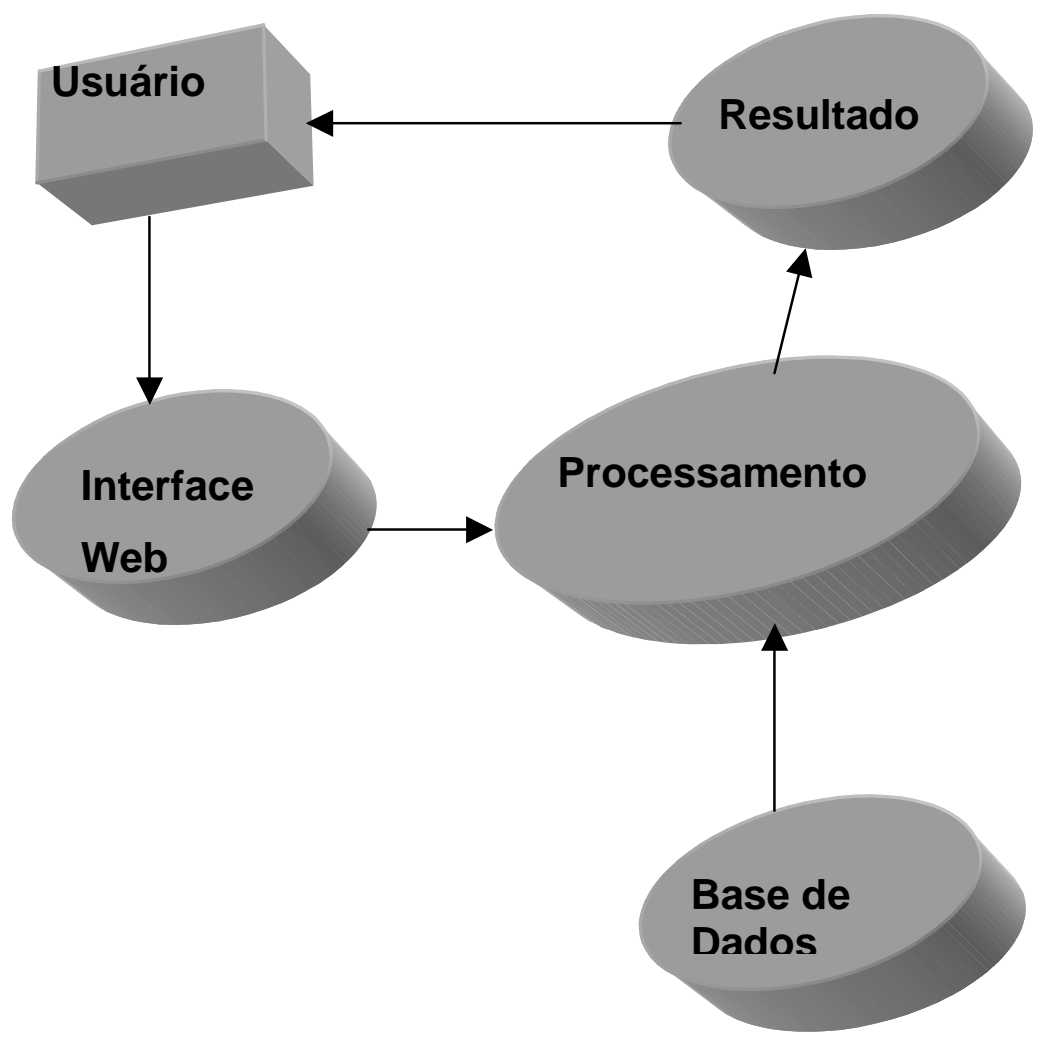

Figura 3.1. Arquitetura do Sistema SIGRIB 
$\mathrm{Na}$ Figura 3.1, é apresentada a arquitetura do sistema proposto. O sistema SIGRIB é composto por quatro módulos básicos: o módulo Interface Web, o módulo constituído pelo banco de dados, o módulo de processamento e o módulo Submapa, cujas funções são descritas a seguir.

\section{- Interface Web}

Este módulo interage diretamente com o usuário e também com o módulo de Processamento. Sua função é receber dados (requisições) fornecidas pelo usuário e enviá-los ao Módulo de Processamento. Os dados a serem fornecidos pelo usuário correspondem ao endereço origem e ao endereço destino, para os quais o usuário deseja saber o menor caminho entre esses endereços. Por ser um módulo importante, este módulo será descrito em detalhes no Capítulo 5. Um exemplo de página Web contendo a página inicial correspondente à pesquisa realizada pelo usuário será mostrada também neste Capítulo.

\section{- Módulo de Processamento}

Este módulo tem a função de receber as duas localidades, no Campus de Ribeirão Preto, fornecidas pelo usuário e acionar um algoritmo para determinar o menor caminho entre essas duas localidades. Para conseguir realizar esta tarefa, este módulo se comunica com o módulo de Banco de Dados. Depois que esta tarefa é completada, este módulo tem ainda a função de gerar uma resposta a ser enviada ao módulo Submapa.

\section{- Módulo Base de Dados}

Este módulo possui dados importantes a serem considerados no mapa digitalizado do Campus de Ribeirão Preto. Esse banco de dados é extremamente necessário para a geração das arestas que compõem o menor caminho. Por ser um módulo importante, este módulo será descrito em detalhes no Capítulo 4. 


\section{- Módulo Resultado}

Este módulo se comunica com o Módulo de Processamento e também com o usuário. Ele recebe o menor caminho fornecido pelo Módulo de Processamento e se incumbe de gerar uma página Web contendo um submapa no qual o menor caminho é destacado na cor "vermelho". Este submapa é enviado ao usuário como resposta à requisição apresentada pelo mesmo. Um exemplo de página Web contendo um submapa correspondente à pesquisa realizada pelo usuário será mostrado no Capítulo 5.

\subsection{Módulo de Processamento}

O módulo de processamento por sua vez se subdivide em outros 2 módulos, como pode ser visto na Figura 3.2.

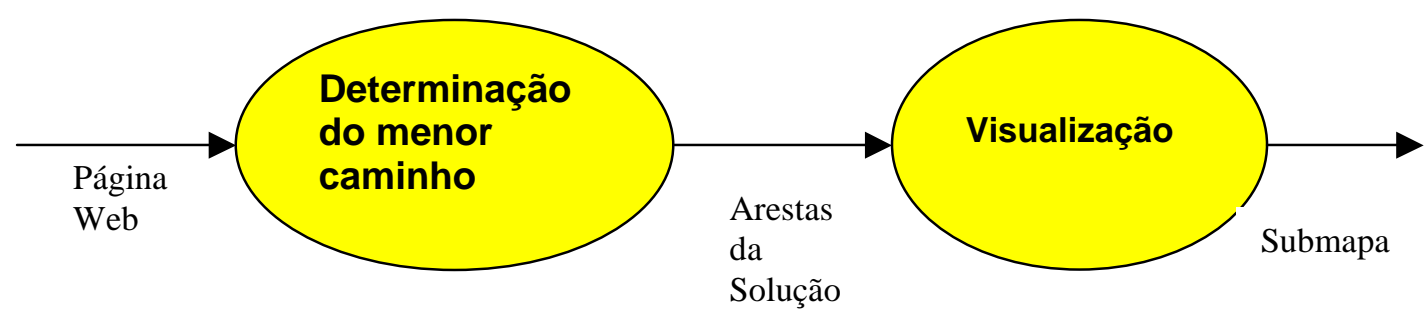

Figura 3.2. Detalhamento do módulo de Processamento

O módulo correspondente a determinação do menor caminho recebe as requisições contidas nas entradas da Página Web, que são os parâmetros que serão enviados na chamada do Algoritmo utilizado para este fim. Este algoritmo e seu funcionamento serão apresentados em detalhes no Capítulo 6. Após o processamento deste algoritmo, uma seqüência de arestas, correspondentes aos segmentos de ruas pertencentes ao caminho otimizado que interliga as duas localidades fornecidas, será enviada ao módulo de Visualização. 
O módulo de Visualização recebe todas as arestas que compõem o caminho determinado e aciona o MapObjects 2.0 para destacar as ruas pertencentes ao menor caminho no mapa, marcando o trajeto, através de uma ferramenta gráfica para a exibição do mesmo.

Foi utilizado o componente Map Objects 2.0 que possui rotinas para que se possa tratar elementos de um banco de dados como objetos, ou seja, este componente tornou-se indispensável para a manipulação do banco de dados criado, o qual será descrito no próximo Capítulo.

Para que o usuário conseguisse diferenciar as ruas pertencentes ao trajeto, ou seja , para destacar as ruas pertencentes ao menor caminho, adotou-se a seguinte estratégia: primeiro utilizou-se de um comando do Banco de Dados SQL para selecionar as ruas pertencentes ao trajeto e depois alterou-se atributos dos dados selecionados, no caso sua cor. Desta forma, o usuário pode diferenciar o traçado do menor caminho através das cores, como pode ser visto na Figura 5.2 do Capítulo 5.

No próximo Capítulo, será descrito em detalhes como foi construída a Base de dados, utilizada no SIGRIB. 


\section{Cap. 4 CONSTRUÇÃO DA BASE DE DADOS}

Neste Capítulo, será descrita uma das componentes básicas que compõem o sistema proposto, que é a Base de Dados.

Para a construção de uma base de dados adequada às consultas que serão requisitadas por um usuário é necessário realizar uma manipulação na planta digitalizada do Campus da USP de Ribeirão Preto.

Para isto, neste capítulo, será apresentado, em detalhes, o processo de inserção desta planta no ARCVIEW, bem como o traçado dos eixos das ruas e a construção de tabelas com informações cadastrais e geográficas dos endereços e pontos mais importantes de localização, dentro do Campus de Ribeirão Preto.

\subsection{Manipulação da planta digitalizada}

A planta digitalizada do Campus de Ribeirão Preto foi fornecida pela COESF.

Esta planta foi obtida a partir de um levantamento aerofotogramétrico realizado pela firma BASE, em outubro de 1998. Seus dados cadastrais são: Elipsóide SAD 69, Projeção UTM , Meridiano Central 45, Datum Horizontal VFranca 91612/V-Jaboticabal 9163 (IBGE), Datum Vertical RN-2924G (IBGE).

Ela foi elaborada no AutoCad e pode ser visualizada na Figura 4.1. 


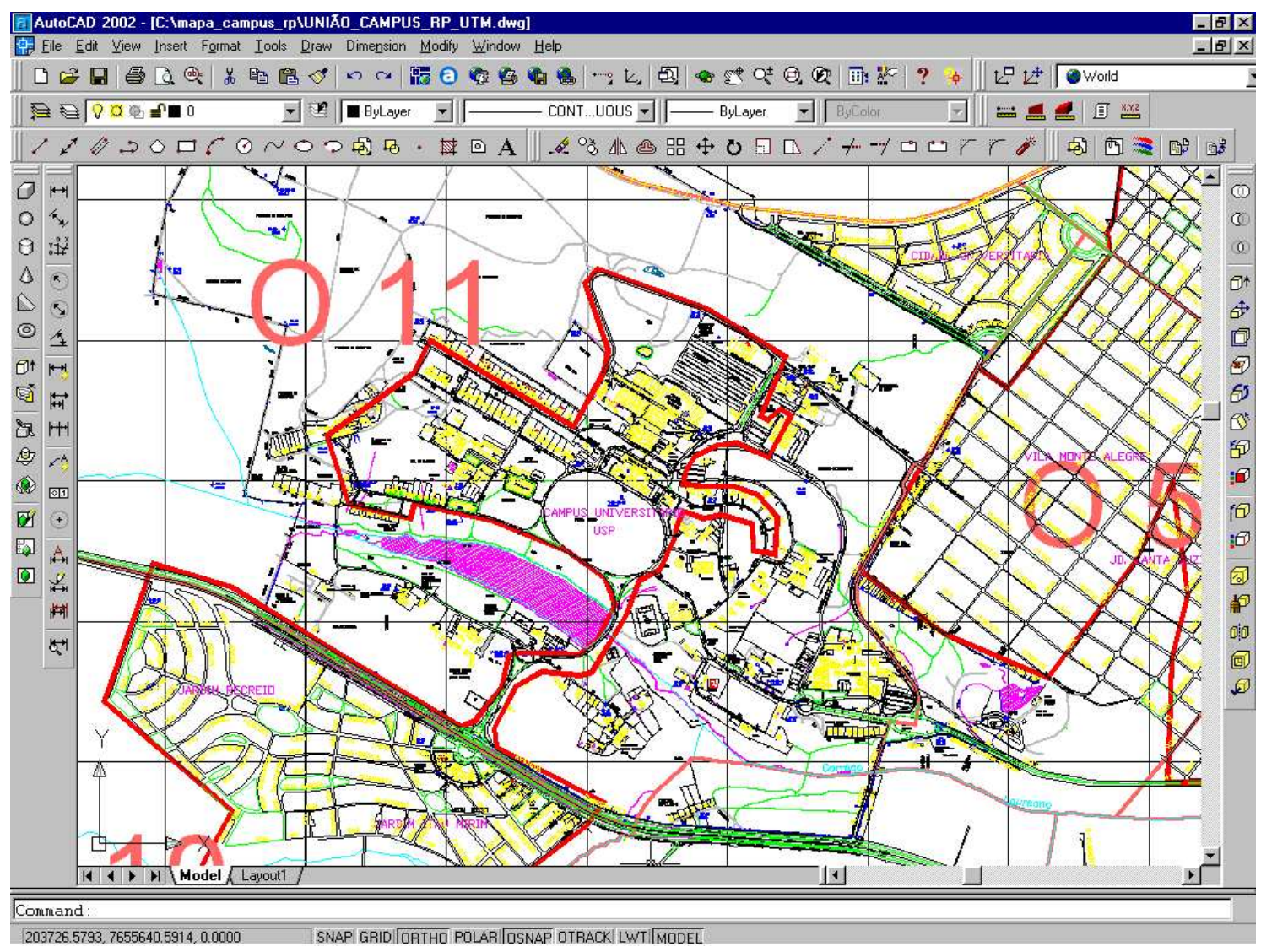

Figura 4.1. Planta digitalizada do Campus de Ribeirão Preto utilizando o AUTOCAD

A planta digitalizada da Figura 4.1 não contém todas as informações desejadas, como por exemplo, os logradouros não estão com os eixos, que serão utilizados para indicação do percurso entre dois pontos de localização desejados, e nem possuem o sentido de orientação das ruas.

Desta forma, a partir desta planta, uma outra planta deveria ser construída, contendo os eixos das ruas (traçados), e com isso a localização de todos os cruzamentos das ruas pode ser obtida. Para a elaboração desse cruzamento de dados foi utilizado o software ARCVIEW 3.2.

Para tanto foi realizado um estudo aprofundado do software ARCVIEW 3.2. Este estudo foi direcionado para a análise da aplicação e implantação do SIG. No entanto, poderia ter sido escolhido qualquer outro software, por exemplo, o SPRING desenvolvido pelo Departamento de Processamento de Imagens do Instituto Nacional de Pesquisas Espaciais - DPI/INPE. 


\subsection{Manipulação de dados no ARCVIEW}

Conceitos de SIG foram utilizados para poder manipular os vários tipos de dados: mapas e tabelas. Escolheu-se o software ArcView 3.2 da ESRI ( Environmental Systems Research Institute, Inc.), cujas características funcionais são:

- Uso de banco de dados relacional, que facilita o manuseio de dados alfanuméricos, não necessitando de um programa gerenciador em separado;

- Possui rotinas voltadas ao gerenciamento urbano;

- Possui agregado ao módulo básico vários recursos de análises e

- Possui suporte para receber extensões complementares disponíveis separadas( ArcView Network Analyst, ArcView Internet Map Server, ArcView Street Map, ArcView Map Object ). (SOUZA, S.M., 2000)

A seguir, será descrito o procedimento para inserção de uma planta digitalizada no ARCVIEW.

\subsubsection{Processo de Inserção de uma planta digitalizada no ARCVIEW}

O primeiro passo foi a inserção da planta digitalizada, através do AutoCad, no ARCVIEW. Para isso é necessário que, com a janela de manipulação de projetos ativada, e por meio do comando File do menu principal, na opção Extensions, se ative a extensão denominada CAD reader, como é mostrado nas Figuras 4.2 e 4.3.

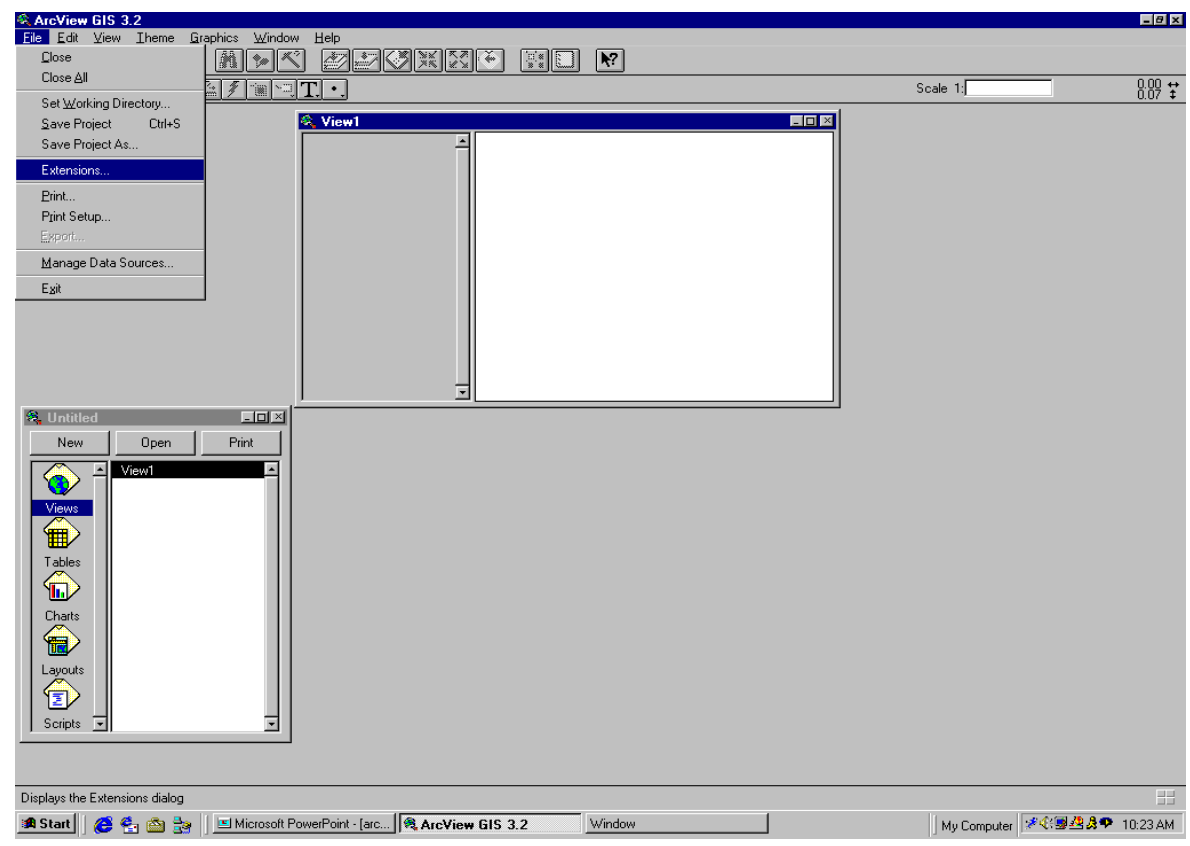

Figura 4.2. Inserção da planta digitalizada no ARCVIEW 


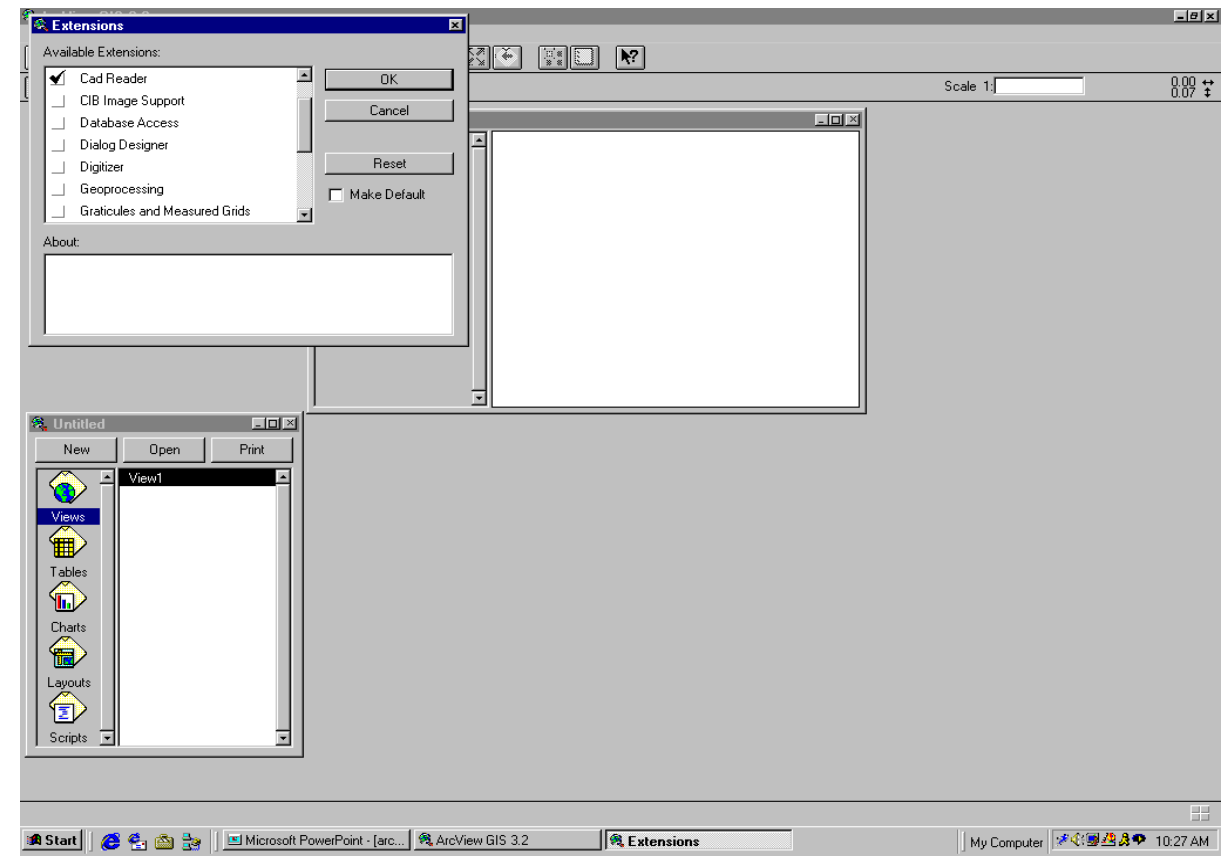

Figura 4.3. Inserção da planta digitalizada no ARCVIEW

O ARCVIEW é um programa organizado em projetos, que é a unidade de trabalho e deve ter um objetivo bem definido. Um trabalho significa uma demanda de determinada análise espacial ou de apresentação que são produtos de níveis de informação (shape) manejados num ambiente de geoprocessamento.

Neste contexto, a inserção de um shape num projeto é feita numa visualização ativa a partir do comando Add theme, como é mostrado na Figura 4.4 .

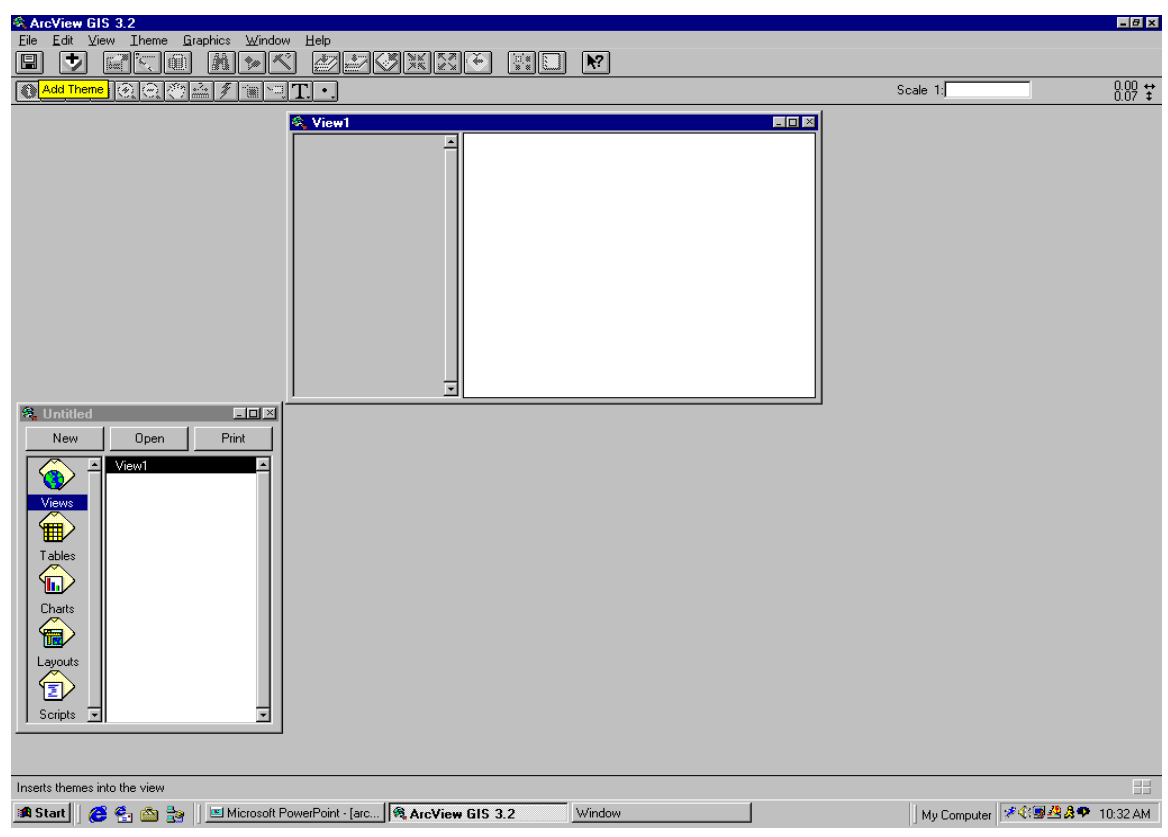

Figura 4.4. Ativação do comando ADD THEME 


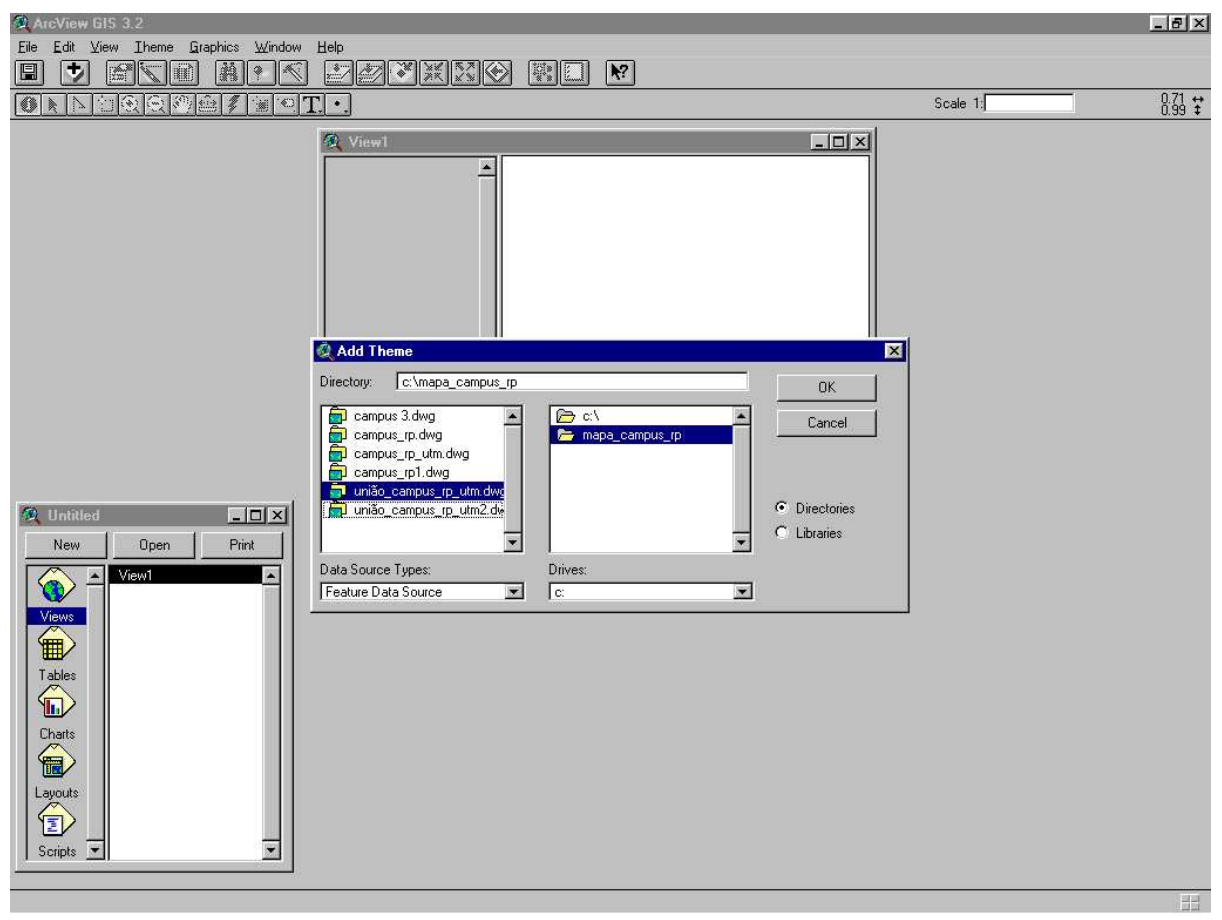

Figura 4.5 - Escolha do arquivo a ser inserido

Após a localização do arquivo que se deseja inserir no Projeto a ser realizado no ARCVIEW (Figura 4.5), deve-se clicar duas vezes no botão esquerdo do mouse sobre o arquivo, para que seja aberta a janela que é apresentada na Figura 4.6 e onde serão selecionados os temas de interesse. No caso do presente trabalho, os temas de interesse são "line", onde tem-se informações de traçado e "annotation", onde tem-se informações de texto. 


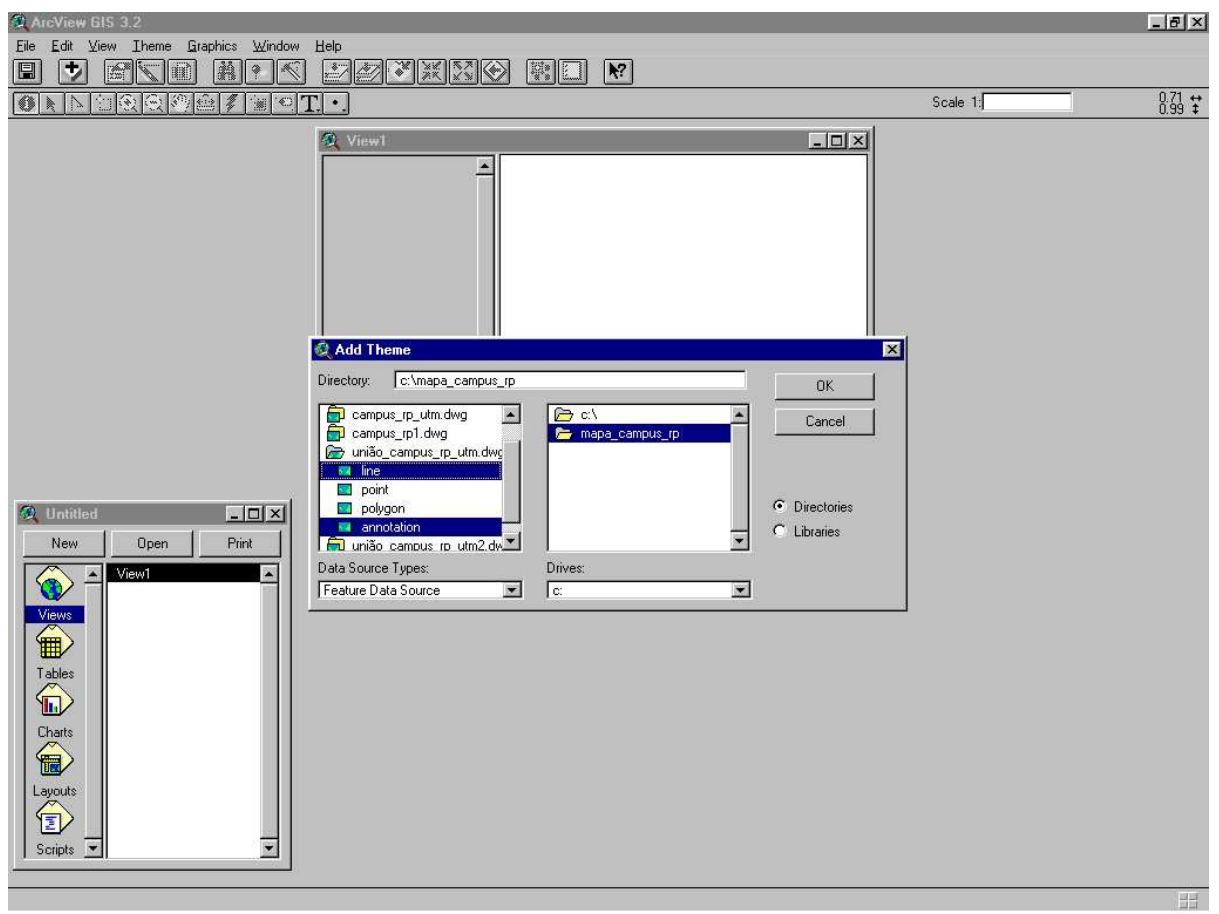

Figura 4.6. Escolha dos temas de interesse

Para ilustração deste procedimento de inserção, na Figura 4.7 pode ser vista a base geográfica da cidade de Ribeirão Preto, inserida no ARCVIEW, seguindo os procedimentos acima descritos.

Como a planta já está georeferenciada em coordenadas UTM, pois, este serviço já havia sido feito no AutoCAD, como pode ser visto na Figura 4.1 os eixos das coordenadas UTM, o ARCVIEW, automaticamente, também já transporta esta informação de georeferenciamento para o Projeto. 


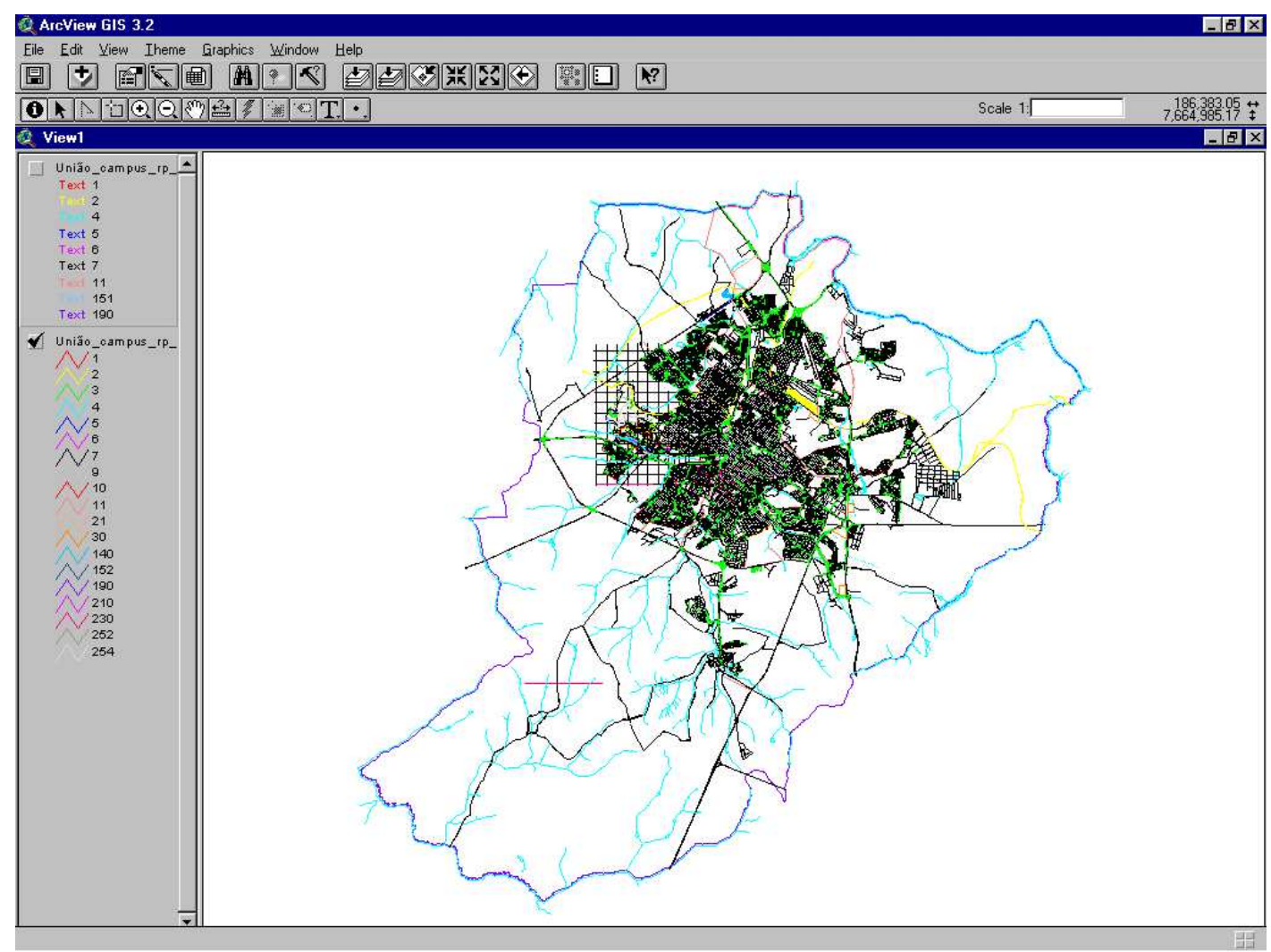

Figura 4.7. Planta digitalizada da cidade de Ribeirão Preto inserida no Projeto

Após a inserção deve ser feita a criação de outro tema no qual será feito o traçado dos eixos das ruas, que determinará o percurso entre dois pontos.

\subsubsection{Como executar o traçado dos eixos das ruas}

O primeiro passo foi a criação de um novo tema "traçado_eixo_ruas", como é mostrado nas Figuras 4.8, 4.9 e 4.10. Inicialmente, deve-se clicar no menu principal "View" e "New Theme" como mostrado na Figura 4.8. Em seguida, é aberta a janela que é apresentada na Figura 4.9 onde seleciona-se o tipo de objeto que se deseja trabalhar; no caso deste projeto o tipo de objeto é linha (line). Após a seleção será aberta outra janela onde se deve nomear o arquivo (formato shp de shape) que será gerado pelo ARCVIEW o que deve ser armazenado no diretório onde está o projeto em estudo. 


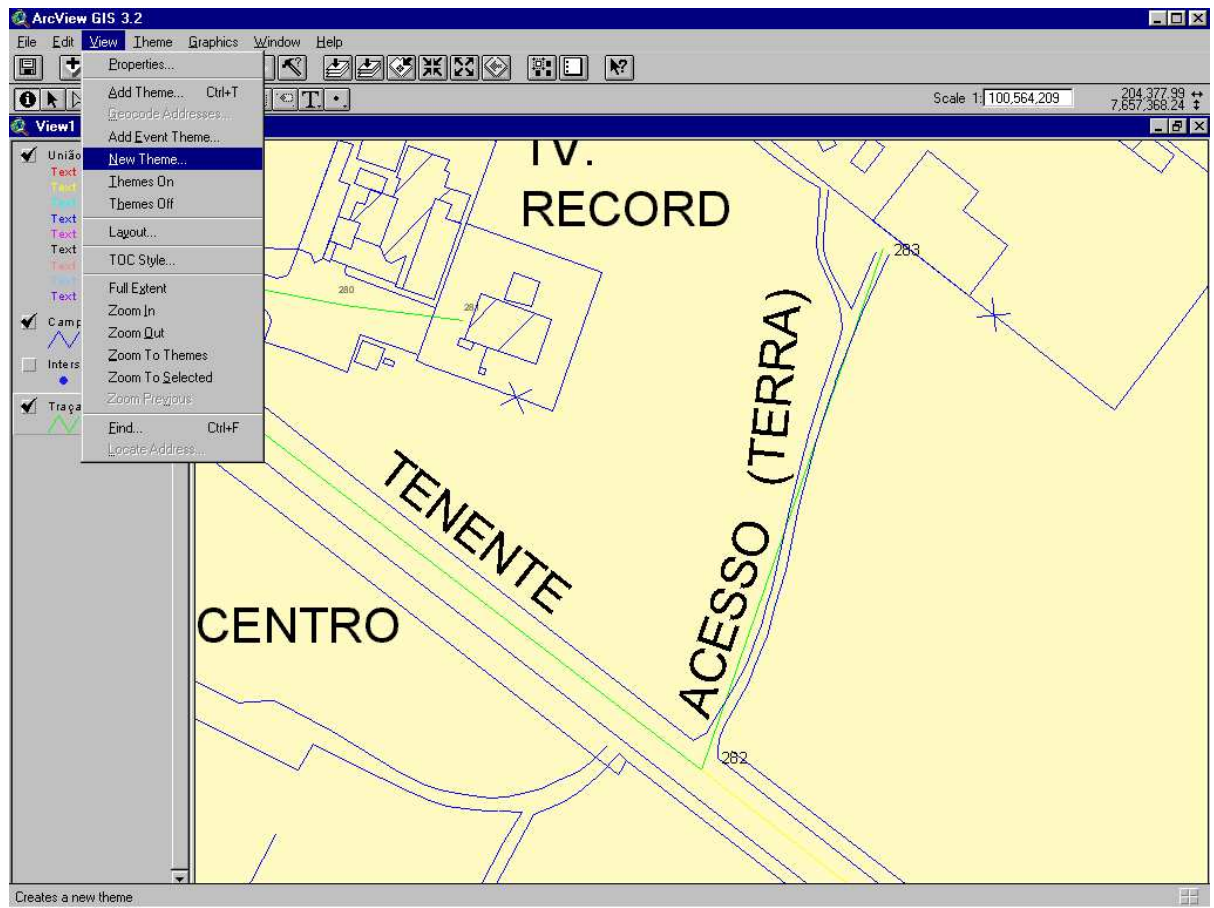

Figura 4.8. Criando um novo tema "Traçado_eixo_ruas"

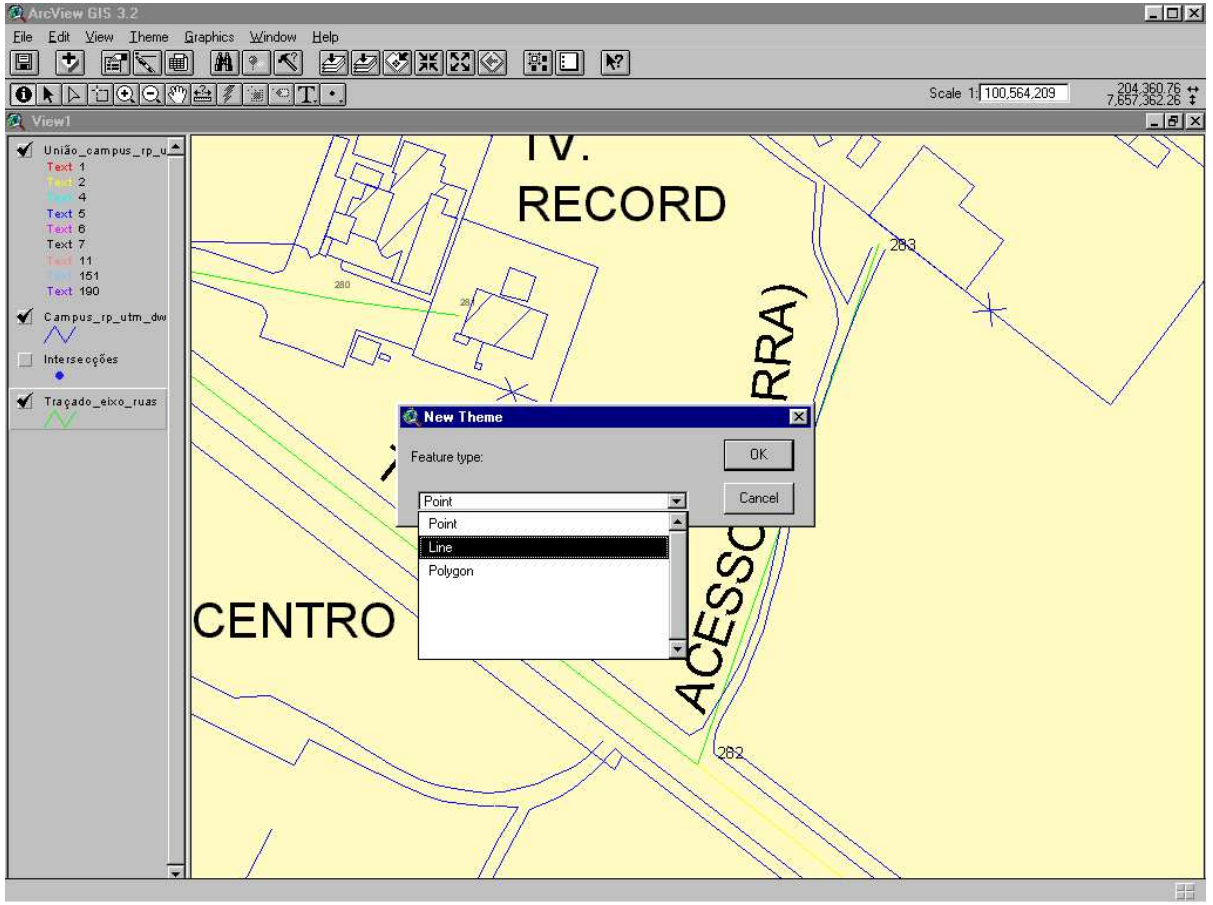

Figura 4.9 - Definindo o tipo de objeto do tema "Traçado_eixo_ruas" 


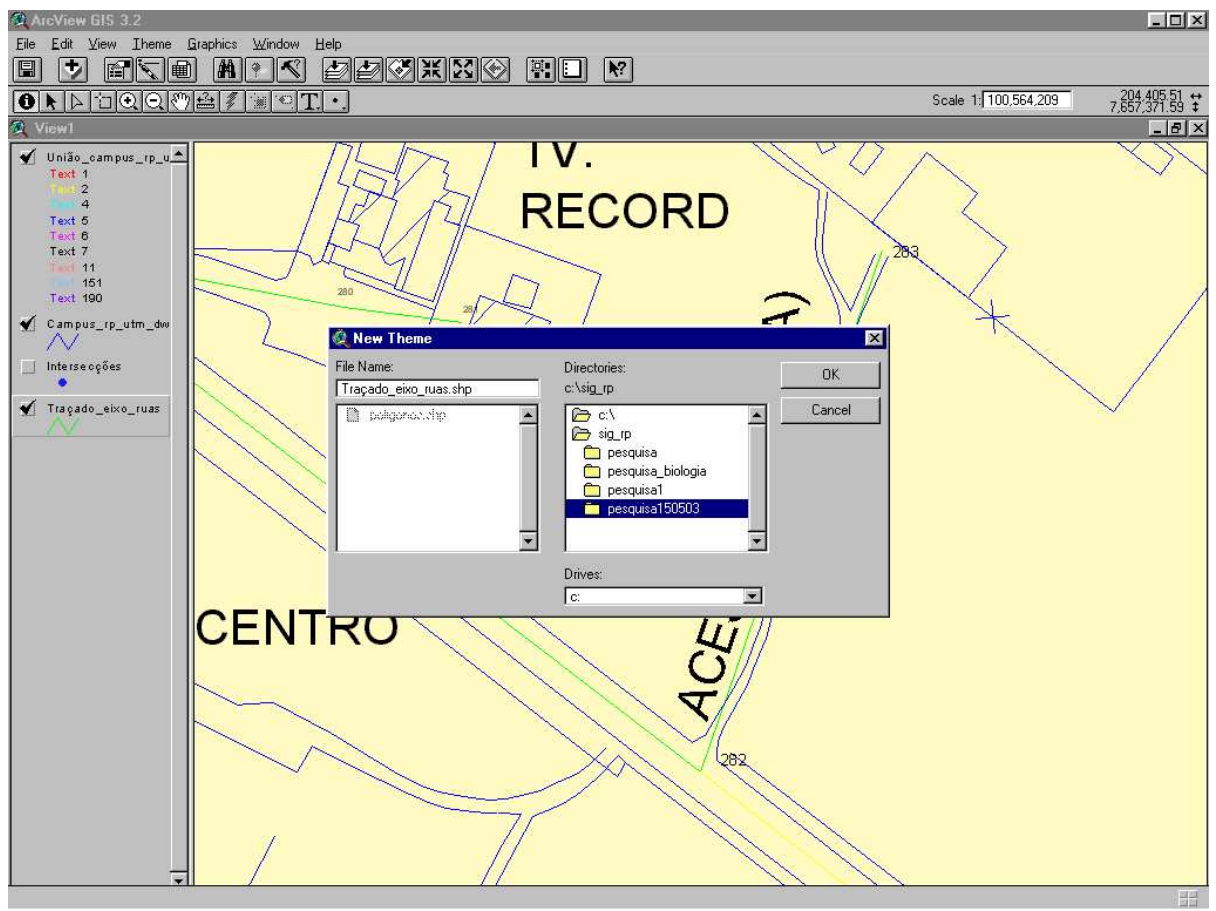

Figura 4.10 - Nomeando o arquivo e salvando o novo tema

Em seguida à criação do tema "Traçado_eixo_ruas" inicia-se a edição dele, o qual determinará o eixo das ruas, para isso ativa-se o tema clicando-se sobre ele e no menu principal em "Theme" e "Start Editing", como é apresentado na Figura 4.11.

$\mathrm{Na}$ Figura 4.12, é visto como é feita a ativação da ferramenta "Snapping", ou seja com o botão direito do mouse clicado seleciona-se "Enable General Snapping".

Para o traçado dos eixos das ruas deve-se clicar no ícone do menu principal "Line" e iniciar o traçado de uma reta entre dois pontos característicos, como é apresentado nas Figuras 4.13 e 4.14 . 


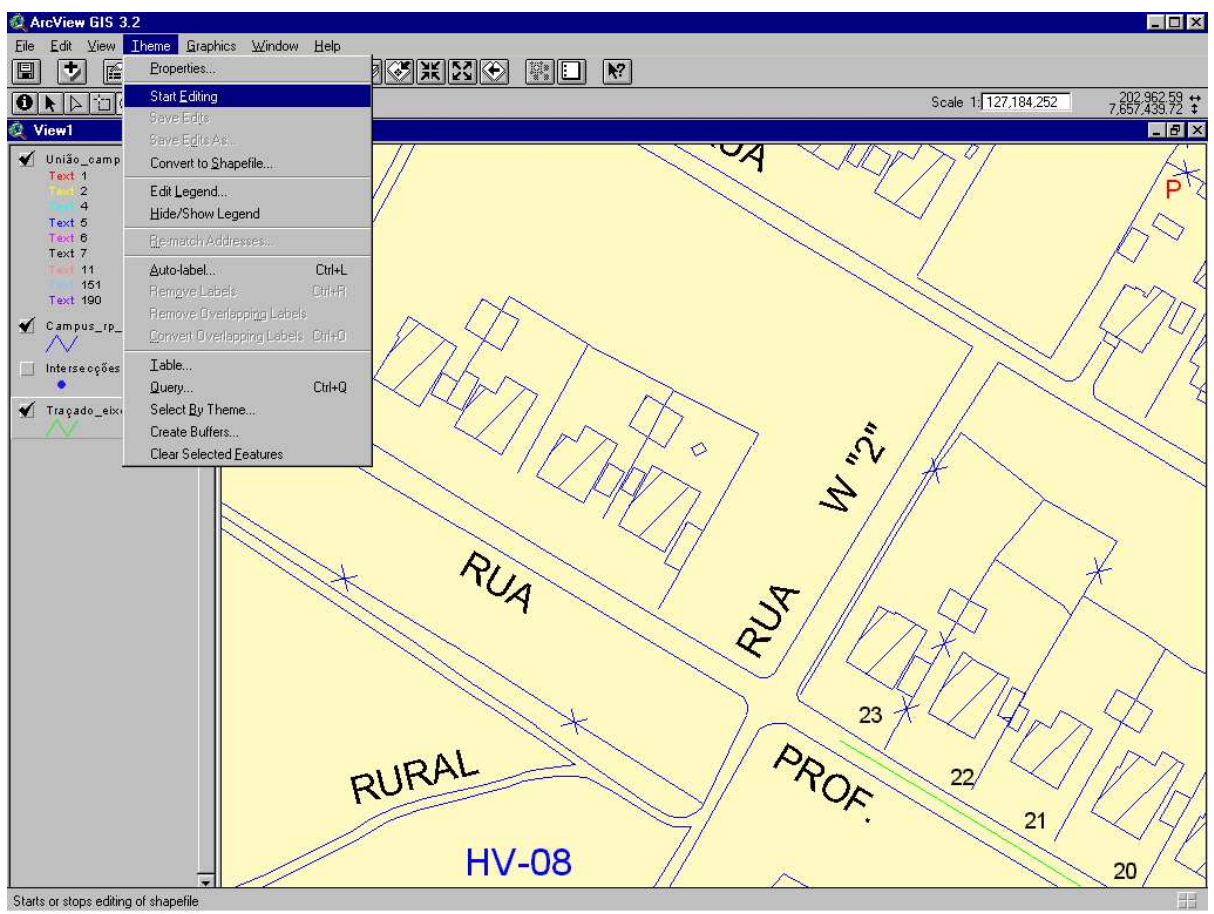

Figura 4.11. Iniciando a editar o novo tema

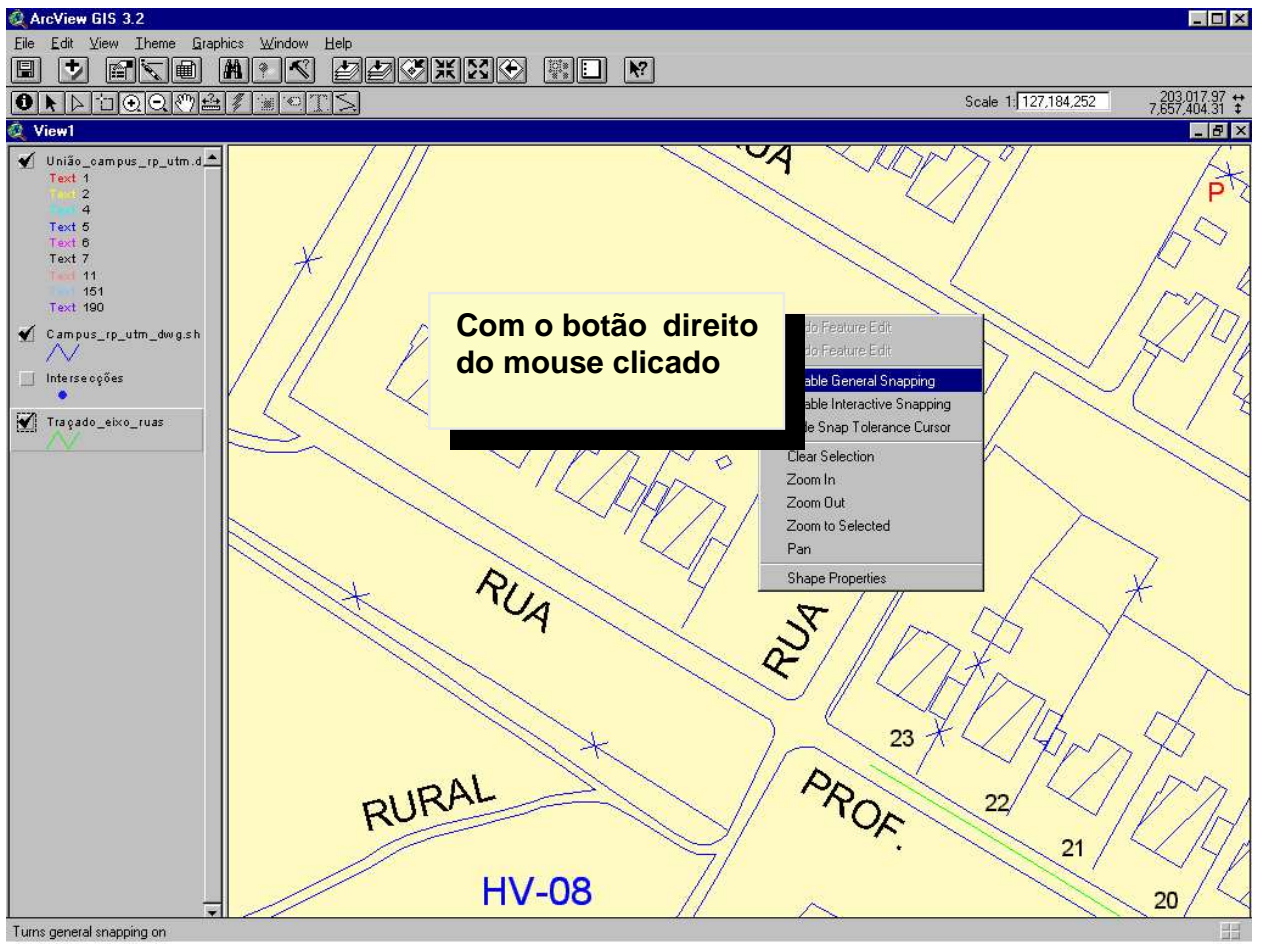

Figura 4.12. Ativando a ferramenta "Snapping" 


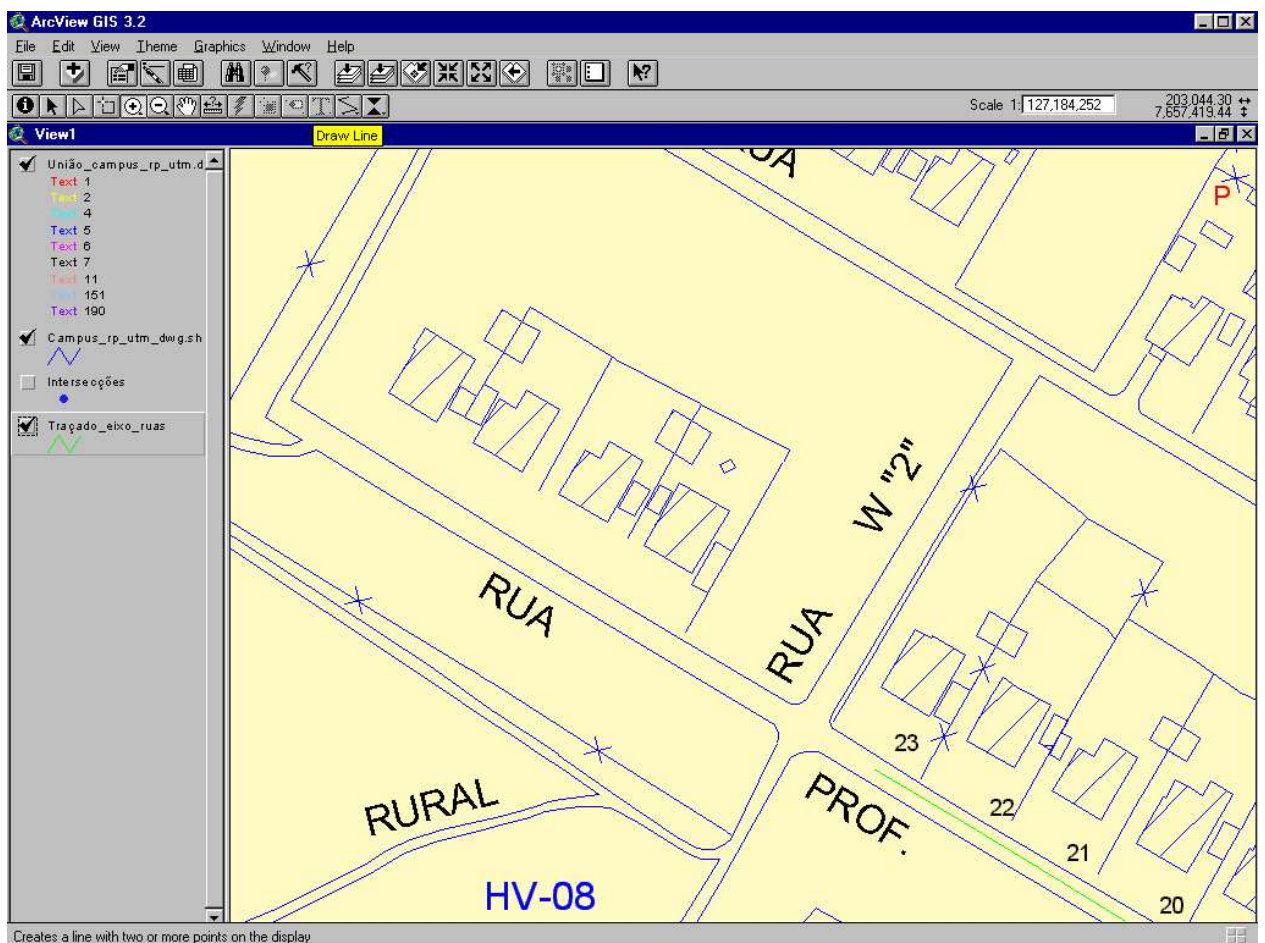

Figura 4.13. Ativando a ferramenta "Draw Line"

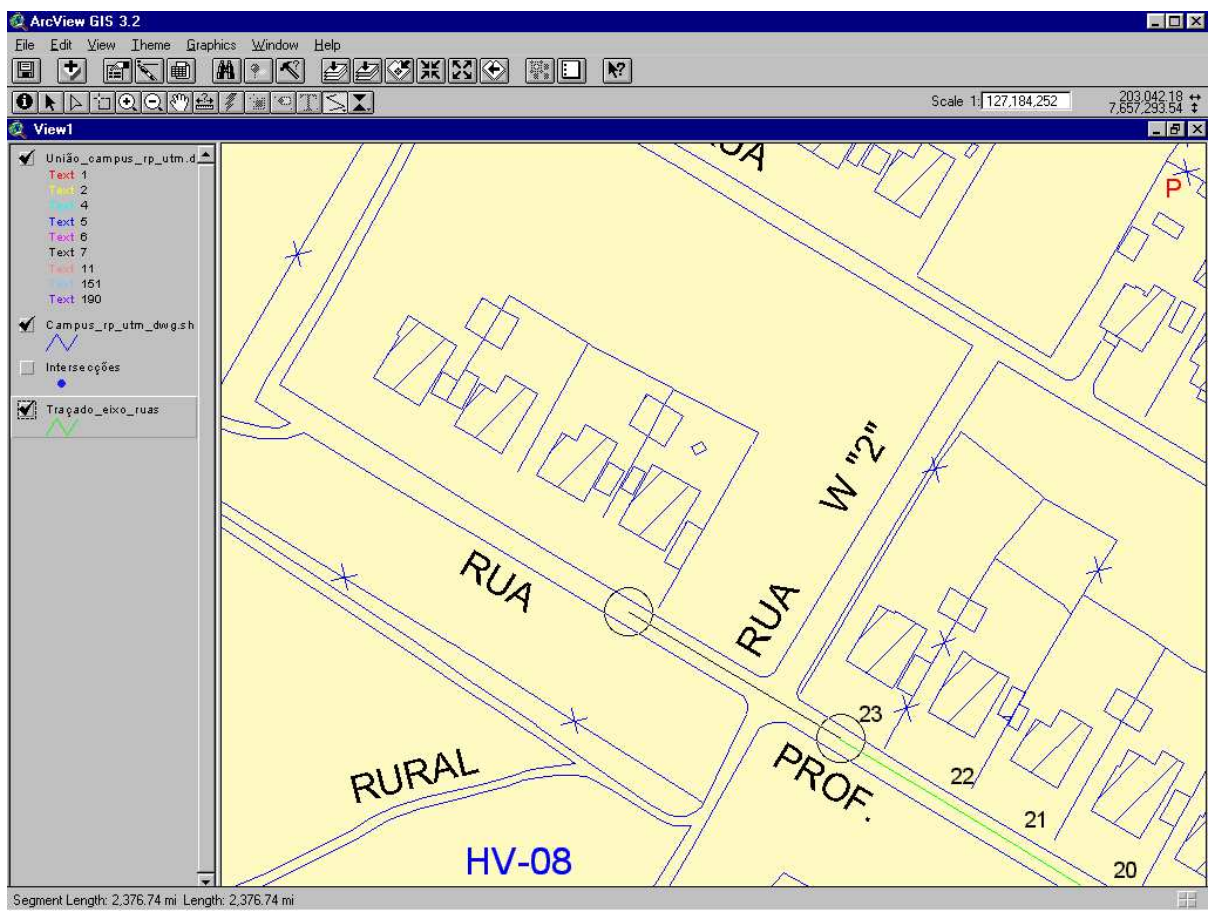

Figura 4.14. Executando o traçado de uma linha (eixo) 
Após o traçado de uma linha necessita-se definir parâmetros para duas características do objeto linha que são: a Identificação (ID) e seu comprimento.

$\mathrm{Na}$ Figura 4.15, pode-se observar que no menu principal foi clicado o ícone "identify" que permite a abertura da janela "Identify Results". Em seguida abre-se a tabela "Attributes of Traçado_eixo_ruas" e deve-se clicar no ícone "Edit" para iniciar sua edição, como é mostrado na Figura 4.16.

Clicando-se na coluna ID da tabela "Attributes of Traçado_eixo_ruas" define-se o número de identificação da reta traçada, aque no exemplo da Figura 4.17 é 166, porque nesse caso a última reta traçada, até então, tinha como ID o número 165.

Agora, na Figura 4.18, mostra-se como é iniciado o cálculo do comprimento da reta, inicialmente, deve-se clicar na coluna comprimento da tabela "Attributes of Traçado_eixo_ruas" e em seguida no menu principal devese clicar em "Field" e selecionar "Calculate", que permitirá a abertura da janela "Field Calculator", mostrada na Figura 4.19.

Nesta Figura, define-se que o comprimento é um número (Type) e digitase a sentença (Shape).RETURNLENGTH, a qual implicará que o ARCVIEW calculará o comprimento da reta traçada.

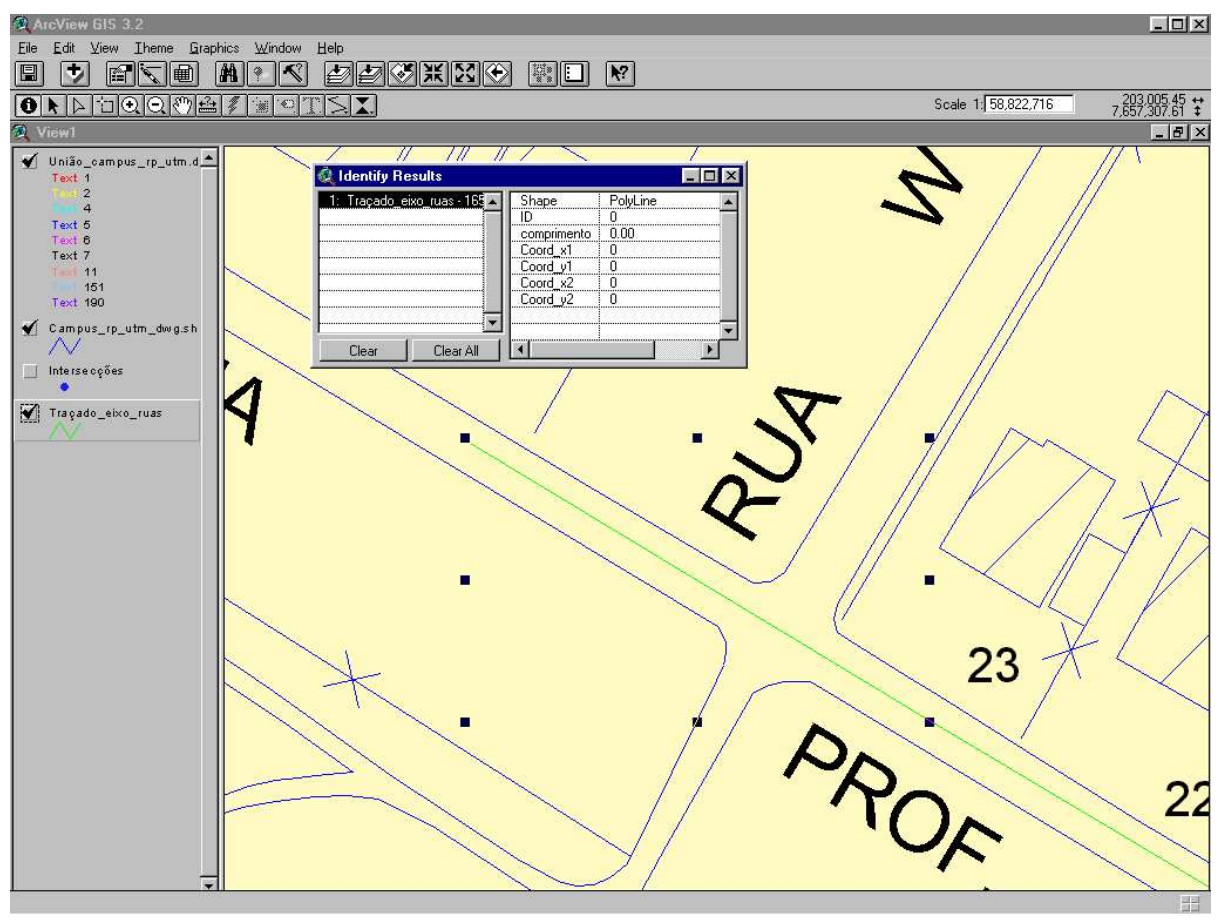

Figura 4.15. Definindo os elementos do objeto linha 


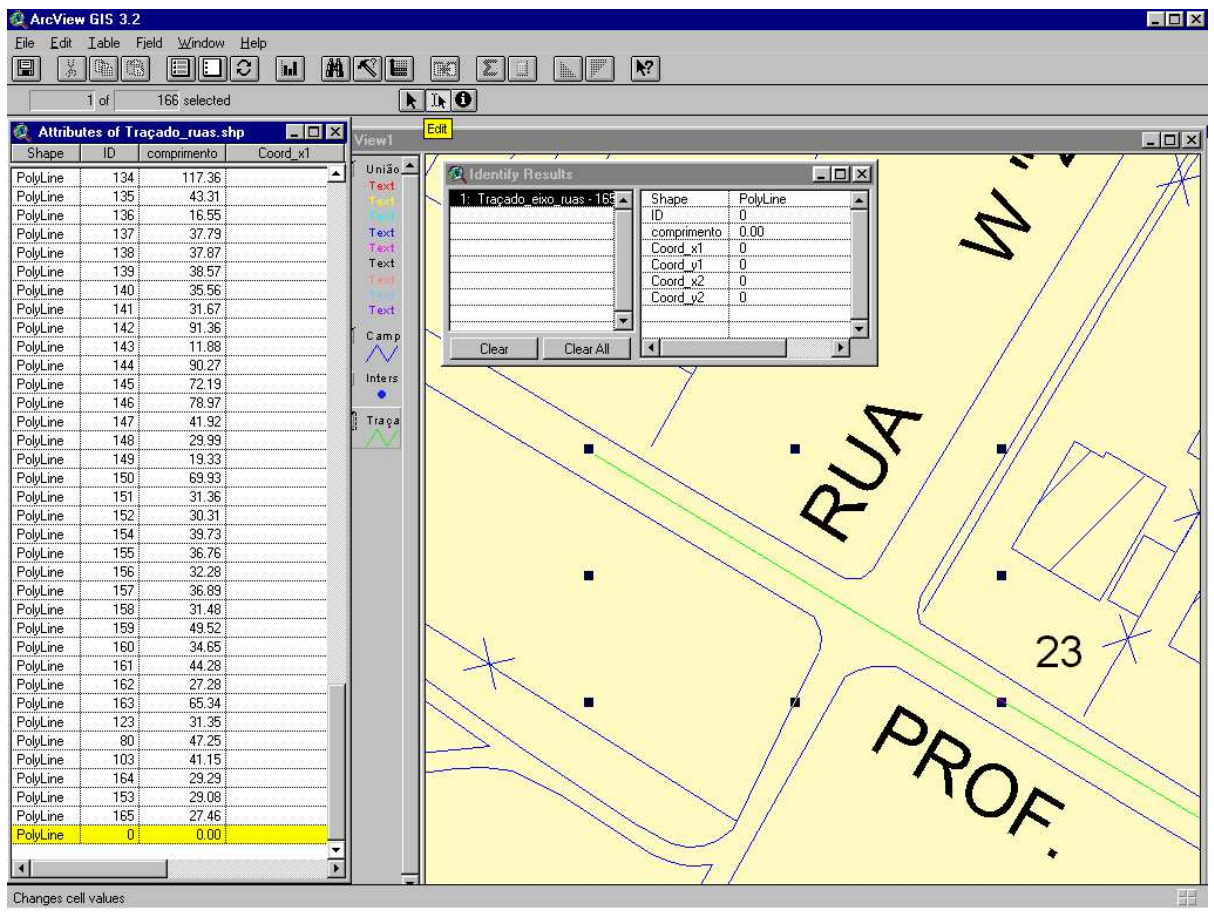

Figura 4.16. Editando a tabela de atributos do objeto linha

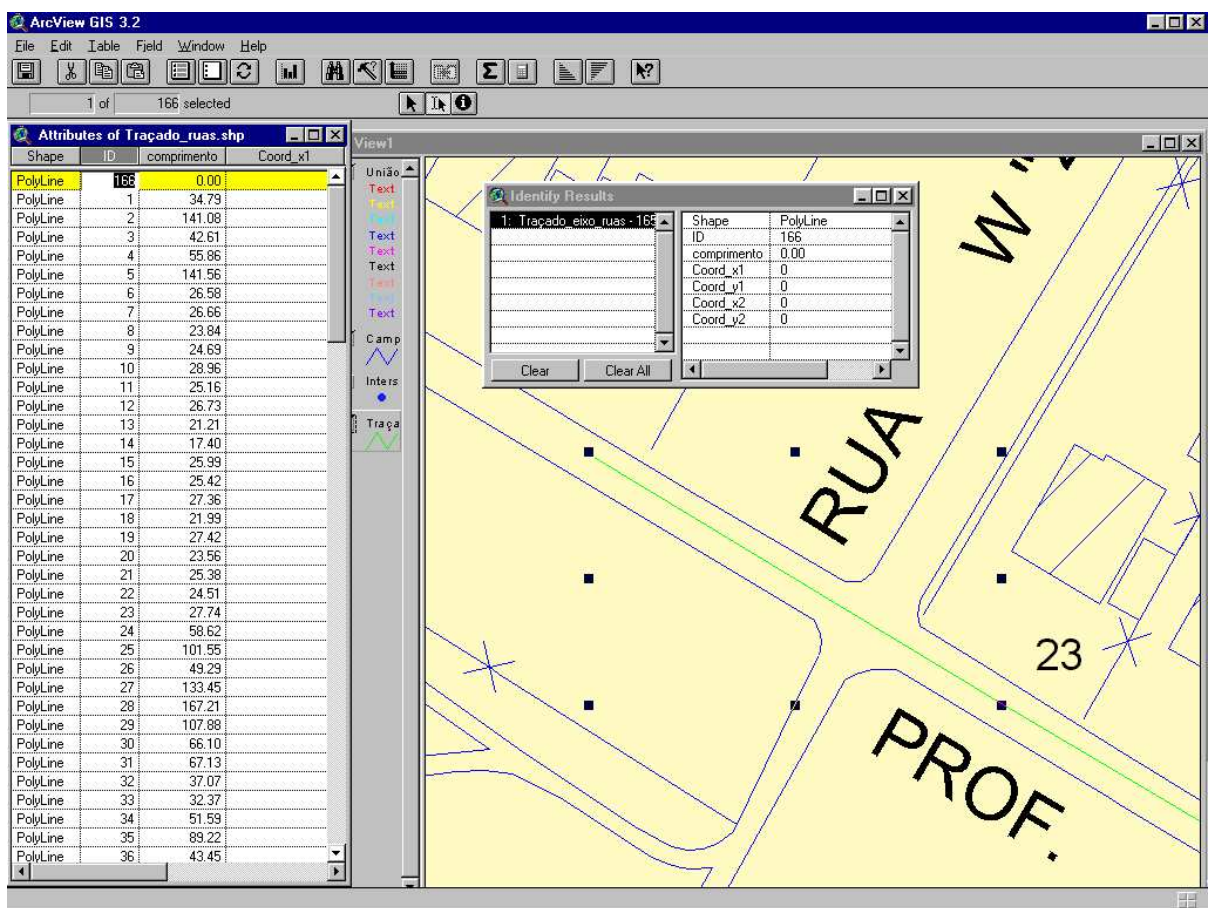

Figura 4.17. Editando a tabela de atributos do objeto linha 


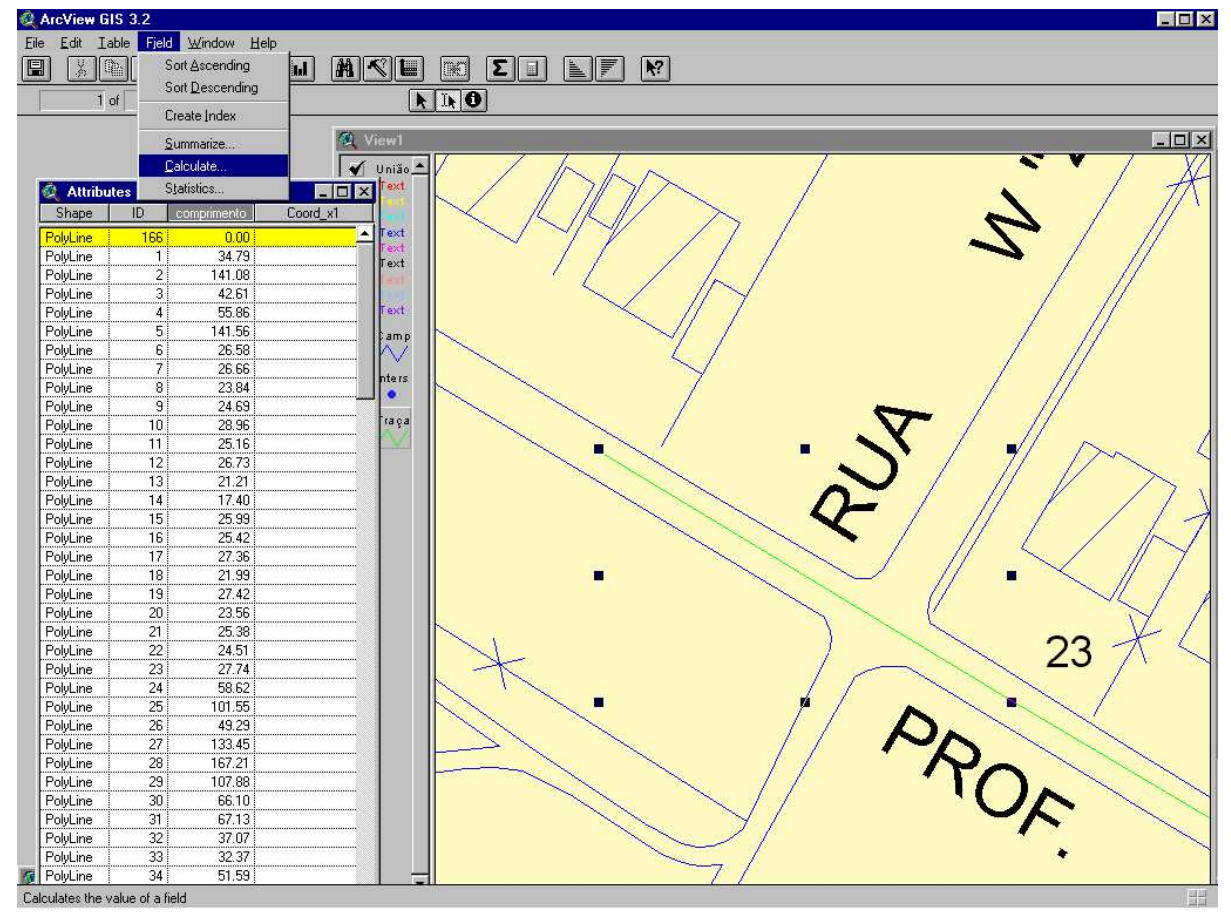

Figura 4.18. Calculando o comprimento do objeto linha

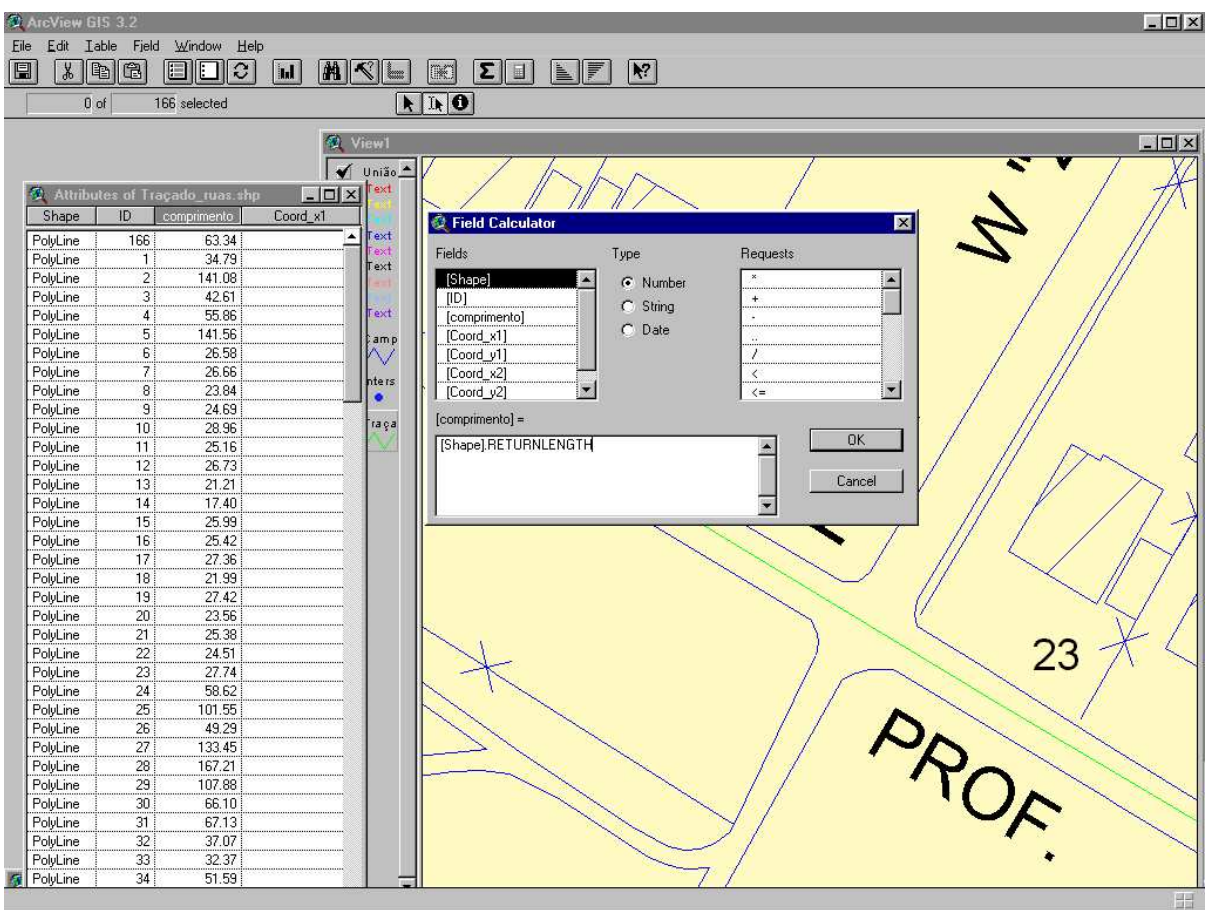

Figura 4.19. Calculando o comprimento do objeto linha 


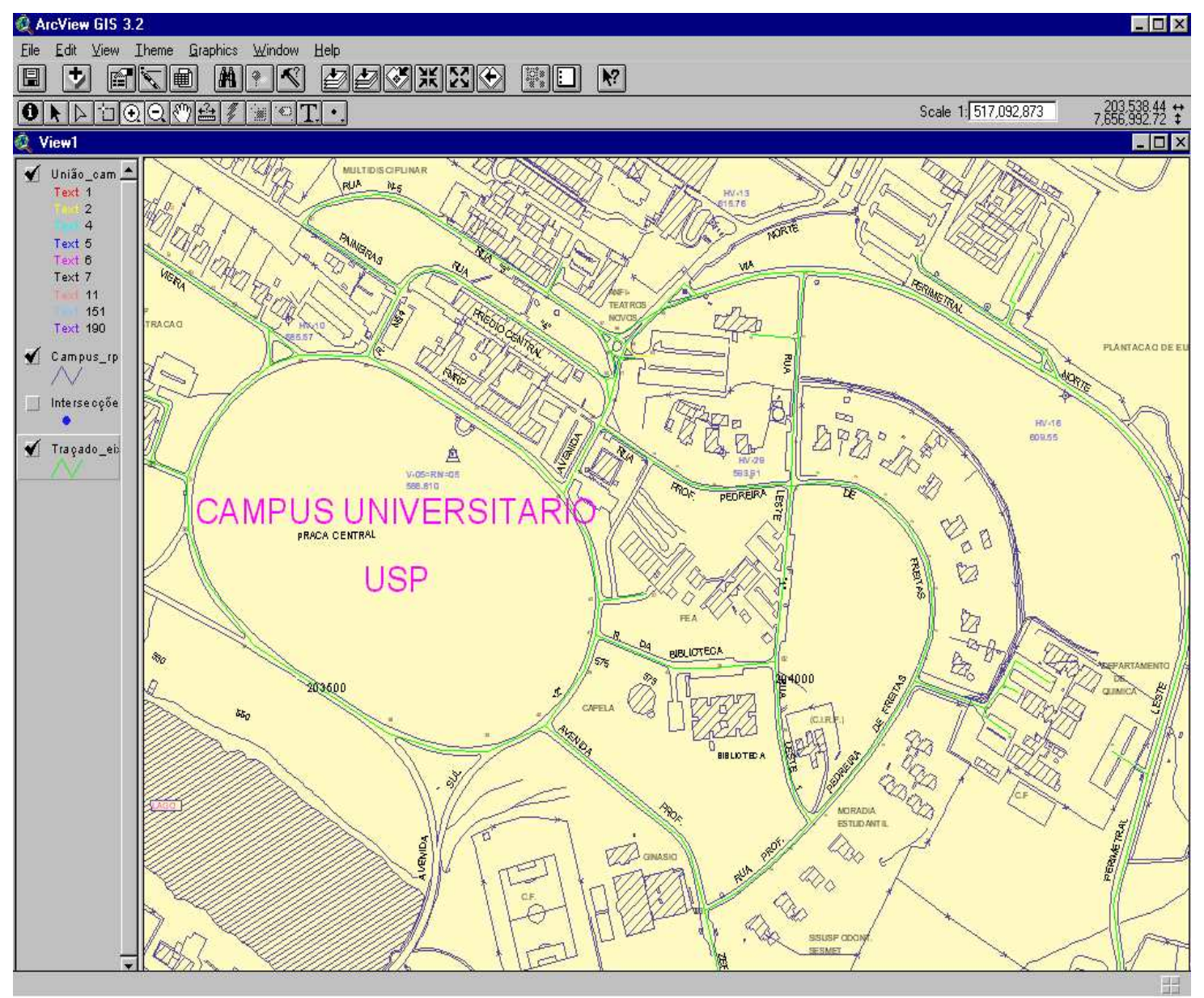

Figura 4.20. Base Geográfica do Campus da USP de Ribeirão Preto inserida no ARCVIEW com os traçados dos eixos.

Na Figura 4.20, pode-se observar a base geográfica do Campus da USP de Ribeirão Preto, com os traçados de todos os percursos possíveis neste Campus.

Em seguida, uma adaptação e vinculação da planta digitalizada no SIG foram realizadas. Nesta fase, vários pontos foram definidos na planta. Para demarcação dos pontos, foi feito um levantamento dos pontos mais importantes do Campus de Ribeirão Preto, junto à Prefeitura do Campus de Ribeirão Preto. Estes pontos foram marcados na planta como pontos principais de referência. Foram definidos 284 pontos correspondentes às localidades importantes do Campus da USP de Ribeirão Preto. Além destes pontos, outros 
pontos auxiliares foram marcados, totalizando 335 pontos ao todo. Esses pontos são referentes a cruzamentos entre ruas.

Esses pontos são georreferenciados através de coordenadas UTM, porque a planta digitalizada já está georreferenciada com base nas coordenadas UTM e o DATUM SAD-69.

Como as bases de dados citadas acima precisam ser vinculadas através de um SIG é fundamental que se tenha um total controle de escala, longitudes e latitudes, relacionadas a todos os dados, para que se possa saber as distâncias entre um ponto e outro, assim como para poder calcular o menor caminho entre as localidades desejadas (DAVIS JR, 1997).

\subsection{Criação da Base de Dados}

Algumas bases foram criadas com informações sobre os principais locais existentes no Campus bem como as vias de tráfegos, de forma a possibilitar a criação de um grafo, cujos pesos entre dois pontos são as distâncias entre eles. A seguir, são descritas todas as bases de dados que foram construídas para a realização deste projeto.

Foram utilizados dois tipos de Base de Dados para a construção do sistema. As duas bases de dados se complementam de forma a se obter a funcionalidade esperada.

A base de dados geométricos criada pelo ARCVIEW 3.2 possui informações georreferenciadas do Campus da USP - Ribeirão Preto. Esta base de dados contém informações sobre cada segmento de reta do mapa (ruas); cada segmento possui um campo de identificação (ID), da forma que ilustra a imagem da Figura 4.21. 


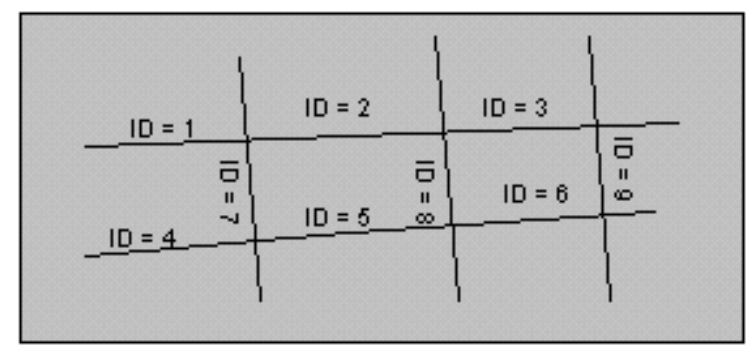

Figura 4.21: Representação dos Identificadores das arestas.

Assim, pode-se referenciar a cada segmento de reta de forma independente, o que possibilita, por exemplo, imprimir as ruas pertencentes ao trajeto de forma destacada em relação às ruas que não pertencem ao trajeto.

A segunda base de dados é criada com a finalidade de determinar o menor caminho entre dois locais distintos no Campus da USP de Ribeirão Preto.

Foi utilizado o software Paradox 7.0 para a construção desta base de dados. Para isto foram construídas 3 tabelas, com informações de vértices adjacentes, informações que relacionam pontos (esquinas) e Ids de ruas e informações que indicam os segmentos pertencentes a cada rua. Abaixo, são descritas as funcionalidades de cada tabela:

\section{Tabela "Adjacentes"}

Define-se a 'matriz de adjacências' como sendo uma matriz que contém dados referentes à comunicação entre vértices e distâncias entre eles (ver Figura 4.22).

Para todos os pontos demarcados no mapa foram calculadas, usando o software ARCVIEW, todas as distâncias de cada ponto ao seu adjacente, armazenando numa base de dados, para cada ponto, o(s) seu(s) respectivo(s) adjacente(s) e a(s) distância(s) em metros correspondente. Um exemplo da tabela gerada pode ser visto na Figura 4.22. 
É nesta tabela que se define, também, o sentido de mão de trânsito, com relação a carros, das ruas. Esse sentido é dado com base na comunicação entre o ponto e seus adjacentes.

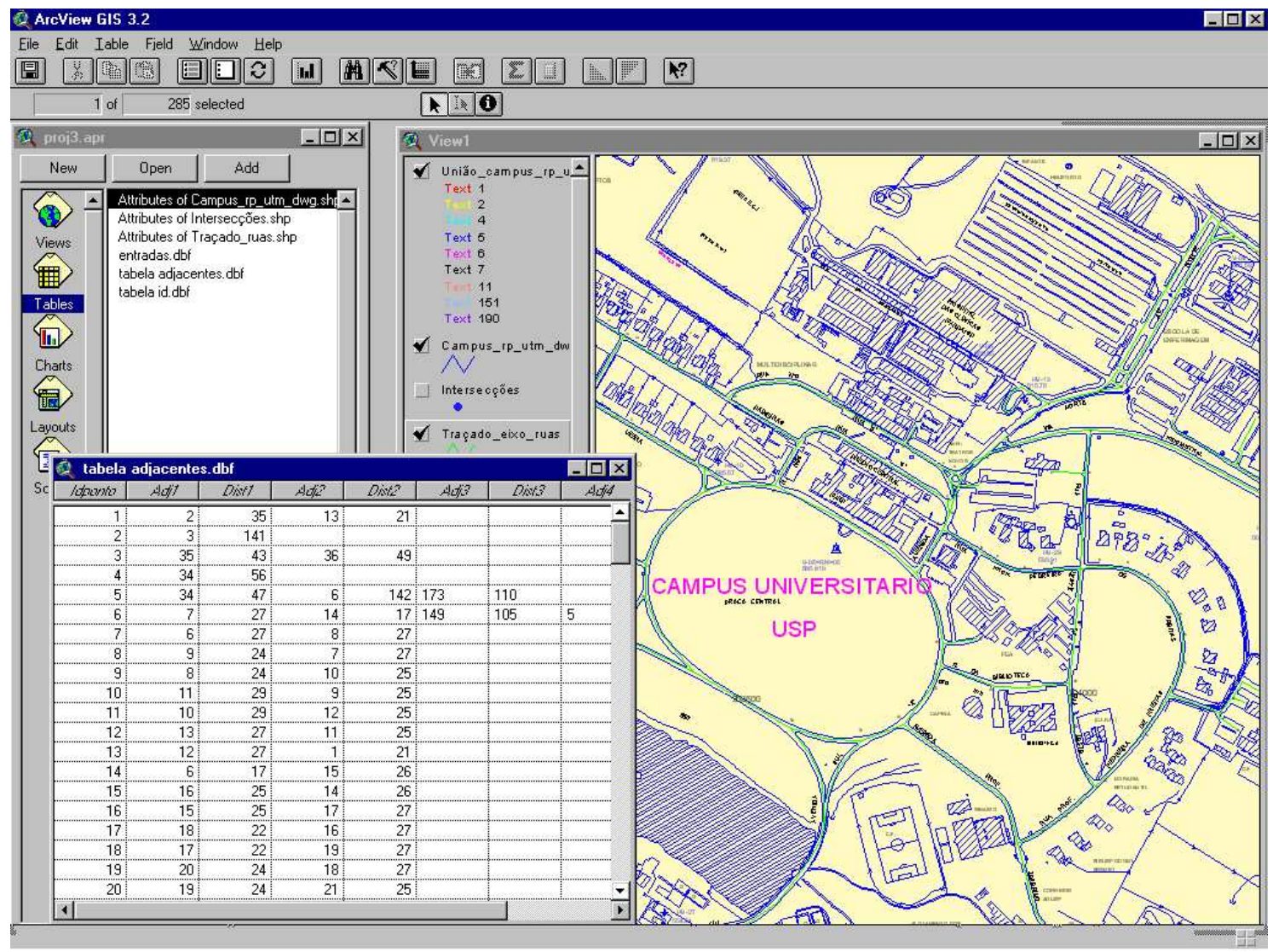

Figura 4.22.Tabela de adjacentes e respectivas distâncias

- Tabela "Ids"

Relaciona vértices com 'Ids' dos segmentos de reta (ver Figura 4.23).

Esta tabela contém todas as arestas existentes. Para cada aresta foi associada uma identificação, denominada de Ids. Na Figura 4.23, esta base pode ser visualizada, onde se tem os pontos que determinam uma aresta com suas respectivas identificações. Por exemplo, entre os pontos 1 e 2 existe uma aresta que é identificada com id $=1$.

Este Banco de Dados permite a criação de um grafo, sobre o qual aplica-se o algoritmo de Dijkstra para a determinação do menor caminho. 


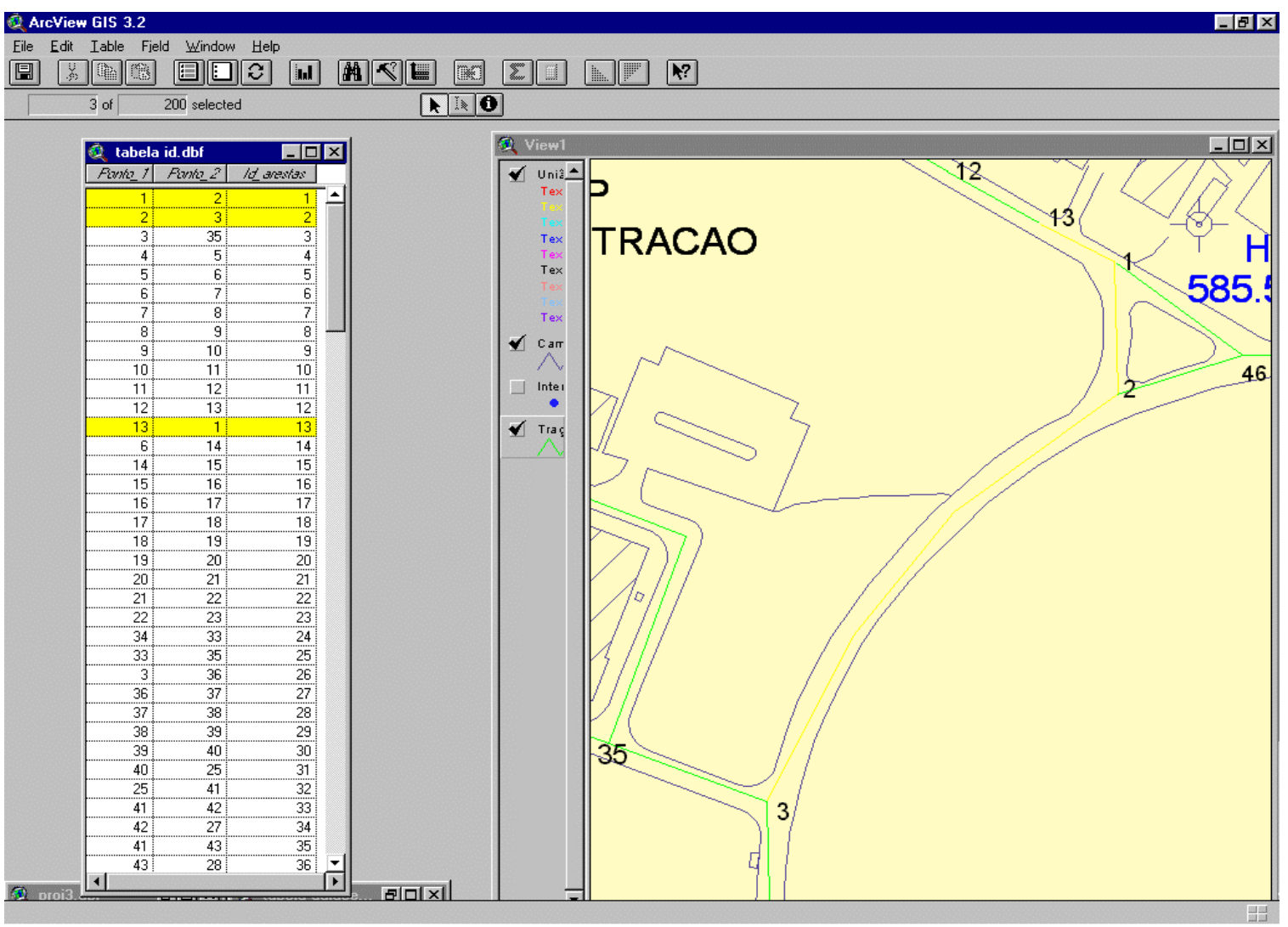

Figura 4.23 - Tabela de Ids: Arestas com respectivos Idendificações

\section{- Tabela "Entradas"}

Relaciona informações dos logradouros (nome da rua e número) com vértices.

$\mathrm{Na}$ Figura 4.24, nota-se os vários pontos que foram marcados. Esses pontos, como já foi dito, se referem às localidades mais importantes do Campus de Ribeirão Preto e alguns servem como auxiliares para indicar mudança de percurso.

Cada ponto recebeu uma identificação (um número) e assim foi gerada uma tabela relacionando cada ponto com o nome da localidade que ele representa no Campus.

$\mathrm{Na}$ Figura 4.24, pode ser visto esta base de dados. Por exemplo, o ponto 1 representa a localidade: Centro de Telefonia, no Campus de Ribeirão Preto. 


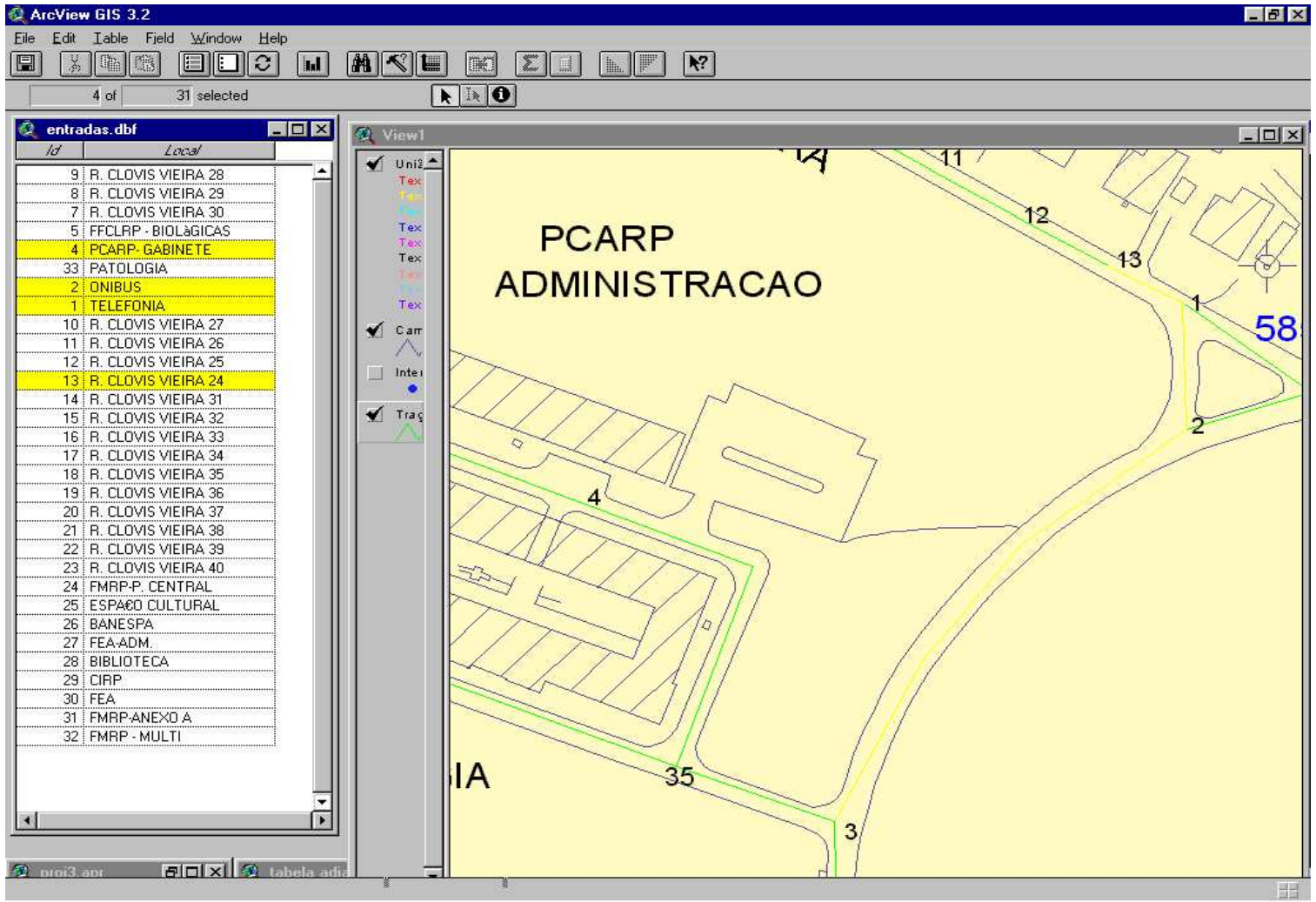

Figura 4.24. Tabela Entradas: Localidades importantes e pontos associados

Após a obtenção dos eixos de ruas e da base de dados de nomes de ruas e pontos de referência, um cruzamento de dados pôde ser feito, para que os nomes de ruas fossem associados ao desenho destas, assim como os desenhos de ruas fossem associados ao seu nome.

O mapa digital do Campus da USP do Ribeirão Preto foi devidamente adaptado ao SIG e tratado da seguinte forma: cada esquina do mapa foi considerada como um vértice de um grafo orientado, onde cada aresta representa um segmento de rua ligando duas esquinas.

Para cada aresta, foi atribuído um peso, correspondendo à distância, em metros, de uma esquina a outra. Este peso entra como parâmetro na base para o cálculo do menor caminho entre dois vértices. 
Para o armazenamento e expansão de tal grafo, foram usadas estruturas de bancos de dados Paradox e SQL.

Para que o usuário tenha acesso ao aplicativo de localização de endereço na cidade de Ribeirão Preto, após o desenvolvimento da etapa de coletas de dados e formulação do banco de dados, fez-se necessário o desenvolvimento de uma Interface para WEB, a qual será descrita e apresentada no próximo Capítulo. 


\section{Cap. 5 DESENVOLVIMENTO DA INTERFACE}

No Capítulo anterior foi apresentada uma das componentes básicas que compõem o sistema SIGRIB, que consiste na manipulação da planta digitalizada do Campus da USP de Ribeirão Preto para a construção de uma base de dados adequada às consultas que serão apresentadas por um usuário.

Neste Capítulo, será apresentada uma outra componente básica do sistema que diz respeito ao desenvolvimento de uma interface, que tem como objetivo estabelecer a comunicação entre o usuário e o sistema propriamente dito.

\subsection{Interface desenvolvida}

Esta interface foi desenvolvida usando linguagem de programação Borland Delphi 5.0. Esta interface possibilita que o usuário, via Internet, possa entrar com os seus dados, isto é, com o endereço de origem e o endereço de destino e acionar o programa que irá se incumbir de determinar o menor caminho entre as duas localidades, como pode ser visualizado na Figura 5.1.

Esses dois endereços servirão de entrada para o Sistema de Localização, e este por sua vez, deverá devolver um submapa contendo o "menor caminho" entre os dois endereços.

Este submapa será recebido pela interface que o exibirá, no formato do tipo BitMap (BMP), ao usuário como resposta. Então, a interface do sistema também se encarrega de gerar uma página de saída, mostrando a solução obtida ao usuário. Nesta página de saída, é exibida também a distância entre 
as duas localidades fornecidas pelo usuário, calculada em metros. Na Figura 5.2 pode ser visualizado um exemplo de uma página de saída gerada em função dos dados fornecidos pelo usuário e apresentados na Figura 5.1.

A interface desenvolvida permite também uma navegação no submapa, realizada através dos links direcionais. Esta navegação é interativa e envolve o processamento em tempo real da imagem resultante. Se o percurso obtido é longo e não é possível exibi-lo em apenas uma tela (subimagem) então o usuário pode visualizar o percurso através de uma seqüência de telas, exibidas a medida que o usuário movimenta o cursor. Os movimentos possíveis são: para a direita, para esquerda, para cima ou para baixo. Um exemplo de um percurso longo envolvendo várias telas será apresentado no próximo capítulo.

\subsection{Aplicativos Utilizados}

Como se pretendia construir um sistema que fosse capaz de enviar respostas gráficas ao usuário, seria necessário um software que pudesse gerar ao usuário a imagem de um mapa digital. Portanto, para o desenvolvimento do sistema foi utilizado o componente E.S.R.I. MapObjects 2.0.

Tal ferramenta, na verdade, é um componente para linguagens de programação, podendo ser vinculado a um compilador. Através desta vinculação, o MapObjects permite que o compilador manipule arquivos gráficos e bases de dados gerados e editados pelo Arcview 3.2. O MapObjects pode ser vinculado com compiladores como Delphi e C Builder.

Com o MapObjects, puderam-se adicionar componentes de mapas para realçar aplicações, construir aplicações leves para visualização de dados, criar traçados customizados e conseguir facilmente o acesso a dados gerados por soluções sofisticadas de SIGs (Garde, 2002).Para as chamadas de funções do MapObjects, optou-se pela implementação da interface em questão utilizando o ambiente de desenvolvimento Borland Delphi 5.0.

A manipulação dos mapas digitais, bem como dos bancos de dados necessários para sua geração, ficou a cargo do aplicativo E.S.R.I. ArcView 3.2, que permite a criação e o gerenciamento de um banco de dados georeferenciado. 


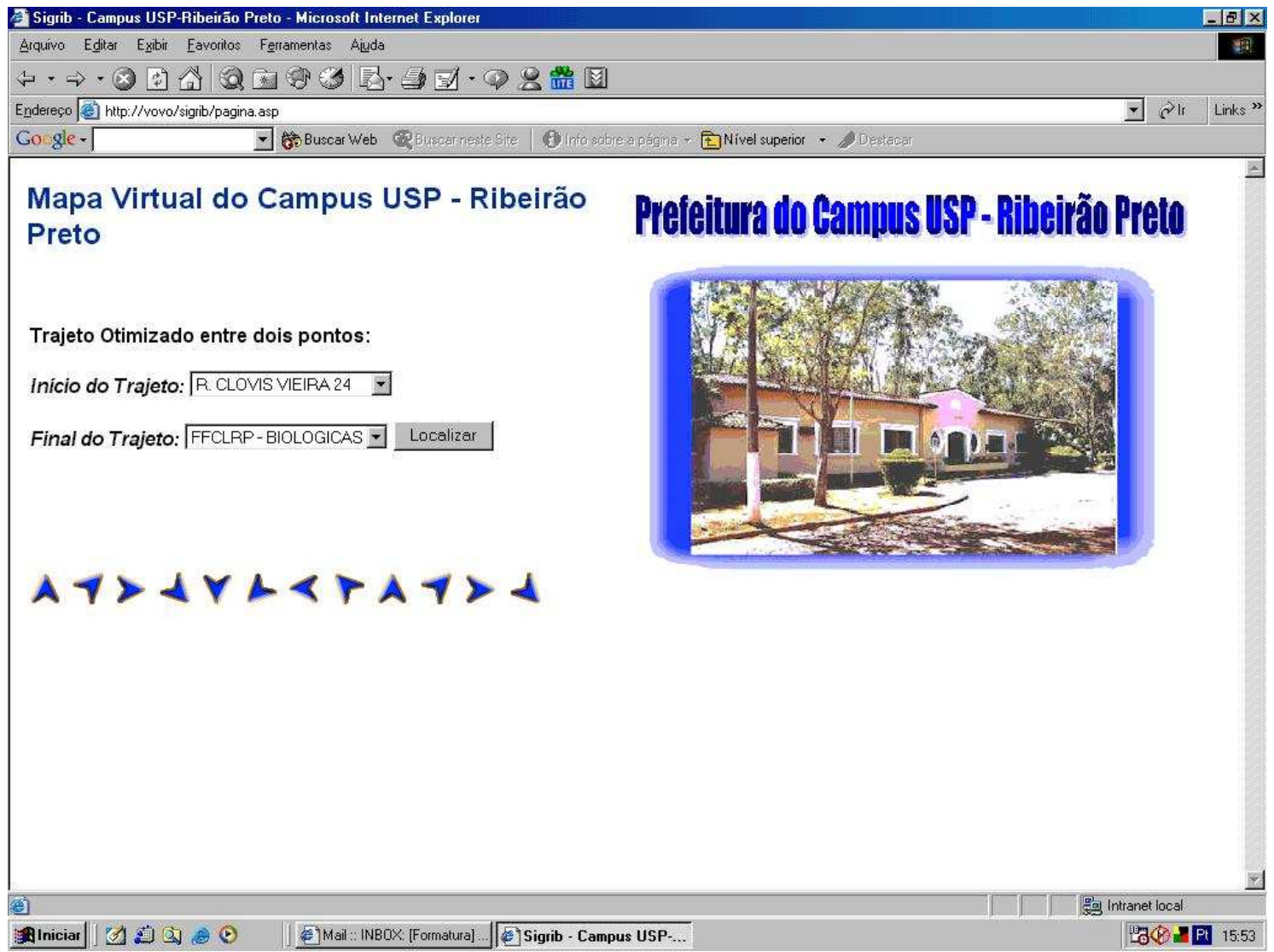

Figura 5.1. Página de Entrada para o Campus de Ribeirão Preto

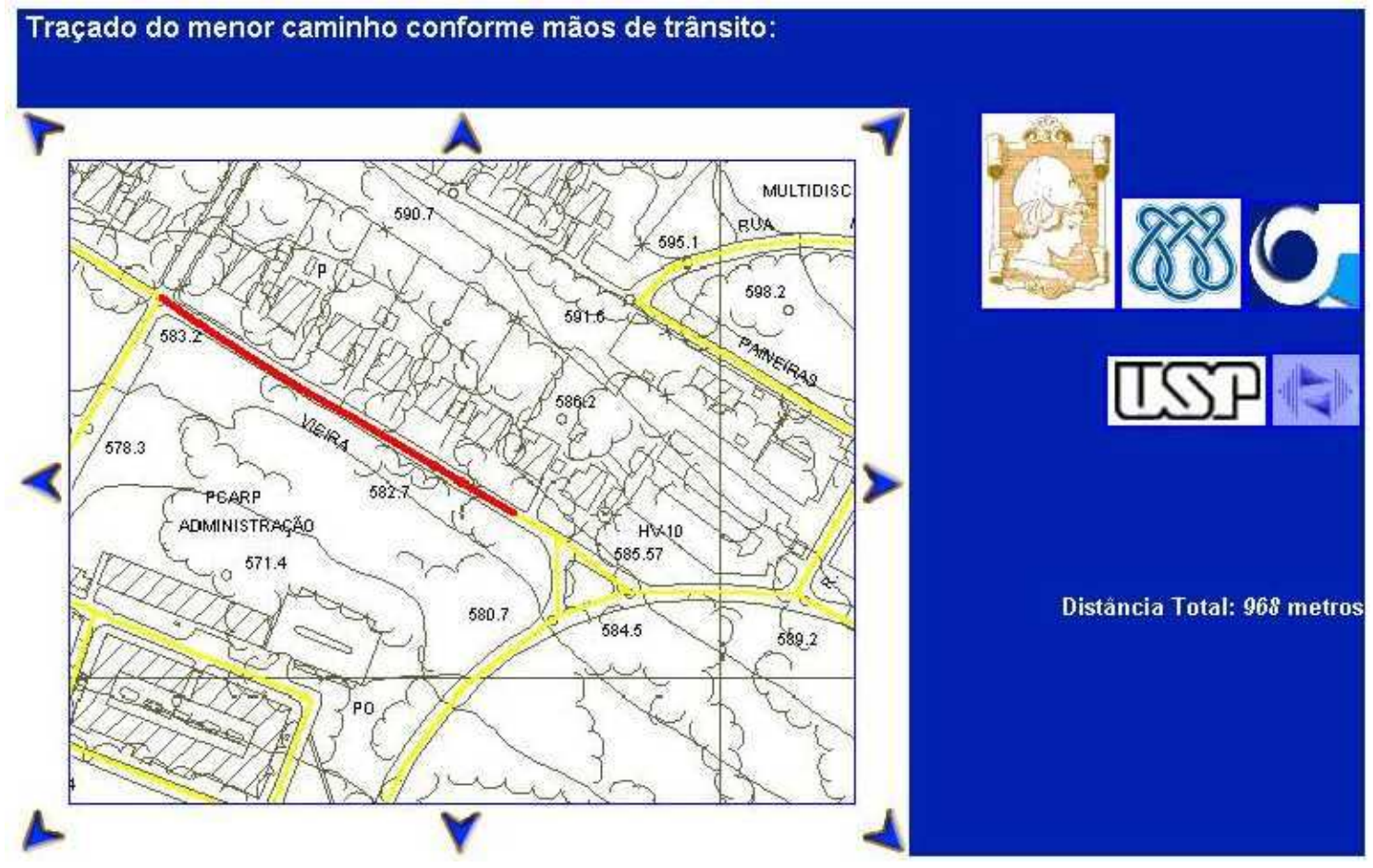

Figura 5.2. Página de saída gerada pela interface 


\section{3 - Determinação do Menor Caminho}

Utiliza-se, neste sistema, o algoritmo de Dijkstra (JOHNSONBAUGH, 1997), (ROMAN, 1989), para a determinação do menor caminho entre dois pontos quaisquer uma vez que o software ARCVIEW 3.2 não dispõe de tal ferramenta.

O software TransCad (Caliper, 1996) é um SIG projetado especificamente para o planejamento, gerenciamento, operação e análise das características dos Sistemas de Transporte.

Ele realiza várias análises de transportes e possui um banco de dados projetado para capturar e analisar dados de transportes (Rose, 2001). Como esses dados de transportes incluem a determinação de rotas, ele poderia ser utilizado para a realização da tarefa proposta no presente trabalho. Contudo, a finalidade deste trabalho é a de descobrir e apresentar à comunidade científica como esta funcionalidade pode ser implementada, usando os softwares que se têm disponível.

Em (Rose, 2001) também se encontra uma análise comparativa entre três softwares de SIG: TransCAD, ARCVIEW, UfosNet.

A mesma metodologia apresentada neste trabalho, certamente, poderá ser estendida para outras cidades, regiões turísticas e outras atividades afim.

No próximo Capítulo, será apresentada a forma na qual o sistema foi implementado, ou seja, como a comunicação entre os vários módulos da arquitetura do sistema SIGRIB, apresentada no Capítulo 3, foi realizada, envolvendo a linguagem Borland Delphi 5.0, o aplicativo MapObjects, a Base de Dados construída e o ARCVIEW. 


\section{Cap. 6 IMPLEMENTAÇÃO DO SISTEMA}

Nos Capítulos anteriores, foram apresentados os componentes que compõem o sistema SIGRIB. Neste Capítulo, será descrito como a implementação do sistema proposto foi realizada, isto é, todos os passos que foram executados para o desenvolvimento de tal sistema, bem como, as dificuldades encontradas para que o sistema pudesse ser validado e disponibilizado para a sociedade via Internet.

\subsection{Estudos Preliminares}

Um SIG proporciona que sejam desenvolvidas aplicações com utilização de mapas, fotos de satélite ou outros elementos para estudos e visualizações geográficas.

Foi então conduzido um estudo do funcionamento do software ArcView 3.2 da empresa ESRI, envolvendo a conexão do mapa digital com o programa e o modo como o mesmo o representa: utilizando-se de poli-retas (retas formadas por diversos segmentos de reta) para as ruas e mantendo seus atributos numa base de dados simples.

Foram analisadas também as funções que podem ser executadas pelo ARCVIEW sobre o mapa digital, buscando-se assim resolver o problema de se encontrar o menor caminho e exibir uma resposta gráfica. Desta forma, usamos o ARCVIEW para fazer o traçado do eixo das ruas bem como numerar os diversos pontos de intersecção, como foi mostrado no Capítulo anterior.

Após o estudo do ARCVIEW 3.2 e a vinculação do mapa digital com o mesmo, foram analisados os próximos passos para o projeto, constando-se 
que seria importante iniciar o estudo e desenvolvimento de um método para disponibilizar o que foi feito na Web, já que isso interferia diretamente na continuidade da implementação do projeto.

Iniciando, então, a atividade de colocar o serviço disponível na Internet, encontrou-se o problema de definir uma interface entre o usuário no Website e o programa no servidor. Para isso foram feitos estudos de software de aplicações para Web.

\subsection{Escolha de softwares para o desenvolvimento da interface}

A parte mais trabalhosa no desenvolvimento do projeto consistiu na decisão entre quais softwares utilizar, quais softwares deveriam ser desenvolvidos e quais suas funções.

O objetivo era a construção de um sistema que funcionasse através da Internet e que fosse capaz de enviar respostas gráficas ao usuário, ou seja, não bastava um software que apenas calculasse a menor distância entre dois pontos em um grafo. Era necessário um software que pudesse enviar ao usuário a imagem de um mapa digital.

Um aspecto fundamental que foi levado em conta é sobre o tempo de resposta do sistema, pois sabemos que o algoritmo mais simples para determinação do menor caminho é o algoritmo de Dijkstra, que é custoso computacionalmente, principalmente quando o número de nós do grafo é elevado.

Para o desenvolvimento do sistema foram estudados e testados diversos meios de implementação, passando-se principalmente por aplicações em Applets Java. Porém, a linguagem Java não foi utilizada na implementação final, por motivos de falta de compatibilidade com outras ferramentas e com o banco de dados disponível.

O sistema é composto de vários módulos já descritos no Capítulo 3 e a Figura 6.1 mostra como estes módulos interagem entre si. 


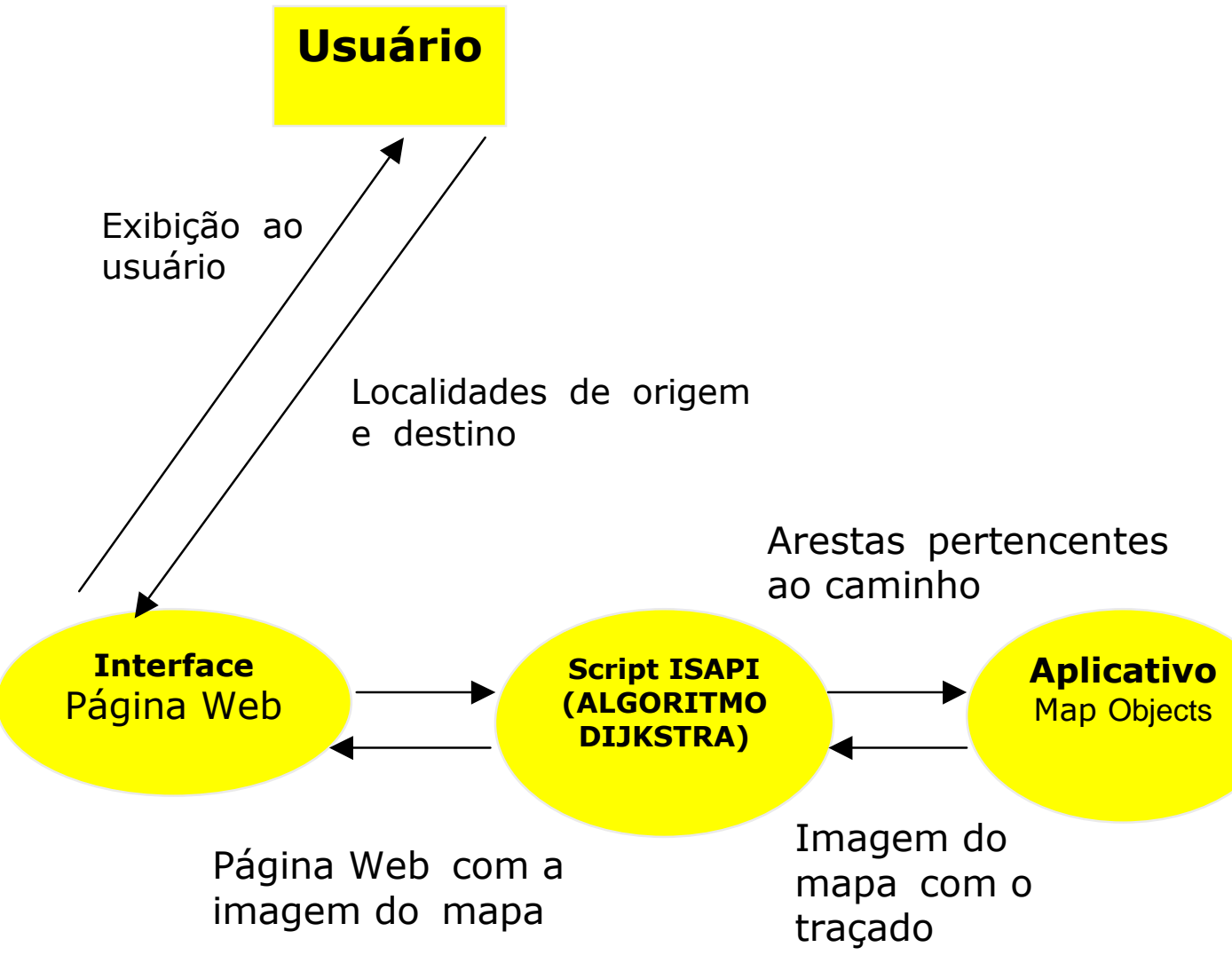

Figura 6.1. Funcionamento do Sistema

A forma como esses módulos foram implementados é descrita a seguir.

\subsection{Página Web (Escrita em Asp/Html)}

A interface que está disponível ao usuário do software desenvolvido é uma página na Internet, escrita em Asp e em Html. Sua função é de apenas coletar os dados digitados pelo usuário do sistema e enviá-los para o script Isapi. A interface foi desenvolvida de maneira bastante simples e objetiva, de modo a proporcionar ao usuário uma certa comodidade na utilização do Sistema de Roteirização de Endereços para o Campus de Ribeirão Preto (ver 5.1 e 5.2$)$.

O script "pagina.asp", utilizado pelo SIGRIB, gera uma página Web através do browser. Esse script disponibiliza ao usuário uma lista default de possíveis rotas entre localidades distintas. Tal script utiliza como parâmetros o início e o fim de uma rota. Além disto, ele passa uma instrução para o 
componente "mapasrib.dll", para que comece o processamento da rota otimizada no servidor.

\subsection{Script Isapi (Aplicação Web)}

Uma das etapas do projeto foi o desenvolvimento de uma aplicação Web no padrão ISAPI (Internet Server Application), que chamaremos de "Script". Um Script Isapi pode ser descrito como um arquivo que pode ser executado via Internet.

Isto permite a criação de páginas dinâmicas na Web, ou seja, o código fonte da página varia de acordo com os parâmetros passados para o Script. Para o desenvolvimento deste script foi utilizada a ferramenta de desenvolvimento Borland Delphi 5.0.

O script Isapi é o programa responsável pela utilização do algoritmo de Dijkstra. Esta aplicação é quem recebe os dados (parâmetros) enviados pela Interface com a Web, e os processa, com o auxílio de um banco de dados da cidade. A finalidade deste script (Figura 6.1) é encontrar o menor caminho entre dois pontos.

Após a determinação do menor caminho, esta aplicação escreve em um arquivo texto, os identificadores de cada aresta do grafo que pertence ao caminho mínimo, e em seguida, a aplicação executa o programa que é o responsável pela manipulação do mapa.

Uma descrição simplificada deste Script será descrita abaixo:

\section{- Determinação dos vértices de inicial e final}

O Script recebe como parâmetros informações sobre as ruas da cidade, precisando, portanto, determinar os vértices referentes a estas informações;

\section{- Aplicação do algoritmo de Dijkstra}

Separa-se a lista de vértices entre "visitados" e "não visitados", sendo que inicialmente todos os pontos são denominados "não visitados", exceto o ponto inicial. Em seguida determina-se a menor distância entre um vértice "visitado" e um "não visitado". O vértice passa então para a lista dos "visitados" e armazena-se a distância do ponto inicial até o mesmo. Continua-se a busca até 
que o vértice objetivo faça parte da lista de vértices "visitados". Desta forma será determinado o menor caminho partindo do vértice inicial até o vértice final. Este algoritmo será descrito em detalhes na seção 6.4.1.

- Chamada de execução para manipulação do mapa: em seguida o Script executa o software responsável pela manipulação do mapa digital e passa a ele os parâmetros referentes ao caminho;

- Aguarda resposta: o próximo passo é aguardar a resposta (imagem BMP) do software executado, a qual contém o desenho de uma região do mapa, com o caminho em destaque;

- Gerar página HTML de resposta: Finalmente, a página que contém o mapa é gerada e enviada para o browser do usuário do sistema.

A Figura 6.1 demonstra o fluxo de dados entre os módulos

Por ser muito importante dentro do contexto do sistema proposto, o algoritmo de Dijkstra (JOHNSONBAUGH, 1997), (ROMAN, 1989) é apresentado a seguir.

\subsubsection{Determinação do menor caminho}

Na resolução de problemas de menor caminho, as aplicações envolvem, naturalmente, problemas relacionados com seqüências de decisões - quer se trate, por exemplo, das escolhas de itinerário ao longo de uma viagem, ou do traçado de uma estratégia em um problema de investimentos. Trata-se de decisões envolvendo alguma forma de custo a ser minimizado (SANTOS, 1996).

Como foi possível buscar no mapa pontos em ruas entrando com seus nomes, ou de localidades específicas que foram designadas no mapa, bastaria então que o Software encontrasse no mapa o menor caminho entre dois pontos dados. Foi constatado que o ARCVIEW 3.2 não consegue realizar tal aplicação, sendo necessário que se utilize uma programação específica sobre ele ou uma aplicação do próprio ArcView, que não se tinha em mãos.

Utilizou-se para esta tarefa o algoritmo de Dijkstra, cuja implementação está descrita a seguir: 


\section{O Algoritmo de Dijkstra}

Seja $G(V, A)$ um grafo orientado e s um vértice de $G$ :

1. Atribua valor zero à estimativa do custo mínimo do vértice $\mathbf{s}$ (a raiz da busca) e infinito às demais estimativas;

2. Atribua um valor qualquer aos precedentes (o precedente de um vértice t é o vértice que precede t no caminho de custo mínimo de $\mathbf{s}$ para t);

3. Enquanto houver vértice aberto:

- seja $\mathbf{k}$ um vértice ainda aberto cuja estimativa seja a menor dentre todos os vértices abertos;

- feche o vértice $k$

- Para todo vértice j ainda aberto que seja sucessor de $\mathrm{k}$ faça:

- some a estimativa do vértice $\mathbf{k}$ com o custo do arco que une $\mathrm{k}$ a j;

- caso esta soma seja melhor que a estimativa anterior para

- o vértice $\mathrm{j}$, substitua-a e anote $\mathrm{k}$ como precedente de $\mathbf{j}$.

A seqüência de diagramas ilustra o funcionamento do Algoritmo de Dijkstra: 
- Inicialmente todos os nós têm um custo infinito, exceto $\mathbf{s}$ (a raiz da busca) que tem valor 0 :

\begin{tabular}{|l|l|l|l|l|l|}
\hline vértices & $\mathbf{S}$ & $\mathbf{U}$ & $\mathbf{V}$ & $\mathbf{x}$ & $\mathbf{y}$ \\
\hline estimativas & 0 & $\infty$ & $\infty$ & $\infty$ & $\infty$ \\
\hline precedentes & - & - & - & - & - \\
\hline
\end{tabular}

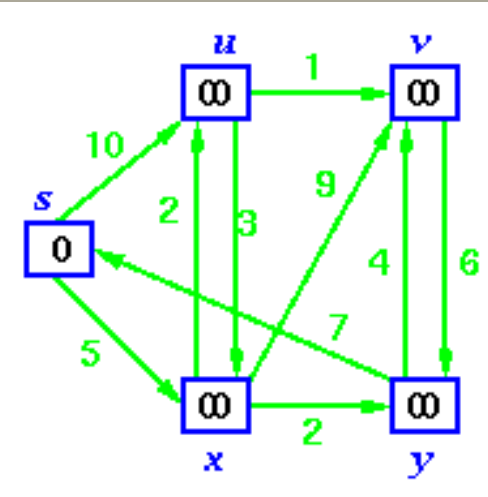

- $\quad$ selecione $\mathbf{s}$ (vértice aberto de estimativa mínima)

- feche $s$

- recalcule as estimativas de u e x

\begin{tabular}{|l|l|l|l|l|l|l|l|}
\hline vértices & S & $\mathbf{U}$ & $\mathbf{V}$ & $\mathbf{x}$ & $\mathbf{y}$ \\
\hline estimativas & $\mathbf{0}$ & 10 & $\infty$ & 5 & $\infty$ \\
\hline precedentes & S & S & - & S & - \\
\hline
\end{tabular}

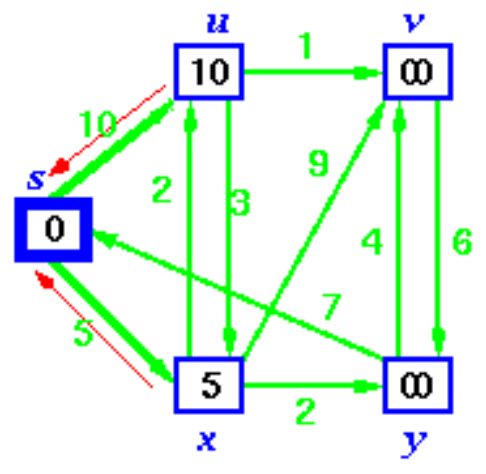

- $\quad$ selecione $\mathbf{x}$ (vértice aberto de estimativa mínima)

- feche $\mathbf{x}$

- recalcule as estimativas de $u, v$ e y

\begin{tabular}{|l|l|l|l|l|l|l|}
\hline vértices & S & $\mathbf{U}$ & $\mathbf{V}$ & $\mathbf{x}$ & $\mathbf{y}$ \\
\hline estimativas & $\mathbf{0}$ & 8 & 14 & 5 & 7 \\
\hline precedentes & S & $\mathrm{X}$ & $\mathrm{X}$ & S & $\mathbf{X}$ \\
\hline
\end{tabular}

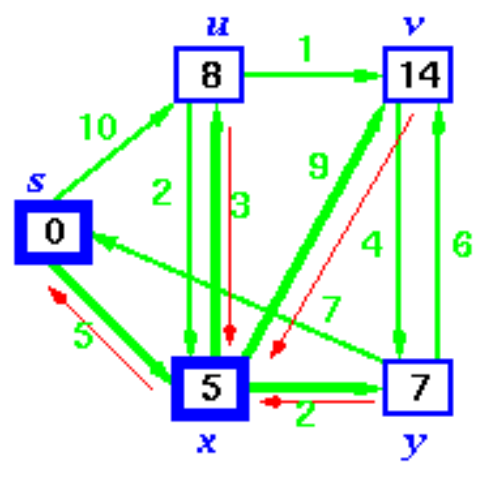

- $\quad$ selecione y (vértice aberto de estimativa mínima)

- feche $\mathbf{y}$

- recalcule a estimativa de $\mathrm{v}$

\begin{tabular}{|l|l|l|l|l|l|l|l|}
\hline vértices & S & $\mathbf{U}$ & $\mathbf{V}$ & $\mathbf{x}$ & $\mathbf{y}$ \\
\hline estimativas & $\mathbf{0}$ & 8 & 13 & 5 & $\mathbf{7}$ \\
\hline precedentes & S & $\mathbf{X}$ & $\mathbf{Y}$ & $\mathbf{S}$ & $\mathbf{x}$ \\
\hline
\end{tabular}

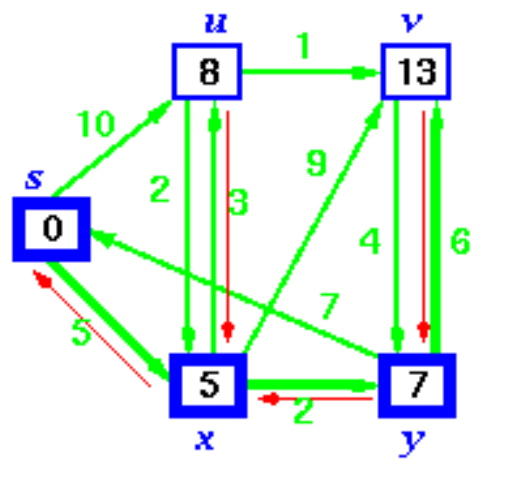




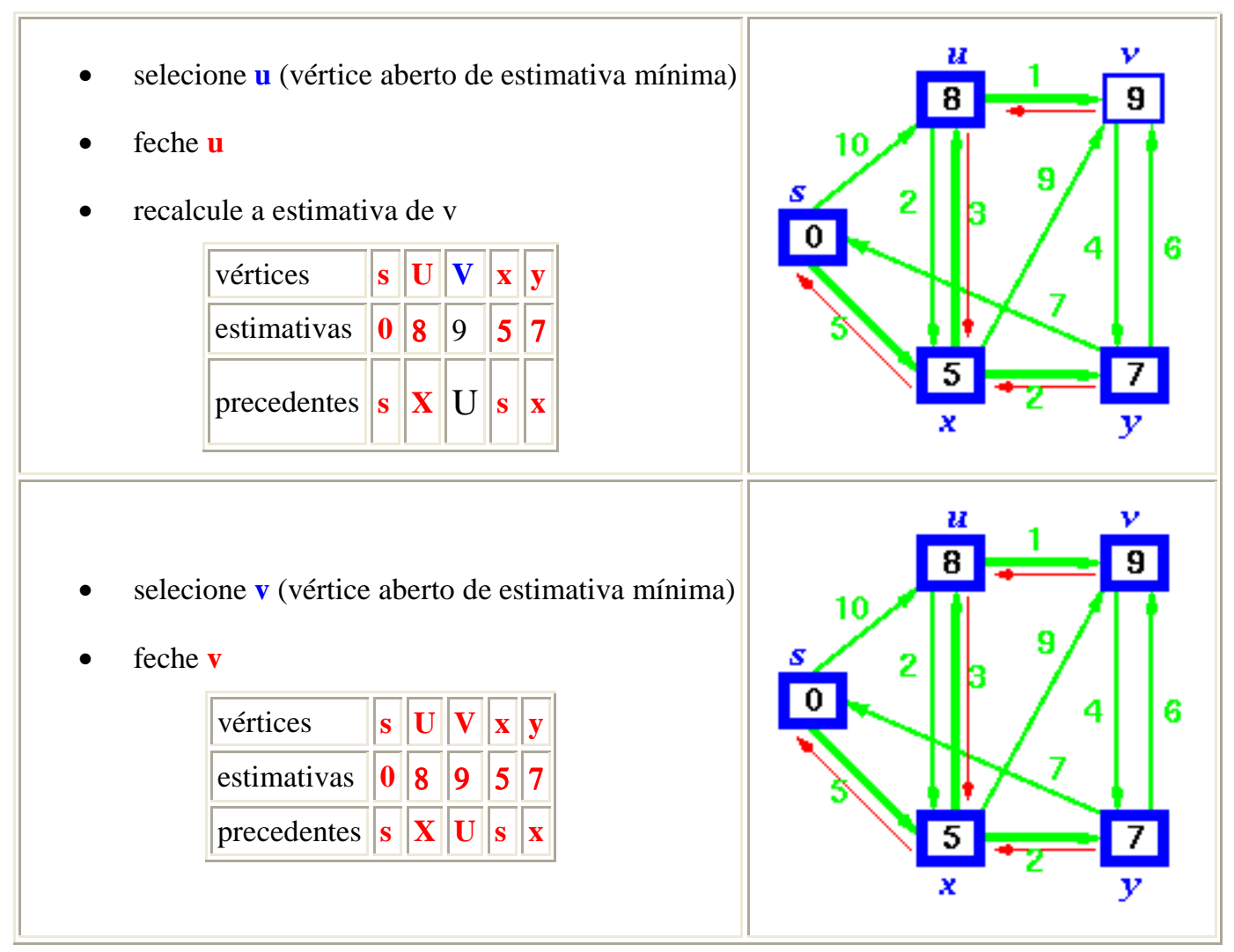

Figura 6.2 - Exemplo do funcionamento do algoritmo de Dijkstra

Quando todos os vértices tiverem sido fechados, os valores obtidos serão os custos mínimos dos caminhos que partem do vértice tomado como raiz da busca até os demais vértices do grafo. O caminho propriamente dito é obtido a partir dos vértices para os seus respectivos precedentes. Por exemplo, partindo-se do vértice $\mathrm{V}$ para chegar em $\mathrm{S}$, tem-se que o menor caminho tem um custo de 9 , passando pelos vértices $U$ e $X$ e finalmente chegando em $S$.

\subsection{Aplicativo - Map Objects}

Este aplicativo foi construído para manipular o mapa do Campus de Ribeirão Preto para destacar as vias pertencentes ao caminho mínimo. Para isto, o software utiliza-se do arquivo texto que foi escrito pelo Script Isapi. O comportamento deste software é o seguinte:

- ao ser iniciado o software carrega automaticamente o mapa da cidade; 
- em seguida, é realizada uma leitura do arquivo texto, para que se saiba quais ruas pertencem ao caminho mínimo;

- a próxima etapa é destacar as ruas pertencentes ao menor caminho, marcando o trajeto, através de uma ferramenta gráfica para a exibição do mesmo;

- por fim, exportar o mapa resultante no formato BMP.

O mapa obtido como "saída" deste programa retornará ao usuário do software através de uma página na Internet, para que o mesmo possa visualizar o caminho pretendido (ver Figura 6.3).

$\mathrm{Na}$ implementação deste sistema, o componente "mapasrib.dll" foi gerado a partir do aplicativo Borland Delphi 5, através do projeto "mapasrib.dpr", respectivamente. Ele utiliza script denominado "ubiblioteca.pas". Esse script tem a seguinte funcionalidade.

\subsubsection{O script ubiblioteca.pas}

O script "ubiblioteca.pas" implementa basicamente o Algoritmo de Dijkstra para o traçado de menor custo, disponibilizando uma página Web como resposta ao usuário.

No que se refere à manipulação do mapa digital, a tecnologia utilizada é um aspecto fundamental.

Foi utilizado o componente Map Objects 2.0 que possui rotinas para que se possa tratar elementos de um banco de dados como objetos, ou seja, este componente tornou-se indispensável para a manipulação do banco de dados que se tinha em mãos.

Para que o usuário conseguisse diferenciar as ruas pertencentes ao trajeto utilizou-se a seguinte estratégia: primeiro utilizou-se de um comando do banco de dadps SQL para selecionar as ruas pertencentes ao trajeto e depois alterou-se atributos dos dados selecionados, no caso sua cor.

Desta forma o usuário pode diferenciar o traçado do menor caminho através das cores, como pode ser visto na Figura 6.3. Nesta Figura, é mostrado um exemplo de um traçado colorido na cor vermelho. 


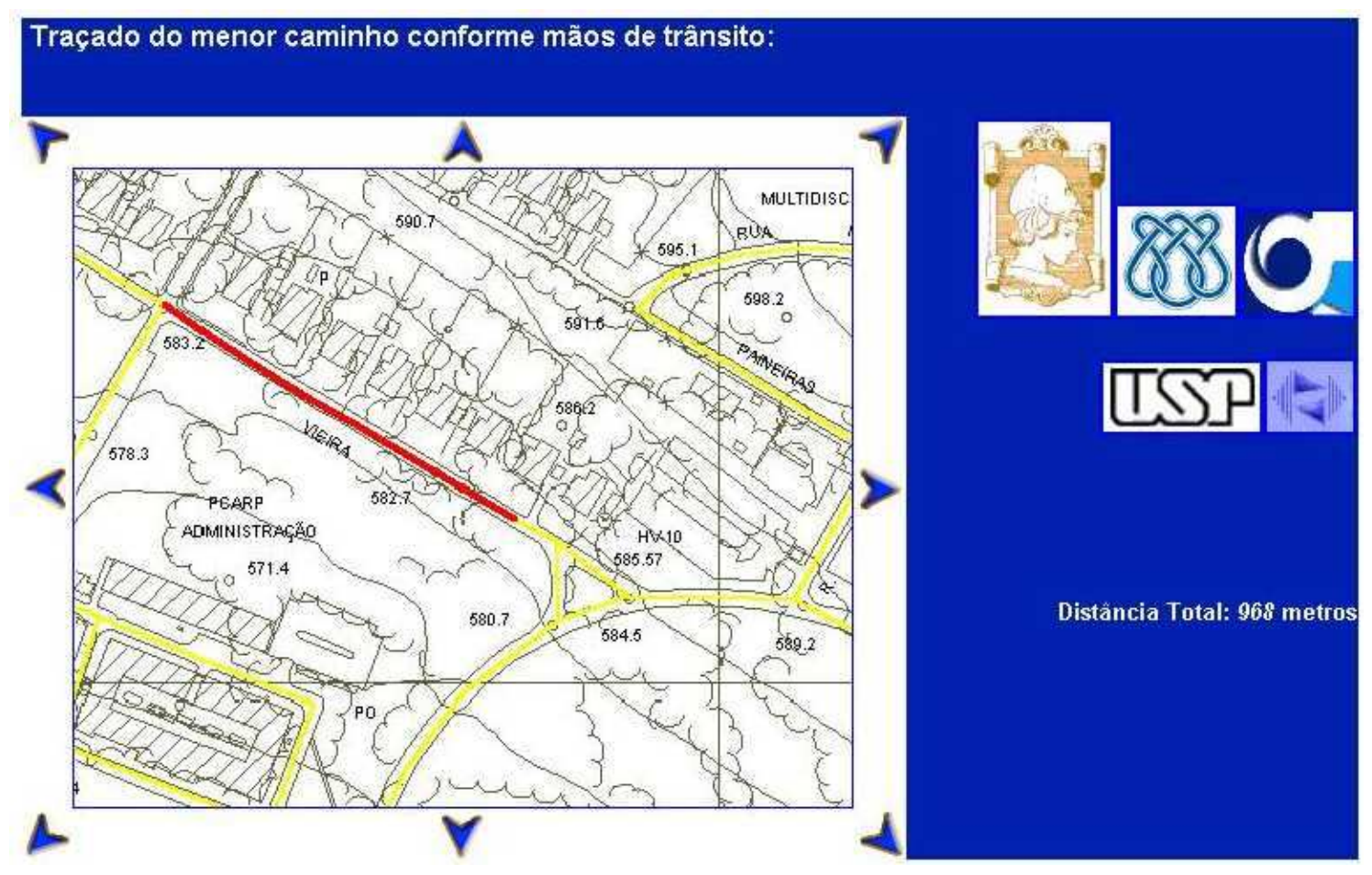

Figura 6.3: Visualização de um traçado.

\subsubsection{O componente projeto.exe}

Foi desenvolvido durante a implementação o componente "projeto.exe", gerado a partir do aplicativo Borland Delphi 5, através do projeto "projeto.dpr".

Esse componente é responsável por passar os parâmetros necessários à manipulação do mapa digital no componente "Esri MapObjects 2.0".

O script utilizado em "projeto.dpr" encontra-se no arquivo "manipulador.pas", cujo código fonte consta do Apêndice A.

Basicamente, este componente associa cada par de vértices a uma aresta do layer de rotas do mapa digital, utilizando o componente "Esri MapObjects 2.0", para incluí-la no mapa resultante de uma consulta.

Graças ao software Esri MapObjects 2.0, puderam-se adicionar os seguintes elementos ao sistema proposto neste trabalho:

- componentes de mapas para realçar aplicações

- construir aplicações leves para visualização de dados

- criar traçados customizados e 
- conseguir, facilmente, o acesso a dados gerados por soluções sofisticadas de SIGs.

Para a integração entre "projeto.exe" e "Esri MapObjects 2.0", foi utilizado o componente OLE do Borland Delphi 5.

O componente "projeto.exe", uma vez ativado no servidor, espera por requisições de submapas, encerrando-se, automaticamente, após algum tempo ocioso, ou seja, quando não existirem mais requisições apresentadas por usuários.

\subsection{Processamento do Software}

O início do processamento se dá com a passagem de parâmetros do componente "pagina.asp".

Esses parâmetros se referem a localidades tratadas pelo sistema como pontos de um grafo orientado. Neste grafo, cada vértice é uma localidade distinta (esquinas, cruzamentos, edificações, etc...) e cada aresta representa um segmento de rua que interliga duas localidades.

Tal grafo, devidamente abstraído, encontra-se armazenado nos bancos de dados listados e serão descritos mais tarde.

Com o processamento da rota otimizada concluída, deve-se fornecer tal caminho a um componente capaz de manipular um mapa digital.

Este componente é o "projeto.exe" já descrito na seção 6.5.2. Através de uma chamada de execução, tal componente é ativado. Neste momento, o componente "mapasrib.dll" entra em estado de espera, aguardando a gravação de um arquivo "bmp" no diretório do sistema.

Com a gravação do arquivo "bmp", o qual contém um submapa resultante do processamento da rota otimizada, é gerada uma página Web contendo tal arquivo "bmp", associada com outros arquivos "asp" e seus respectivos arquivos "bmp" correspondentes às consultas nas regiões do mapa. 


\subsection{A Base de Dados}

Como já descrito anteriormente, o sistema trata seus mapas como grafos orientados. Estes grafos encontram-se armazenados nas duas bases de dados descritas no Capítulo anterior e foram armazenadas nas seguintes estruturas de dados, cujos nomes aparecem entre aspas, pois, são os mesmos nomes utilizados na implementação do SIGRIB:

\section{- "TABELA adjacentes.dbf"}

Esta tabela contém o mapa de vértices, com seus respectivos vértices adjacentes. Para cada vértice adjacente, é associado um custo que, no caso deste sistema, refere-se à distância em metros de uma localidade à outra. Esta base é utilizada pelo componente "mapasrib.dll".

\section{- "caminhos.db"}

Esta tabela contém a rota gerada referente a uma consulta feita pelo usuário, ou seja, o conjunto ordenado de localidades (vértices) desde a origem até o destino. Esta base é construída pelo componente "mapasrib.dll" e utilizada pelo componente "projeto.exe".

\section{- "TABELA ID.dbf"}

Esta tabela contém a associação de uma aresta do grafo a uma aresta do layer de rotas do SIG. Estas bases são utilizadas pelos componentes "projeto.exe" e "Esri MapObjects 2.0".

\section{- "entradas.dbf"}

Estas tabelas contém o conjunto de vértices default para a origem e o destino de uma rota. Elas associam um nome a cada vértice e são utilizadas pelo componente "página.asp". 


\section{- "transição.db"}

Esta tabela indica se a visualização do submapa é resultante de uma consulta ou de uma transição (navegação no mapa), indicando o número do submapa resultante que deve constar do nome do arquivo "bmp" gerado. Esta base é manipulada pelos componentes "mapas.dll" e "mapasrib.dll" e utilizada por "projeto.exe".

- "CAMPUS_RP_UTM.dwg" (SIGRIB)

Esta tabela, geradas a partir do aplicativo Esri ArcView 3.2, correspondem ao projeto SIG. Esta tabela associada às demais tabelas geradas pelo Esri ArcView 3.2, geram os layers manipulados pelos componentes "projeto.exe" e "Esri MapObjects 2.0".

\subsection{A Estrutura de Diretório}

Para que o sistema funcione corretamente, deve haver um servidor Web instalado no servidor. O servidor recomendado é o Microsoft Personal Web Server, ou variantes. A estrutura de diretórios no servidor deve ser a seguinte:

Em "/Inetpub/scripts":

mapasrib.dll

Em "/Inetpub/wwwroot/SIGRIB":

pagina.asp (respectiva)

l.gif

n.gif

ne.gif

no.gif 


$$
\begin{aligned}
& \text { o.gif } \\
& \text { prefeitura.gif } \\
& \text { s.gif } \\
& \text { se.gif } \\
& \text { so.gif } \\
& \text { legenda.gif }
\end{aligned}
$$

Em "/Inetpub/wwwroot/SIGRIB/Aplicativo com MapObjects":

projeto.exe (respectivo)

Em "/Inetpub/wwwroot/SIGRIB/mapas":

CAMPUS_RP_UTM.dwg (arquivos associados)

Em "/Inetpub/wwwroot/SIGRIB/tabelas":

transicao.db

TABELA adjacentes.dbf

TABELA ID.dbf

entradas.dbf

caminhos.db

\subsection{Resultados}

Nesta seção, descreve-se sobre a disponibilização do software SIGRIB a Sociedade via internet e apresenta-se também alguns exemplos para ilustrar o funcionamento do mesmo.

\subsubsection{Disponibilização do Sistema SIGRIB}

O software SIGRIB está disponível a Sociedade e este é o principal resultado obtido.

Com suas funções bem definidas e implementadas, este projeto encontra-se instalado, atualmente, num dos servidores Web do Laboratório de 
Inteligência Artificial (LABIC) do ICMC. O endereço referente ao projeto encontra-se em:

http://143.107.231.67/SIGRIB/pagina.asp

Alguns testes de chamada remota foram realizados nesta etapa do projeto, com acessos sendo feitos partindo de outros terminais, diretamente pelo IP do servidor utilizado. Estes testes obtiveram sucesso, na medida em que o SIGRIB recebeu os parâmetros necessários ao seu processamento pela rede, posteriormente gerando e enviando de volta a visualização da pesquisa.

O SIGRIB deve estar ativo para gerar o "mapa-resposta" e conseqüentemente a página de saída.

Para que o SIGRIB não ficasse ativo indefinidamente, sem que haja requisições, uma espécie de contador do tempo em que este ficasse ocioso foi implementado. Feito isto, o SIGRIB passou a ser dotado de um timer que encerra sua aplicação em caso de timeout (tempo limite excedido). Desta forma, se durante um certo intervalo de tempo não houver requisições, o SIGRIB automaticamente encerra o seu processamento.

\subsubsection{Experimentos}

Para mostrar o funcionamento do sistema SIGRIB, nesta seção, serão apresentados alguns resultados obtidos na utilização do sistema.

Exemplo 1 Neste exemplo, uma requisição é apresentada ao SIGRIB para localizar a casa no. 24, na Rua Clóvis Vieira até a casa de no. 30, nesta mesma rua. Na Figura 6.4, encontra-se cópia da página Web inicial e na 


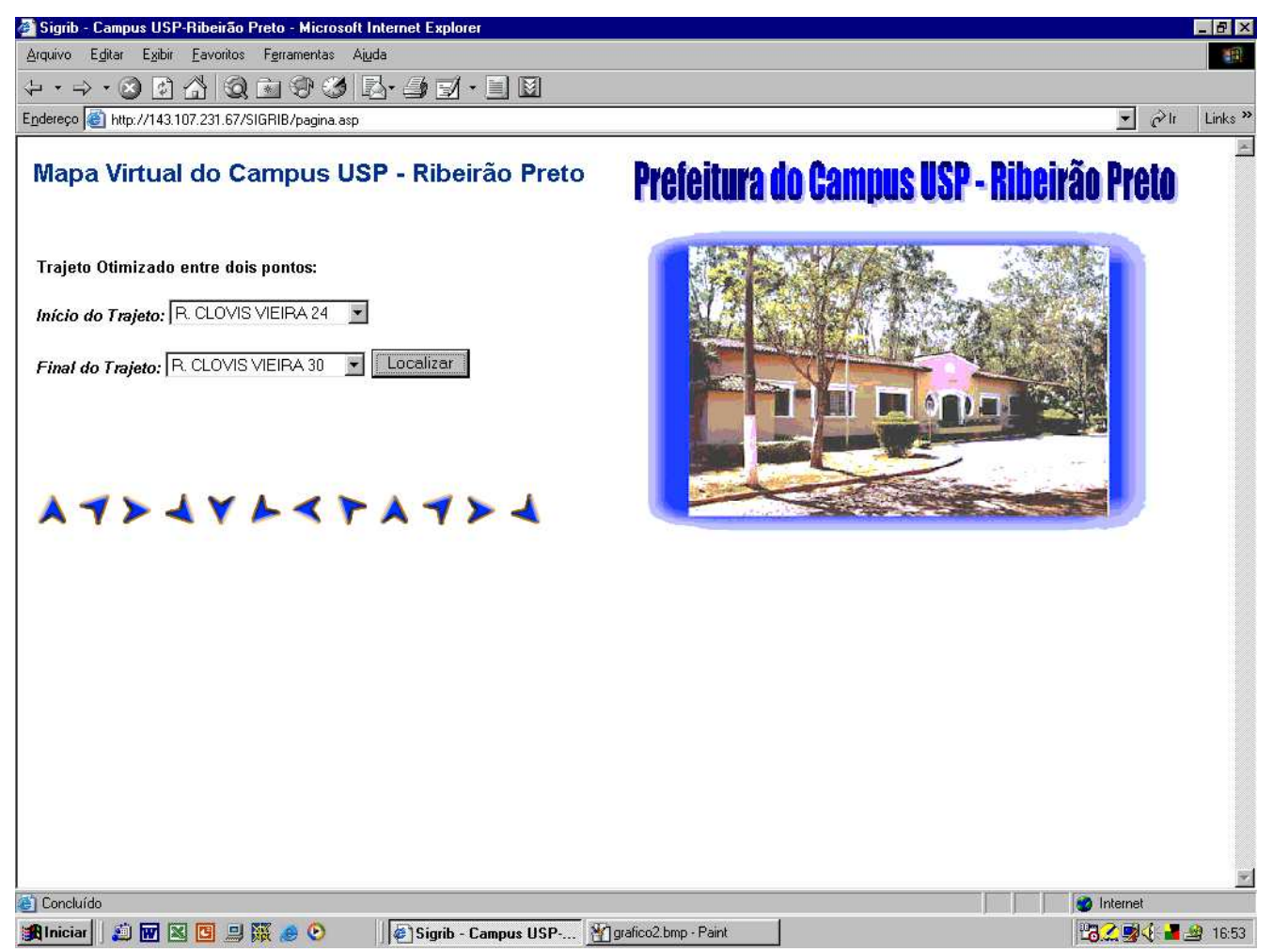

Figura 6.4. Busca pelo menor caminho entre duas casas na Rua Clóvis Vieira

e na Figura 6.5 pode-se visualizar o menor caminho entre estas duas localidades.

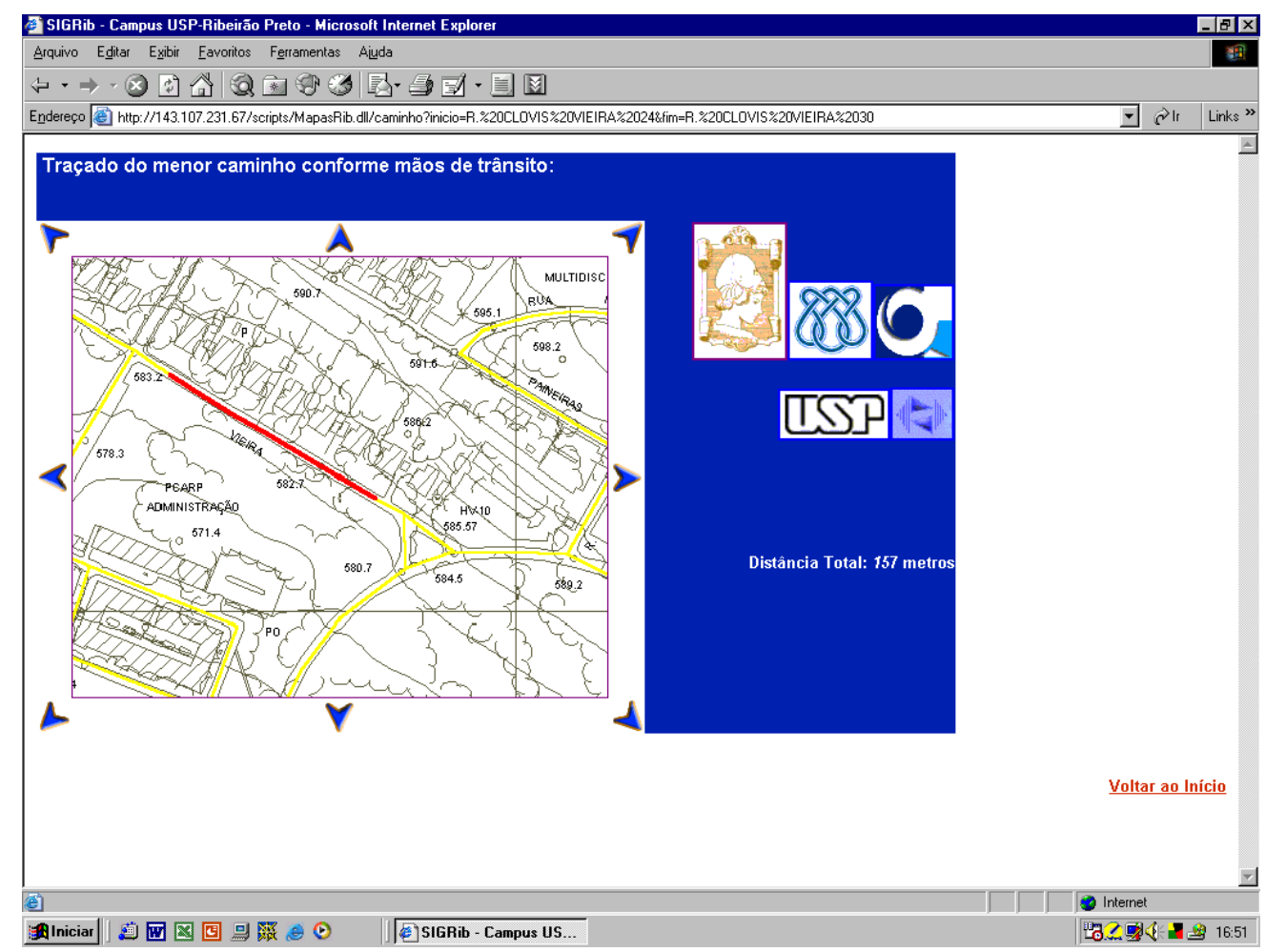

Figura 6.5. Visualização do menor caminho entre duas casas na Rua Clóvis

Vieira 


\section{Exemplo 2}

Na Figura 6.6, uma requisição é apresentada ao SIGRIB partindo-se da Clovis Vieira, 24 até o CIRP. Nesta Figura, nota-se um caso de se ter dois caminhos possíveis e o sistema SIGRIB optou por escolher aquele que possui o menor caminho. Isto exemplifica a eficiência do sistema na indicação do menor caminho.

Neste caso, como o percurso é longo, quatro telas foram obtidas clicando-se na seta indicando movimentação nas direções indicadas do percurso no mapa. Assim, pode-se ver nas Figuras 6.7 a 6.10, o percurso todo necessário para se deslocar de um ponto a outro. Nestas Figuras, pode-se encontrar também a distância entre essas duas localidades que é de 1091 metros. Existem dois caminhos possíveis entre estas duas localidades. Um deles é mostrado na Figura 6.11 e outro na Figura 6.12, respectivamente. Observe que neste caso, o software optou pelo menor caminho, pois o outro caminho possível que é mostrado na Figura 6.12 corresponde a uma distância de $1.211,00 \mathrm{~m}$.

Prefeitura do Gampus USP - Rihheirão Preto

Trajeto Otimizado entre dois pontos:
Inicio do Trajeto: R. CLOVIS VIEIRA24
Final do Trajeto: $\mathrm{CIRP}$

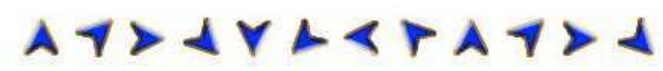

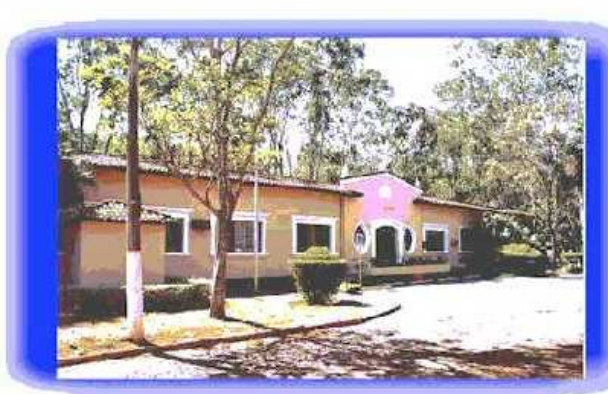

Figura 6.6. Tela inicial para o Exemplo 2 


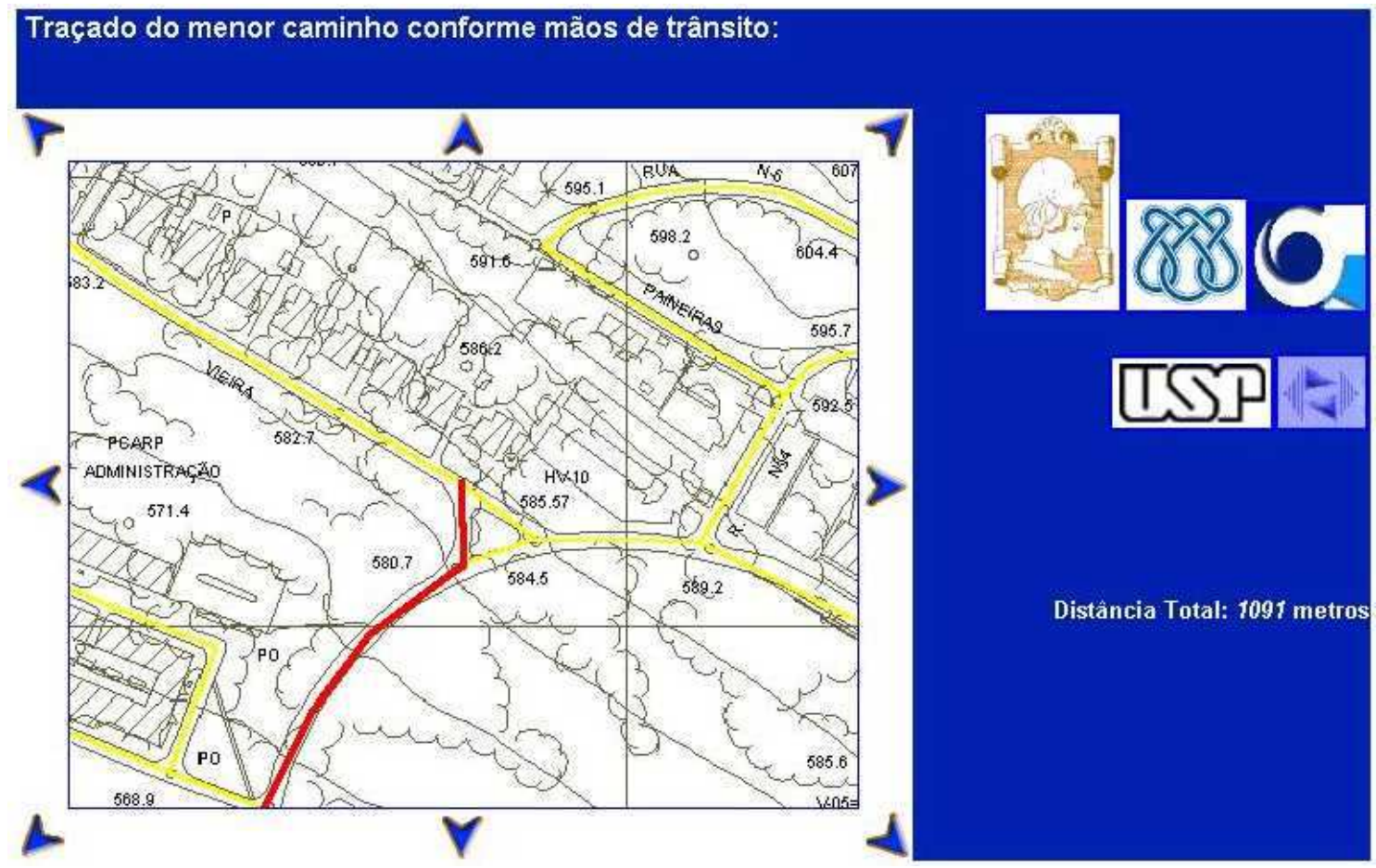

Figura 6.7. Primeira parte do caminho do Exemplo 2

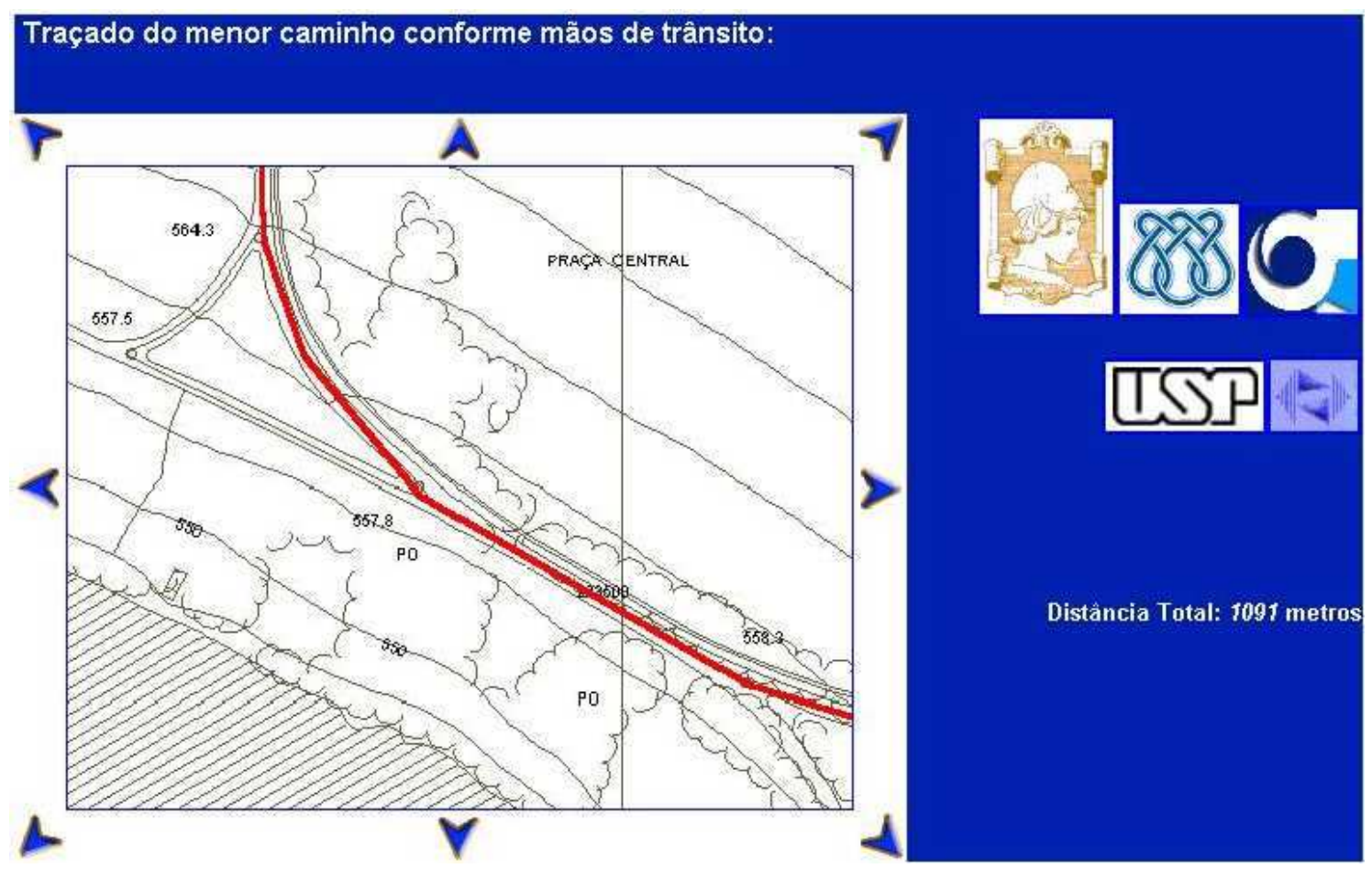

Figura 6.8. Segunda parte do caminho do Exemplo 2 


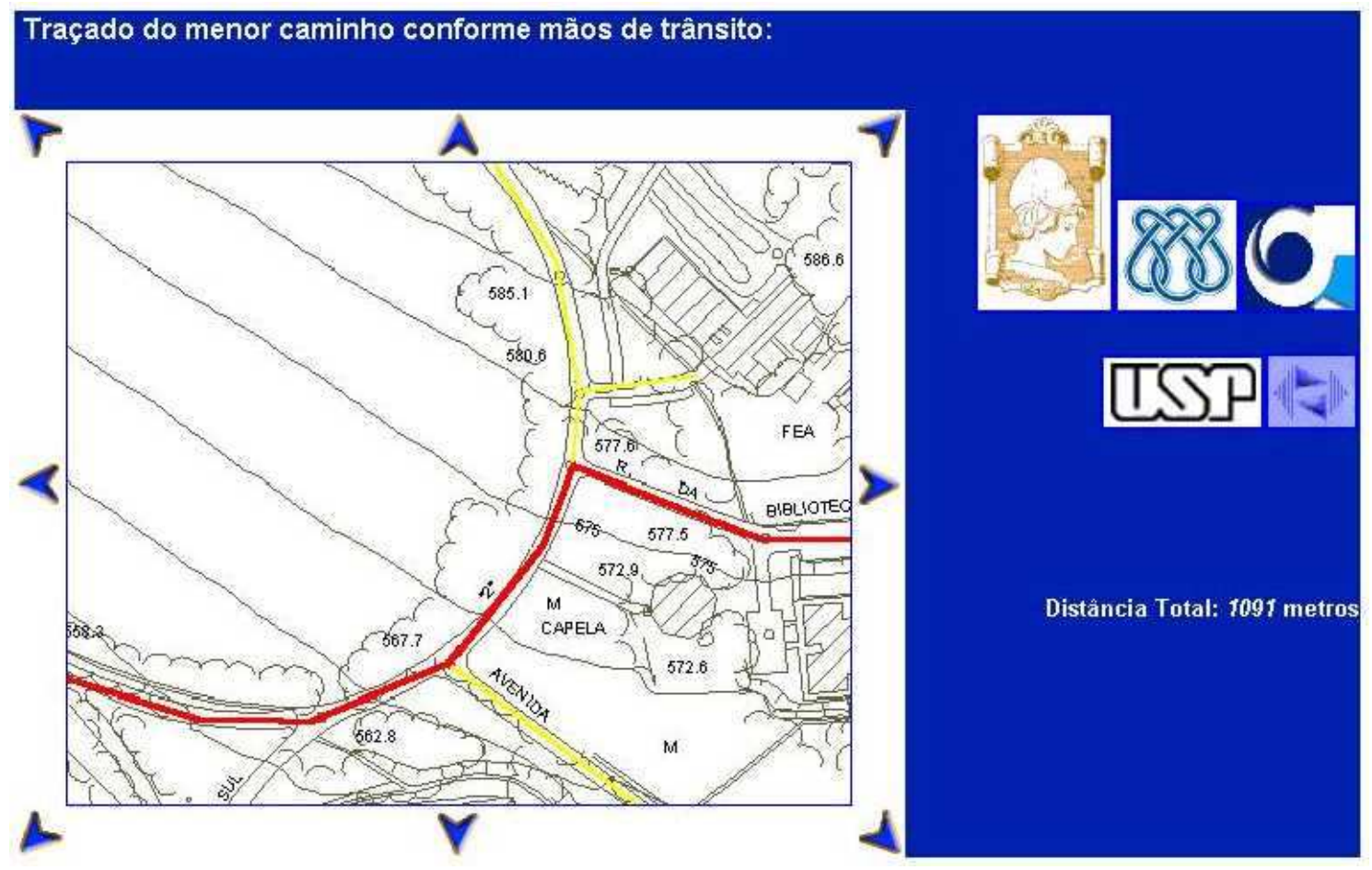

Figura 6.9. Terceira parte do caminho do Exemplo 2

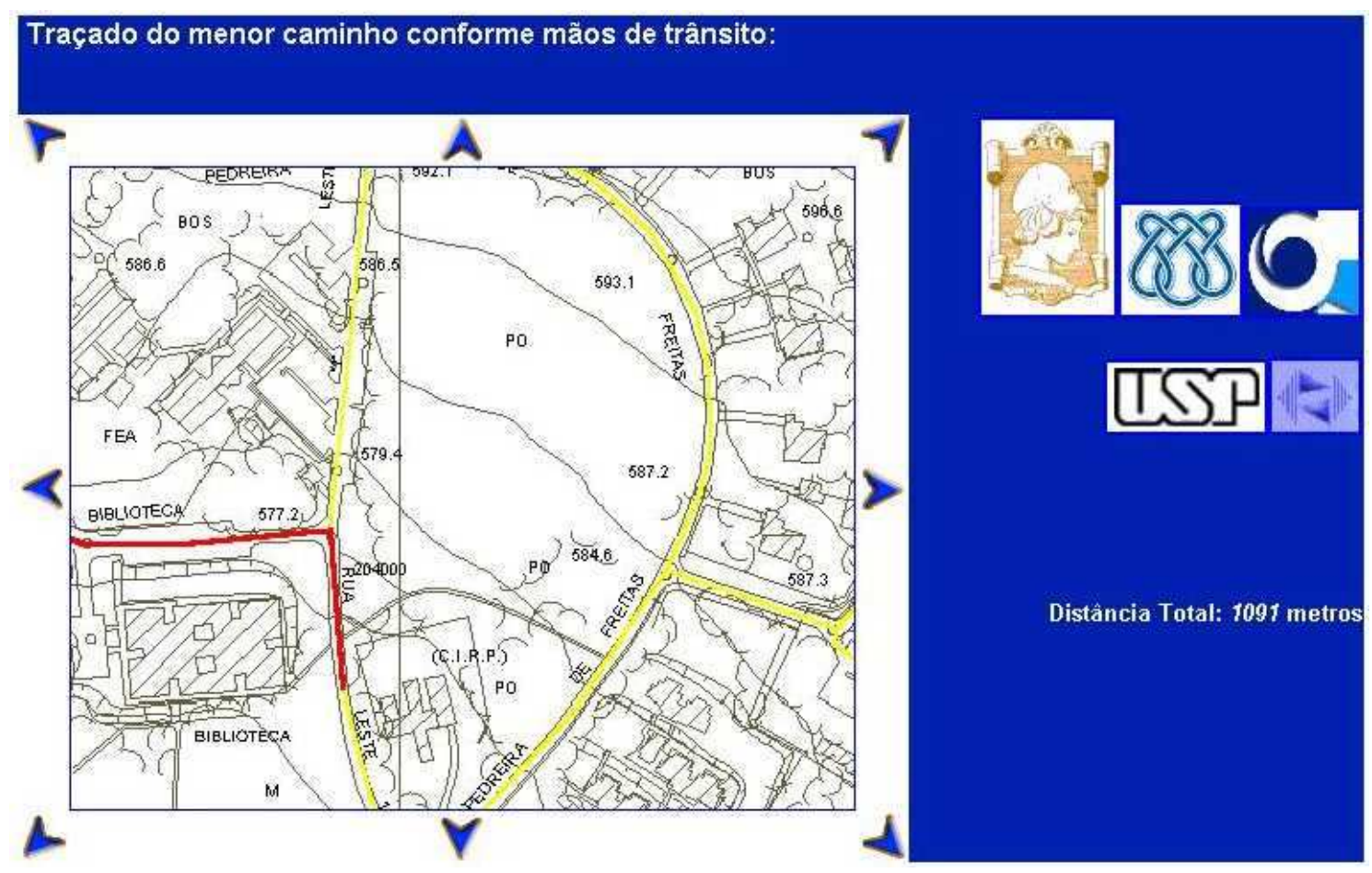

Figura 6.10. Quarta parte do caminho do Exemplo 2 


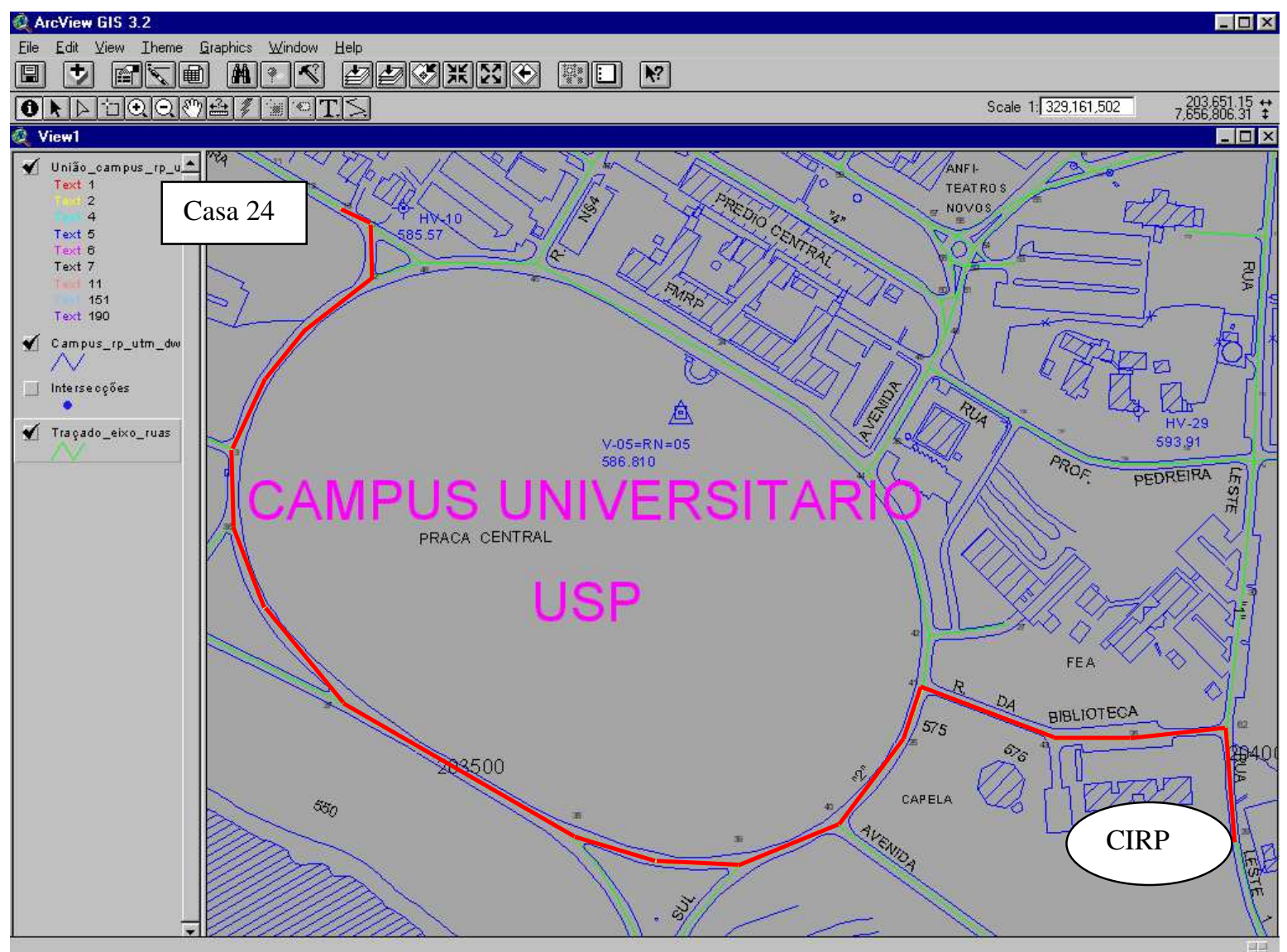

Figura 6.11. Primeiro Caminho escolhido pelo SIGRIB (distância de $1.091 \mathrm{~m}$ )

\section{ArcView GIS 3.2}

Eile Edit Yiew Iheme Graphics Window Help

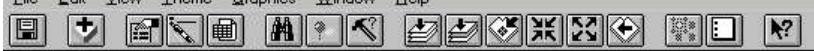

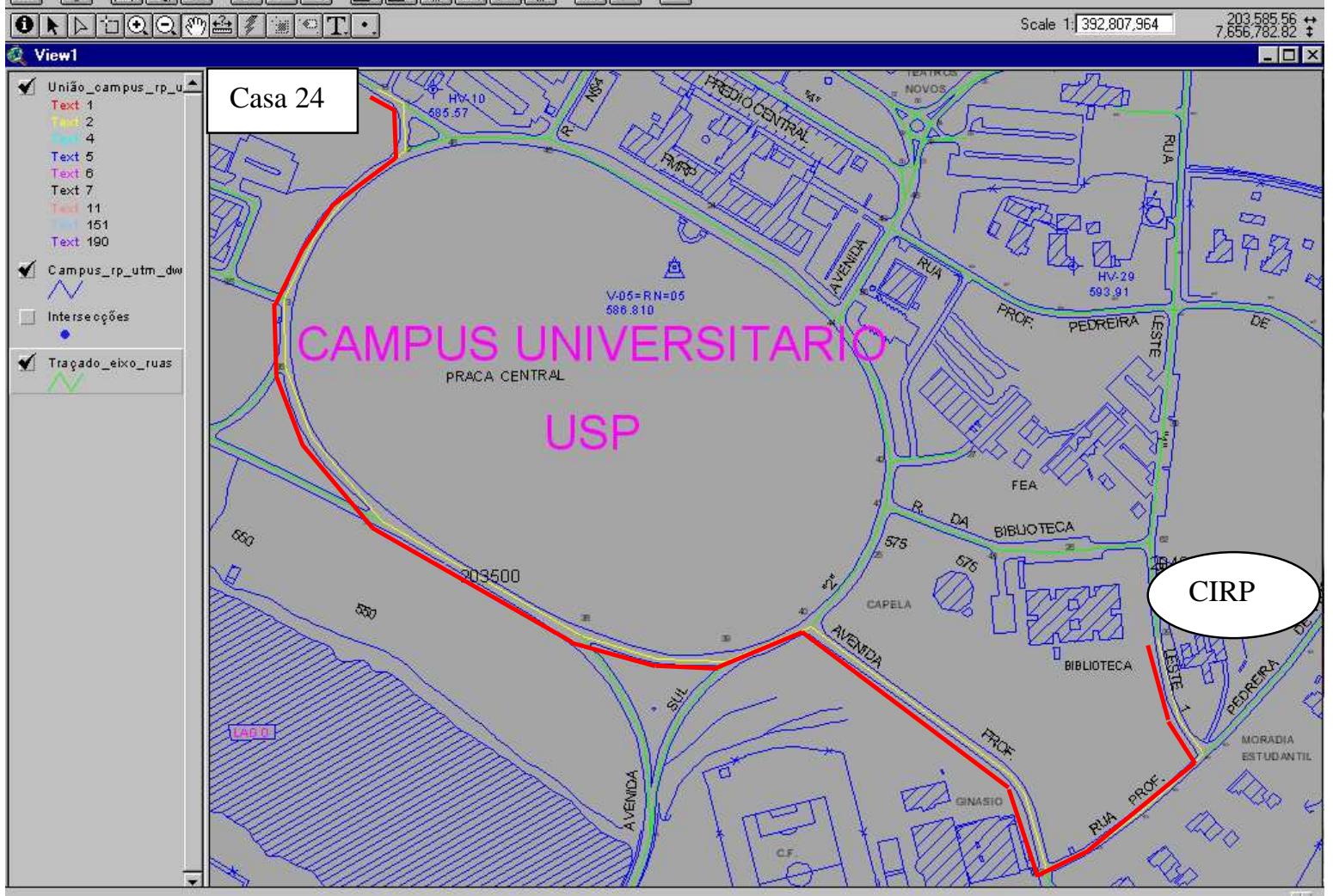

Figura 6.12. Caminho alternativo para o Exemplo 2 (distância de $1.211 \mathrm{~m}$ ) 


\section{Cap. 7 CONCLUSÃO}

Neste trabalho foi proposta uma metodologia para desenvolvimento de um sistema de roteirização de endereços, via internet, determinando-se o menor caminho entre duas localidades.

Essa metodologia foi direcionada para o Campus de Ribeirão Preto, mas pode ser perfeitamente utilizada para outro Campus, regiões, cidades e outros. A metodologia proposta foi implementada e testada, gerando um software que foi denominado SIGRIB.

O SIGRIB foi amplamente testado e os testes demonstram a sua eficiência na determinação do menor caminho entre duas localidades, fornecendo a distância, em metros, correspondente, entre as duas localidades.

Uma das vantagens do sistema SIGRIB é que, por estar disponível na Internet, ele pode ser acessado de qualquer parte do mundo. Assim, visitantes do exterior que pretende ter uma idéia da Unidade do Campus de Ribeirão Preto, onde estará visitando, poderá acessar a página onde se encontra o software SIGRIB e conseguir trajetos envolvendo a Unidade do Campus de interesse.

A utilização do SIGRIB poderá ser útil também para estudantes novos, de outros estados do país, que não conhecem bem o Campus onde irão estudar. E não se limita a isto, diariamente chegam pessoas de todas as partes querendo fazer uma entrega de documentos ou de materiais de construção, em alguma Unidade do Campus. Esses usuários, certamente, 
serão beneficiados, pois, poderão ter em mãos, uma cópia do mapa do caminho a ser seguido para chegar até a Unidade procurada.

Além disto, este trabalho é inédito para o Campus de Ribeirão Preto e coloca este Campus entre os poucos Campus a ter este tipo disponibilizado à sociedade.

A seguir são apresentados vários pontos que serão investigados como trabalhos futuros.

Existem vários pontos que podem ser melhorados no sistema proposto e são apresentados a seguir.

O primeiro deles se refere a sua disponibilização. O software SIGRIB foi disponibilizado numa máquina do LABIC - ICMC - USP. No entanto, pretendese conseguir permissão para que ele seja instalado em algum servidor do Campus da USP de Ribeirão Preto.

O segundo ponto se refere a ampliação da base de dados construída para o sistema SIGRIB, para que contenha também informações sobre algumas localidades de maior importância na cidade, como pontos turísticos, hospitais, universidades, órgãos governamentais, entre outros.

Um outro ponto, ainda em relação a bases de dados do sistema SIGRIB é que ela, tal como está até o momento, contém informações apenas de localização de pontos importantes no Campus de Ribeirão Preto, onde para cada localização existe a informação de suas localizações mais próximas (adjacentes) e a distâncias entre estas. Contudo, ela poderia ser estendida para conter informações do tipo: quantos professores/funcionários existem numa determinada Unidade, nomes de professores/funcionários em uma determinada Unidade, endereços de homepage/mail de professores/funcionários de uma determinada Unidade. Desta forma, o SIGRIB poderia ser utilizado em sua total potencialidade.

Um outro ponto a ser melhorado no sistema SIGRIB relaciona-se às várias localizações possíveis de serem encontradas no Campus de Ribeirão Preto através da utilização deste software. Tal como está o software, até o momento, existem 280 localizações que são disponibilizadas ao usuário. No entanto, isto é adequado somente para pequenas regiões, pois, se o usuário quiser encontrar uma outra localização que não pertença a lista 
disponibilizada, ele deverá fazer aproximação com base nas existentes. Para uma cidade, seria necessário ter disponível uma base de dados que possuísse todas as intersecções possíveis, existentes na cidade toda, e aí, então, o usuário poderia digitar duas localizações quaisquer para fazer a busca.

Este problema pode ser resolvido de duas formas:

- utilizando-se a metodologia proposta no SIGRIB uma solução seria construir esta base o que poderia levar um tempo enorme.

- uma outra solução seria modificar a forma de busca, na qual o usuário digitaria os nomes das localidades desejadas e uma busca no mapa digital seria feito com base na seqüência de caracteres constituída pelos nomes das ruas e/ou localidades envolvidas na busca. 


\section{REFERÊNCIAS}

- ALMEIDA, M. F. B.; "Roteirização de veículos para o transporte de alunos da zona rural utilizando um Sistema de Informações Geográficas. São Carlos. Dissertação - Universidade Federal de São Carlos, 1998.

- ALVES, C.M.A. e SOUZA, M.P., "A utilização de SIG para ponderação de fatores ambientais na localização de atividades econômicas", Anais do XII Simpósio Brasileiro de Recursos Hídricos, realizado em Vitória-ES, 1997.

- BELHOT, M. J.; "A formação de rotas de veículos na distribuição física: modelos e métodos de solução. Rio de Janeiro. Dissertação - Pontifícia Universidade Católica, 1993

- BOSE, R. C. A.; "Modelos de roteirização e programação de entregas em redes de transportes. São Paulo. Dissertação - Escola Politécnica - USP, 1991.

- BURROUGH, P. A., "Principles of Geographical Information Systems", Clarendon Press - Oxford, 1985.

- CAMARGO, P., "Desenvolvimento e organização das redes de transporte: modelos de análise selecionados e aplicados ao Estado de São Paulo". Dissertação - Escola Politécnica - USP. 1993. 
- ChAVES, E. D., "Análise da qualidade de dados georeferenciados utilizando a tecnologia GPS", Dissertação de Mestrado, EESC-USP, 22/05/1998.

- CUNHA, C. B.; "Algoritmos para roteamento e programação de veículos no contexto da distribuição física". São Paulo. Dissertação - Escola Politécnica - USP, 1991.

- CUNHA, C. B.; "Uma contribuição para o problema de roteirização de veículos com restrições operacionais". São Paulo. Tese - Escola Politécnica - USP, 1997.

- CALIPER CORPORATION, "Routing and logistics with TransCAD", version 3.0, 1996.

- DANTAS, A. S.; "Metodologia para a localização de um centro de distribuição domiciliar da Empresa Brasileira de Correios e Telégrafos com o auxílio do Sistema de Informação Geográfica". Brasília. Dissertação Universidade de Brasília, 1998.

- DAVIS JR, C. A.; "Aumentando a eficiência da solução de caminho mínimo em SIG. In CONGRESSO DE GEOPROCESSAMENTO - GIS BRASIL 97, Curitiba, CD-ROM, 1997.

- DELUQUI, K. K.; "Roteirização para veículos de coleta de resíduos sólidos domiciliares utilizando um Sistema de Informação Geográfica". São Carlos. Dissertação- EESC-USP, 1998. 
- DUTRA, N. G. S., "Planejando uma rede escolar municipal para reduzir custos de deslocamentos". São Carlos. Dissertação- EESC-USP, 1998.

- GALVÃO, R. D.; FERREIRA, V. J. M.; HENRRIQUES, H. B. S.; "Roteamento baseado em Sistemas de Informação Geográfica". In SIMPÓSIO BRASILEIRO DE PESQUISA OPERACIONAL. Florianópolis. Anais p.708-713, 1994.

- GARDE, I. D.; MANECHINI, C.; ROMERO, R. A. F., Desenvolvimento de um Sistema de Mapa Virtual para a Cidade de São Carlos, RIC - Revista de Iniciação Científica, no. 4, p. 71-74, set/2002.

- GIBBONS, G.; SCHMIDKUNZ, E.; HEATLY, R. O., "GIS sources" Cleveland, OH : Advanstar Communications, Marketing Services, 1995.

- HOFMANN-WELLENHOF, B.; LICHTENEGGER, H.; COLLINS, J. , "GPS: Theory and Practice", Springer-Verlag, $3^{\mathrm{a}}$ edition, 1997.

- LethAM, L., "GPS Made Easy", Rocky Mountains Books, 1998.

- LEICK, A., "GPS Satellite Surveying", John Wiley \& Sons, Inc., New York, $2^{a}$ edition, 1995.

- LIMA, R.S., "Um sistema de apoio à decisão para localização de serviços de educação e saúde", Anais do XIV Congresso de Pesquisas e Ensino em Transportes, Tese de Doutorado, EESC-USP, 200p., 2003. 
- LOGSDON, T., "The Navstar Global Positing System", Van Nostrand Reinhold Publ. Inc., New York, 1997.

- JOHNSON, A. I.; PETTERSON, C. B.; FULTON, J. L.; "Geographic Information Systems (GIS) and mapping :practices and standards", Philadelphia : ASTM, 1992.

- JOHNSONBAUGH, R.; "Discrete Mathematics"; Prentice Hall, 1997.

- MARQUES, H. N.; "Um Sistema de Informação para usuários de transporte coletivo em cidades de médio porte". São Carlos. Dissertação, EESC-USP, 1998.

- NOVAES, A. G.; "Métodos de otimização aplicados aos transportes". São Paulo. Edgar Blücher, 1978.

- PEIXOTO, R. S. S. L.; "Utilização de Sistemas de Informação Geográfica para o gerenciamento de cidades de pequeno porte". São Carlos. Dissertação. EESC-USP, 1997.

- PELIZADO, C., "Avaliação de desempenho do algoritmo de um programa comercial para roteirização de veículos". Dissertação (Mestrado) - Escola de Engenharia de São Carlos - Universidade de São Paulo, 2000.

- PFEIFFER, S. C., "Subsídios para a ponderação de fatores ambientais na localização de aterros de resíduos sólidos, utilizando o sistema de informações geográficas. Tese Doutorado, EESC-USP, 2001. 
- ROMAN, S. "An Introduction to Discrete Mathematics". Second Edition, Harcout Brace, Jovanovich Publishers, 1989.

- ROSE, A. , "Avaliação comparativa de alguns sistemas de informação geográfica aplicados aos transportes", Dissertação (Mestrado) - Escola de Engenharia de São Carlos- Universidade de São Paulo, 2001.

- ROSSETO, C. F.; CUNHA, C. B.; "Aplicação do geoprocessamento na roteirização de veículos". In: Congresso de Geoprocessamento - GIS Brasil 94, Curitiba. Anais $\quad$ p. 35-44, 1994.

- SALTORADO, P.; "O roteamento de veículos: uma avaliação sobre sua introdução na coleta de resíduos sólidos urbanos". São Carlos. Dissertação (Mestrado) EESC-USP, 1998.

- SANTOS, C. M., "A viabilização de softwares comerciais na roteirização de veículos de serviços de entregas, visando a geração de respostas rápidas e eficientes.", Dissertação (Mestrado) EESC-USP, 1999.

- SÁ, L. A. C. M., "Modelagem de Dados Espaciais para Sistemas de Informação Geográficas - Pesquisa na Emergência Médica", São Carlos, 2001, 87p., Tese (de Doutorado), Escola de Engenharia de São Carlos, Universidade de São Paulo.

- SANTOS, C.M., "Avaliando a localização dos postos de saúde em uma cidade média brasileira com auxílio de um SIG-T", Revista Engenharia Civil, no. 7 , pp. $47-58,2000$. 
- SEGANTINE, P. C.L. (2001). " Estudo do Sinergismo entre os Sistemas de Informação Geográfica e o de Posicionamento Global", Tese de Livre Docência, EESC-USP, 223 pág., 2001.

- SILVA, A. N. R.; WAERDEN, P., "First steps with a Geographic Information System for transportation", São Francisco. Ribeirão Preto, 1997

- SILVA, A. N. R.; "Os sistemas de informação geográfica e a engenharia de transportes no Brasil". In: WORKSHOP SISTEMAS DE INFORMAÇÃO GEOGRÁFICAS - ANPET, São Carlos, 1995. Anais.

- SOUZA, J.M., "Uso do Sistema de Informações Geográficas na Análise e otimização do atendimento a locais de potencial de risco de incêndios, para a cidade de São Carlos (SP)", Dissertação de Mestrado, STT-EESC-USP, 144 pág., 2000.

- Várias edições da Revista InfoGeo. 


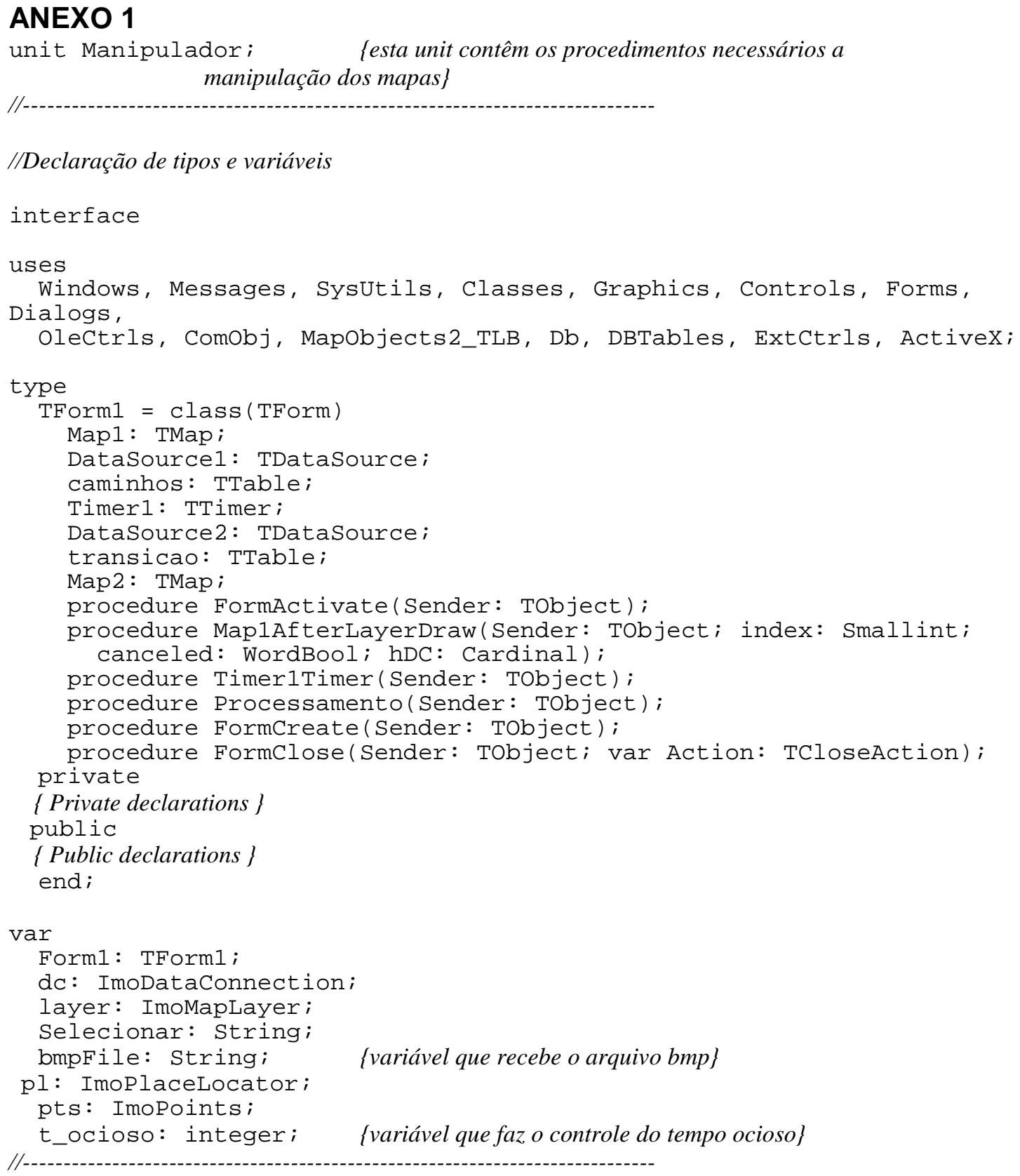

implementation \{implementação dos procedimentos\}

$\{\$ R * . D F M\}$

I/--

procedure ExportBMP() ; \{este procedimento exporta a BMP gerada para o

begin aplicativo ISAPI\}

Application.ProcessMessages;

Form1.Map1.ExportMap (moExportBMP, bmpFile, 1); end;

$/ /--$

procedure TForml.Processamento(Sender: Tobject); $\quad$ (este procedimento seleciona os IDs

correspondentes

ao menor caminho

no banco de 


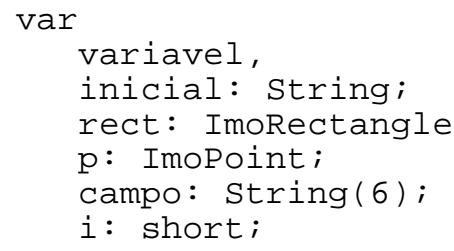

dados $\}$

begin

Caminhos.Open; $\quad$ [abre o banco de dados "Caminhos"\}

variavel := IntToStr(transicao('NrArq')); $\quad$ "variavel" recebe a string correspondente ao número da requisição\}

bmpFile := 'c: \inetpub\wwwroot \SIGRIB \resp' + variavel + '.bmp'; //"bmpFile" recebe a string correspondente ao destino do arquivo de saída

//início do processamento dos IDs

inicial := Caminhos ('Pt1');

Selecionar $:=$ 'ID $=$ ' + inicial;

i $:=2$;

campo:= 'Pt'+IntToStr(i);

while caminhos (campo) <> 30000 do

begin

variavel := caminhos (campo);

inicial $:=$ caminhos (campo);

Selecionar := Selecionar + ' or ID $=$ ' + variavel;

$i:=i+1$;

campo := 'Pt'+IntToStr(i);

end;

pts := pl.Locate(inicial);

$\mathrm{p}:=\mathrm{pts}$. Item $(0)$;

Rect := Map1.Extent;

Map1.TrackingLayer.Refresh (True, rect);

map1.centerat $(\mathrm{p} \cdot \mathrm{x}+($ caminhos ('deltax')*300), $\mathrm{p} \cdot \mathrm{y}+$

(caminhos ('deltay')*300));

caminhos.Close; $\quad$ \{fecha o banco de dados "caminhos"\}

ExportBMP;

end;

$/ /---$

procedure TForm1.FormActivate (Sender: TObject);

\{ativa o form de saída

com o $B M P$

correspondente\}

$\operatorname{var}$

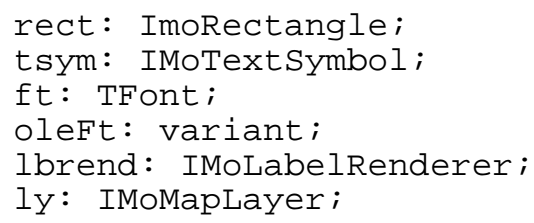

begin

ft $:=$ TFont. Create;

ft.name := 'Arial';

ft.size := 7;

oleFt := FontToOleFont (ft);

dc :=

IMoDataConnection (CreateOleobject ('Mapobjects2. DataConnection'));

\section{//conexão com mapas}

dc.Database := ' (CADLine)' + 'C: \Inetpub\wwwroot \SIGRIB \mapas \';

layer := IMoMapLayer (CreateOleobject ('Mapobjects2.MapLayer'));

layer.GeoDataset $:=$ dc.FindGeoDataset ('CAMPUS_RP_UTM.dwg');

Map1.Layers.Add (Layer); 


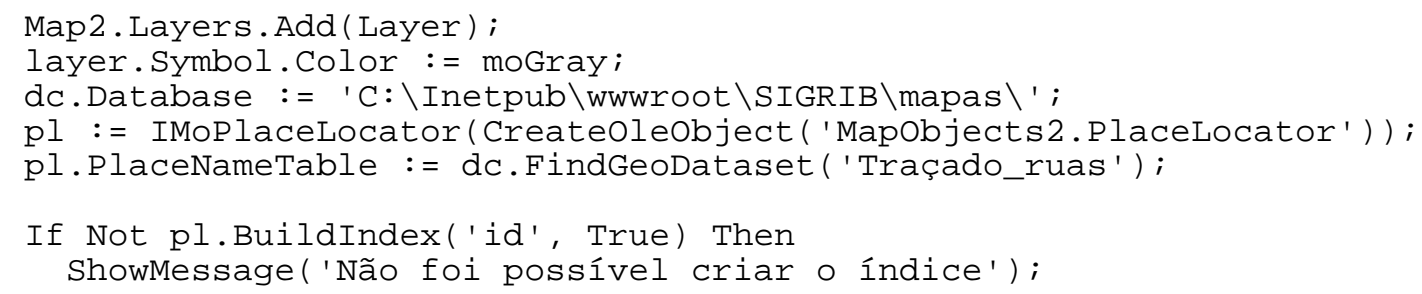

//selecionando componentes do mapa

layer := IMoMapLayer (CreateOleobject('Mapobjects2.MapLayer'));

layer.GeoDataset := dc.FindGeoDataset ('Traçado_ruas') ;

Map1.Layers. Add (Layer);

layer. Symbol. Color $:=$ moYellow;

layer.Symbol.Size := 2;

dc.Database := ' (CADText)' + 'C: \Inetpub\wwwroot \SIGRIB $\backslash$ mapas $\backslash$ ';

layer := IMoMapLayer (CreateOleObject ('Mapobjects2.MapLayer')) ;

layer.GeoDataset := dc.FindGeoDataset ('CAMPUS_RP_UTM.dwg');

Map1.Layers.Add (Layer);

layer. Symbol. Color := moBlue;

ly $:=$ IMoMapLayer (Map1.Layers.item('CAMPUS_RP_UTM.dwg')) ;

ly.Symbol. Color : =\$FFFF00;

lbrend :=

IMoLabelRenderer (Createoleobject ('Mapobjects2. LabelRenderer')) ;

ly.Renderer := lbrend;

lbrend.DrawBackground :=False;

lbrend.Field :='TEXT';

lbrend.HeightField :='HEIGHT';

tsym := IMoTextSymbol (CreateOleObject ('Mapobjects2.TextSymbol')) ;

tsym := lbrend. Symbol (0);

tsym.font := IFontDisp(IDispatch(oleFT));

ft.free;

Rect $:=$ Map1.Extent;

Rect.ScaleRectangle (0.04);

Map1.Extent := Rect;

pts := IMoPoints (CreateOleObject('Mapobjects2.Points')); end;

//---.--

procedure TForml.Map1AfterLayerDraw(Sender: Tobject; index: Smallint; canceled: WordBool; hDC: Cardinal); (este procedimento seleciona as arestas do mapa correspondentes ao caminho indicado e pinta-as de vermelho\}

var

sel: ImoRecordset;

lys: IMoLayers;

layer: IMoMapLayer;

sym: Imosymbol;

begin

If Selecionar <> ' ' Then

begin

lys := Map1.Layers;

layer := IMoMapLayer (CreateOleObject('Mapobjects2.MapLayer')) ;

layer := IMoMapLayer(Iys.Item('Traçado_ruas'));

sel := layer.SearchExpression(selecionar);

If Not sel.EOF then

begin

sym := IMoSymbol (CreateOleobject ('Mapobjects2.Symbol'));

sym. Symboltype := moLineSymbol;

sym. Style := moSolidLine;

sym. Size $:=3$;

sym.Color := moRed; end;

Map1.DrawShape (sel, sym); 


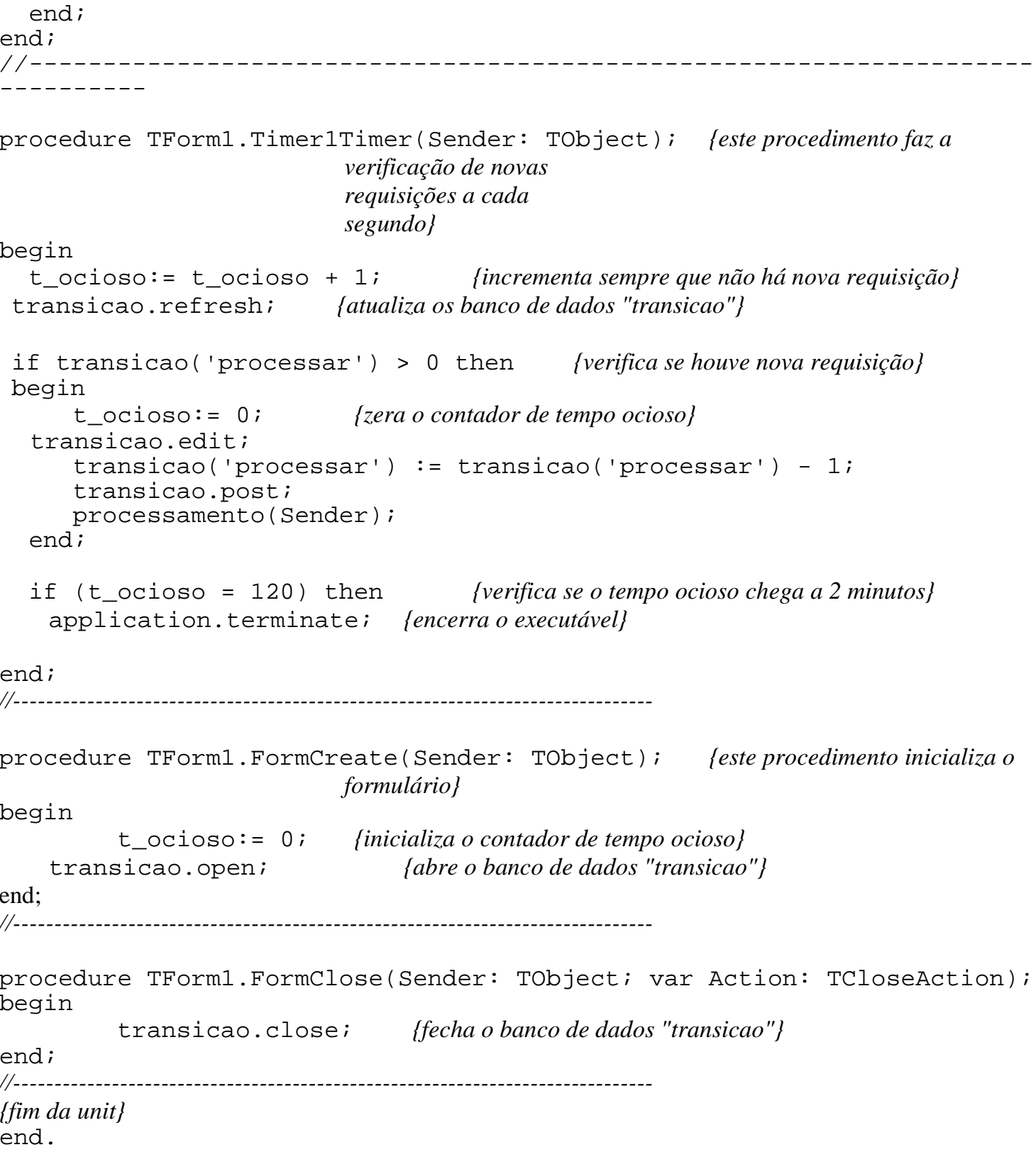




\section{ANEXO B - Programa 2}

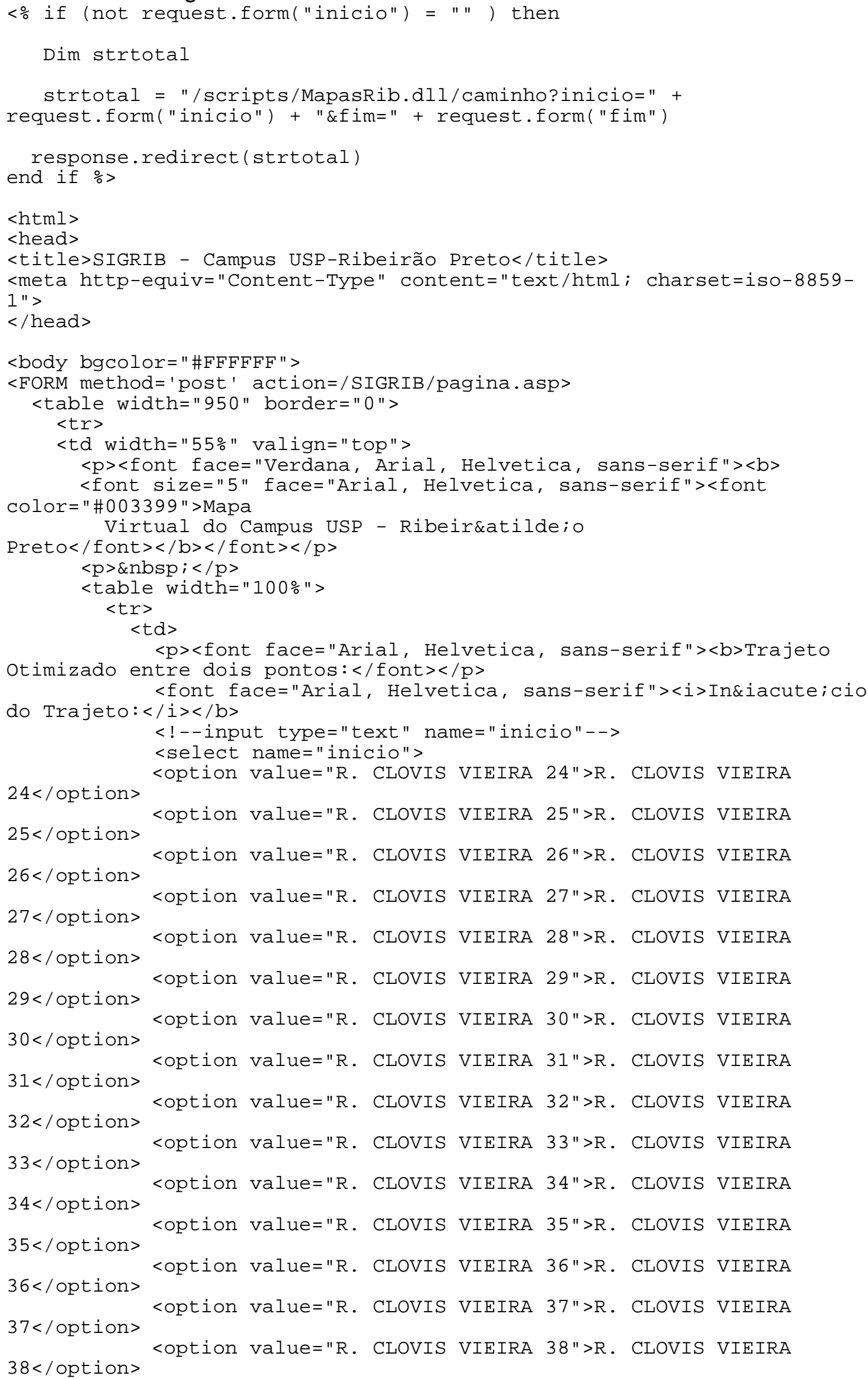




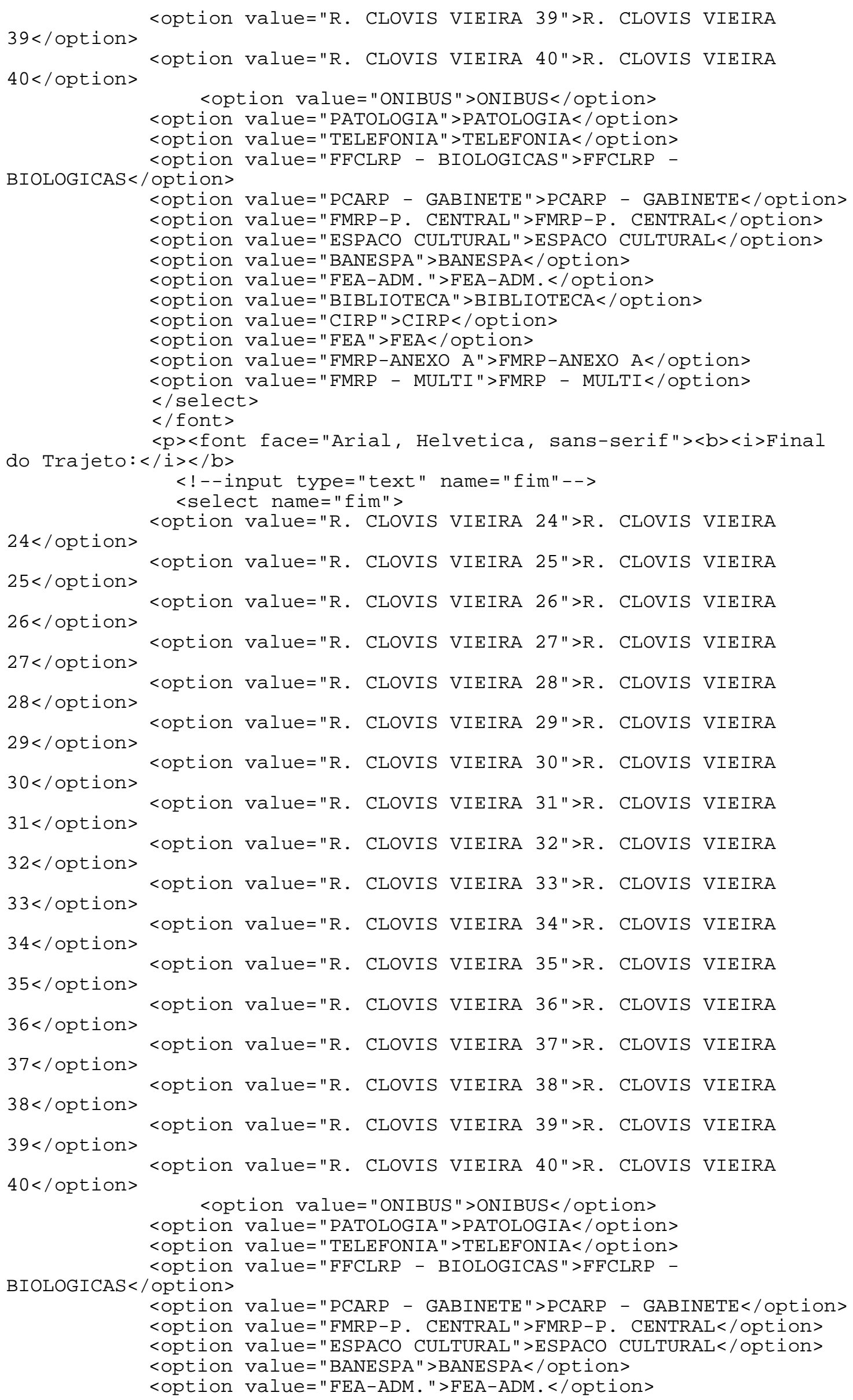




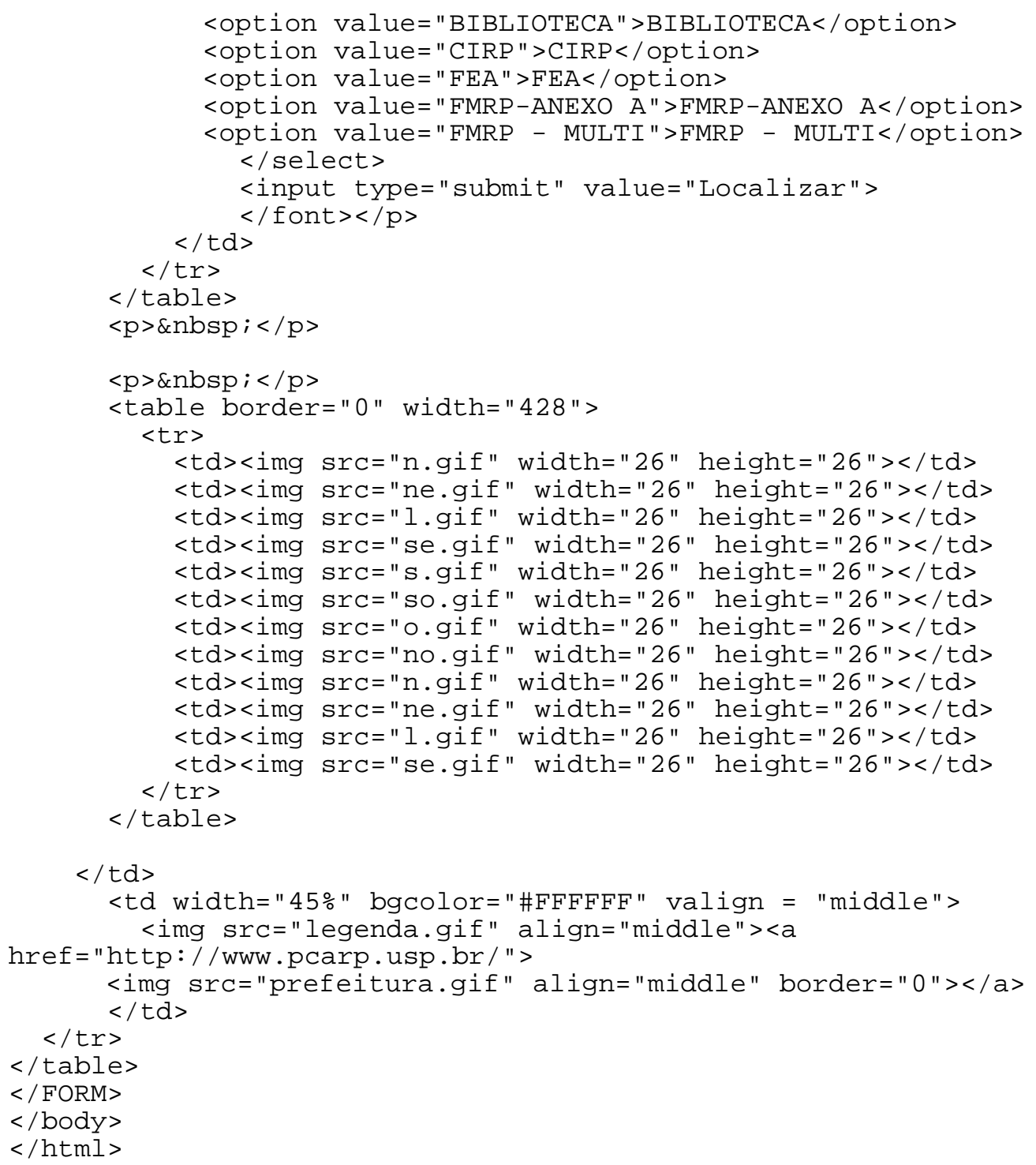

